University of Louisville

ThinkIR: The University of Louisville's Institutional Repository

8-2012

\title{
Child behavioral inhibition, parental overcontrol, and parental anxiety as predictors of adolescent anxiety.
}

Benjamin M. Keizer

University of Louisville

Follow this and additional works at: https://ir.library.louisville.edu/etd

\section{Recommended Citation}

Keizer, Benjamin M., "Child behavioral inhibition, parental overcontrol, and parental anxiety as predictors of adolescent anxiety." (2012). Electronic Theses and Dissertations. Paper 733.

https://doi.org/10.18297/etd/733

This Doctoral Dissertation is brought to you for free and open access by ThinkIR: The University of Louisville's Institutional Repository. It has been accepted for inclusion in Electronic Theses and Dissertations by an authorized administrator of ThinkIR: The University of Louisville's Institutional Repository. This title appears here courtesy of the author, who has retained all other copyrights. For more information, please contact thinkir@louisville.edu. 
CHILD BEHAVIORAL INHIBITION, PARENTAL OVERCONTROL, AND

PARENTAL ANXIETY AS PREDICTORS OF ADOLESCENT ANXIETY

$$
\text { By }
$$

Benjamin M. Keizer

B.S., South Dakota State University, 1998

M.S., University of West Alabama, 2006

\author{
A Dissertation Submitted to \\ the Faculty of the College of Education and Human Development of the \\ University of Louisville \\ in Partial Fulfillment of \\ the Requirements for the Degree of
}

Doctor of Philosophy

Educational and Counseling Psychology

University of Louisville

Louisville, KY

August 2012 
CHILD BEHAVIORAL INHIBITION, PARENTAL OVERCONTROL, AND PARENTAL ANXIETY AS PREDICTORS OF ADOLESCENT ANXIETY

By

Benjamin M. Keizer

B.S., South Dakota State University, 1998

M.S., University of West Alabama, 2006

A Dissertation Approved on

June 15, 2011

by the following Dissertation Committee:

Kathy Rudasill, Dissertation Chair

Linda Shapiro

Patrick Possel

Kevin Chapman 


\section{DEDICATION}

This dissertation is dedicated to my

loving wife Jennifer

without whose love and support I could

not have finished this journey. 


\section{ACKNOWLEDGEMENTS}

Proverbs 3:6-7 (ESV) reads: "Trust in the Lord with all your heart, and do not lean on your own understanding. In all your ways acknowledge him, and he will make straight your paths." First, I would like to express that without a deep and abiding relationship with my savior Jesus Christ, I would have never been able to navigate the long and winding road of the last three years.

Next, I need to recognize the vital role my inwardly and outwardly beautiful wife Jenny played in earning what I consider not my degree, but our degree. Every day I left for campus I knew that she was dedicated to being a woman of excellence as a wife, mother, supporter and personal confidant. You are truly my best friend. Thanks also to my children who persevered through having a father that was not around as much as he would have liked to be: Lyla, Elsie (Brown), Gabrielle (Gabby), Lincoln (Towhead), and Silas. I promise I will make it up to you soon.

Along my education journey I have providentially had many people placed in my life that have supported and guided me. First on the list is my Dissertation Chair / coacademic advisor / mentor / co-instructor / expert movie reviewer, Dr. Kathy Rudasill. Without Kathy's commitment to my success I would not have been able to finish this dissertation / graduate in a timely manner. Indeed, Kathy's devotion to graduate students in the form of teaching them to do research well, achieve lofty goals, and graduate in a reasonable amount of time is her legacy. I would also like to express gratitude to my coacademic advisor and dissertation committee member, Dr. Linda Shapiro, for her 
direction and encouragement during the past three years along with the other two members of my dissertation committee Dr. Patrick Pössel and Dr. Kevin Chapman. I feel deeply blessed for the helpfulness, flexibility, and cohesiveness of this great Dissertation Committee.

Last, but certainly not least, I would like to thank my extended family. To my parents, Henry and Ruth Keizer, thank you for your support in being there for my wife and children during those times when I could not meet all of their needs. To my other parents and psychology mentor, Dr. Lyle and Pam Carlson - I am forever grateful for all of your logistical, emotional, and spiritual support in making this dream a reality. Without both of your encouragement I would without a doubt never had the courage to leave the active Army and pursue becoming a psychologist. To my siblings, Dr. David Keizer and Katie Keizer, thanks for being my live test subjects during our formative years and for your friendship as we all became adults. 


\begin{abstract}
CHILD BEHAVIORAL INHIBITION, PARENTAL OVERCONTROL, AND

PARENTAL ANXIETY AS PREDICTORS OF ADOLESCENT ANXIETY
\end{abstract}

Benjamin Keizer

June 15,2011

This dissertation examined the prediction of anxiety symptoms over time during developmentally significant periods - the transition to middle school (12 years old) and the transition to high school ( 15 years old). Specifically, relationships between child behavioral inhibition, paternal anxiety, maternal anxiety, and parental control and concurrent levels of adolescent anxiety at each time point were analyzed. Despite a strong research base supporting individual connections between child behavioral inhibition, levels of parental control, parental anxiety symptoms and adolescent anxiety, the joint, longitudinal associations have received scant attention in the literature. The current study also compared two different models of adolescent anxiety, a mediated model of adolescent anxiety and a moderated model of adolescent anxiety, to determine which better fit the data.

Data for the study was part of the Study of Early Child Care and Youth Development (SECCYD), a study funded by the National Institute of Child Health and Human Development (NICHD). Participants initially enrolled in the study were 1,364 children (659 girls and 705 boys) and their caregivers and were recruited from 10 different geographic locations in the United States. 
The current study demonstrated associations between child behavioral inhibition, paternal anxiety, maternal anxiety, parental control and adolescent anxiety and suggests that they predict adolescent anxiety at 15 years. This study also indicated that earlier levels of adolescent and parental anxiety predict later levels of adolescent and parental anxiety and that parental anxiety symptoms have implications for concurrent and future levels of adolescent anxiety. Further research concerning the risk and protective factors as they relate to the etiology of adolescent anxiety should be explored to positively guide therapeutic interventions and shape appropriate parental behaviors. 


\section{TABLE OF CONTENTS}

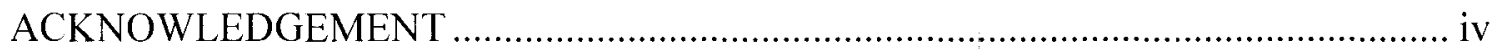

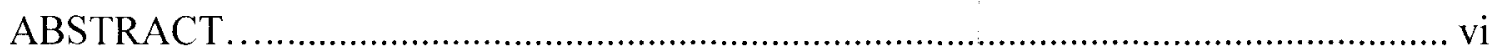

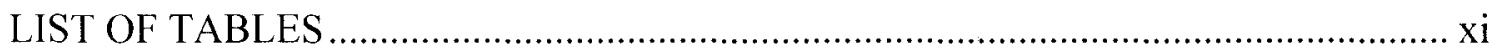

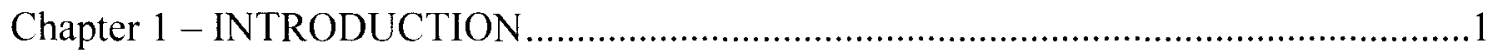

Problem Statement .............................................................................

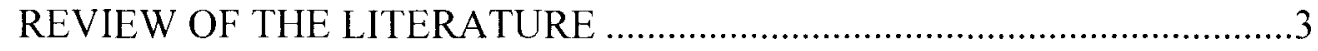

Introductory Background ................................................................... 3

Theoretical Frameworks of Study .........................................................5

Bioecological Model of Development............................................5

Bioinformational Theory ................................................................. 7

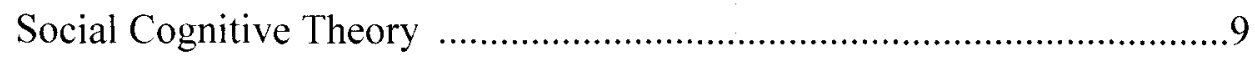

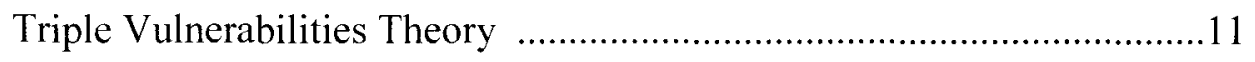

Theoretical Interconnection .............................................................. 13

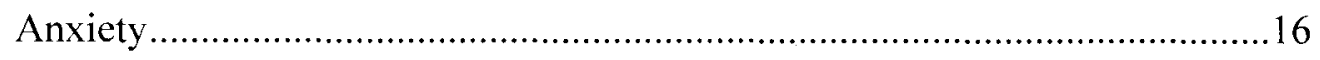

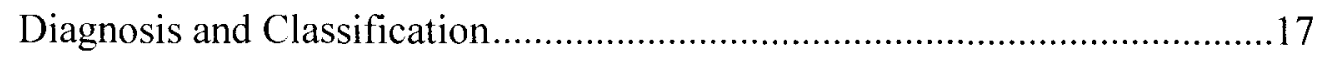

Risk Factors Associated with Anxiety Disorders .....................................19

Temperament \& Behavioral Inhibition.............................................20

Parenting Behaviors .....................................................................22

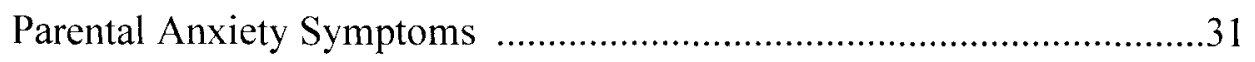

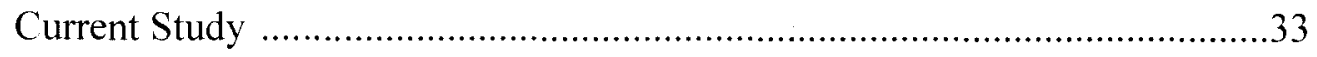

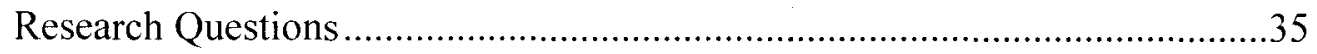




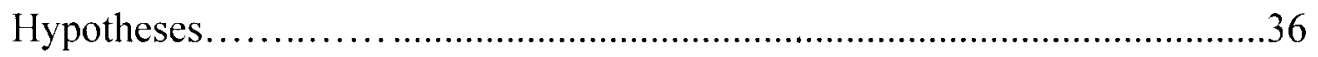

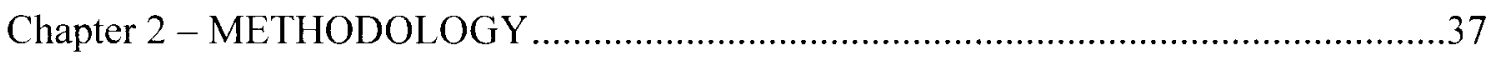

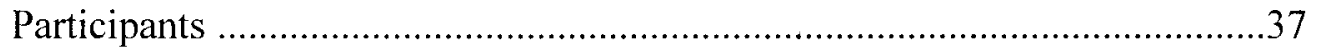

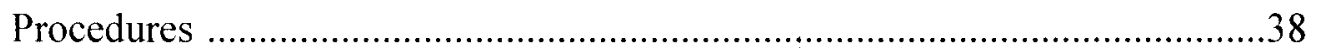

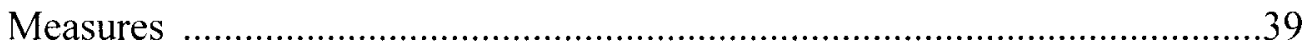

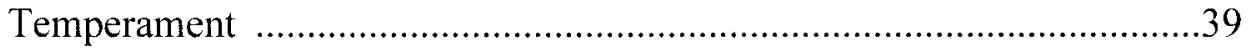

Children's Behavior Questionnaire ....................................................39

Child/Adolescent Anxiety ......................................................................

Child Behavior Checklist-Anxiety scale ............................................40

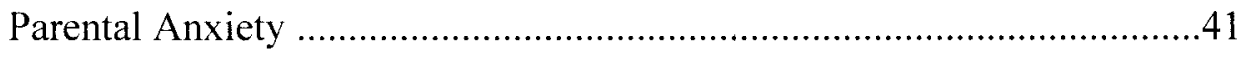

State-Trait Anxiety Inventory ..........................................................41

Parental Control ....................................................................................

Parental Control and Autonomy …………......................................42

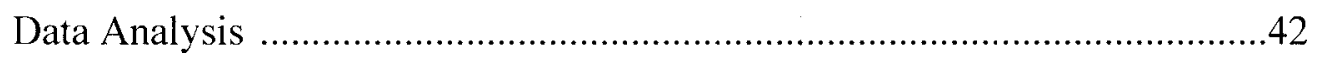

Preliminary Considerations .................................................................42

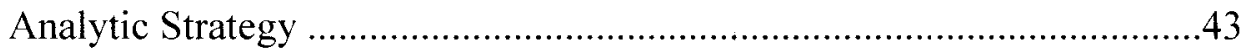

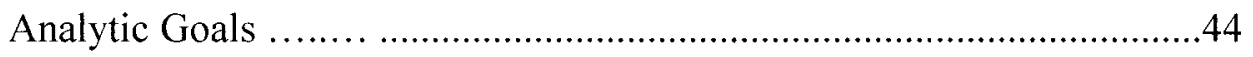

Chapter 3 - RESULTS.......................................................................................

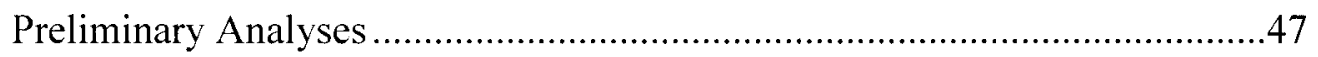

Structural Equation Modeling Analyses..................................................52

Mediated Model of Adolescent Anxiety ………………………...............53

Moderated Model of Adolescent Anxiety ..............................................57

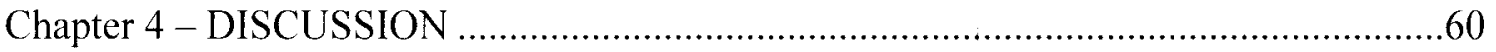


Hypothesis One: Joint Relationships ……………………....................................60

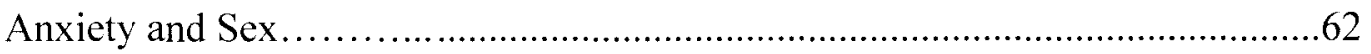

Hypothesis Two: Mediated Model of Adolescent Anxiety ...........................................64

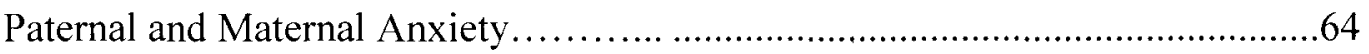

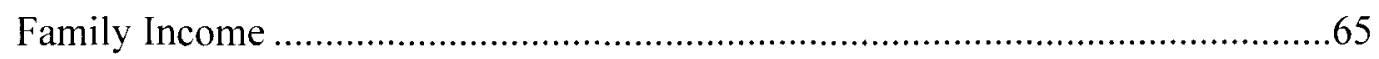

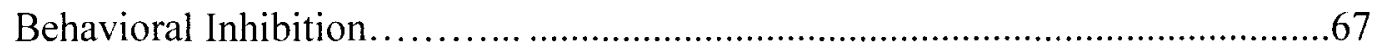

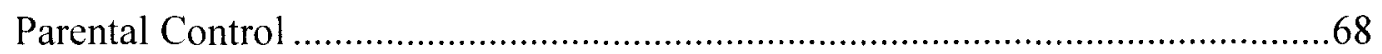

Hypothesis Three: Assessing Mediation.....................................................................70

Hypothesis Four: Assessing Moderation ...............................................................70

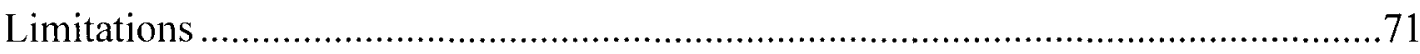

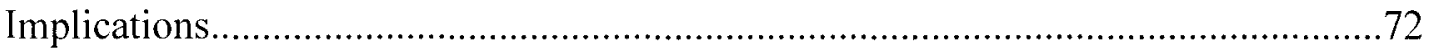

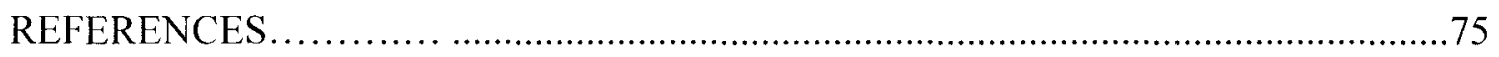

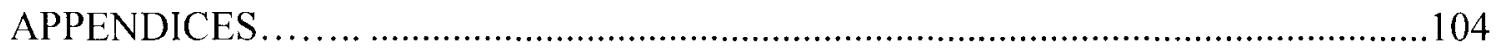

APPENDIX A: Children's Behavior Questionnaire...........................................104

APPENDIX B: Child Behavior Checklist-Anxiety scale...................................106

APPENDIX C: State-Trait Anxiety Inventory ..................................................107

APPENDIX D: Parental Control and Autonomy ................................................108

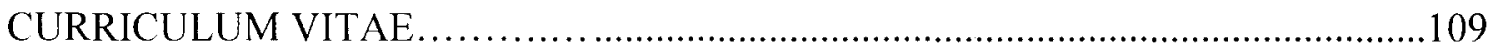




\section{LIST OF TABLES}

1. Means, Standard Deviations, and Minimum and Maximum Values of the

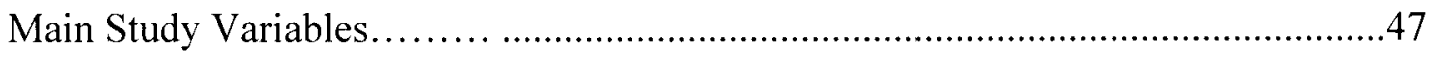

2. Zero order correlations between the Main Study Variables and Family Income .........48

3. Means, Standard Deviations and F ratios of the Main Study Variables as a

Function of Ethnicity.

4. Means, Standard Deviations and t scores of the Main Study Variables as a

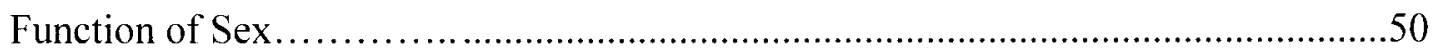

5. Zero order correlations for the Main Study Variables ...........................................51

6. Longitudinal Paired Samples Mean differences, Standard Deviations, and t Scores

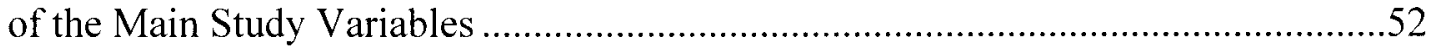

7. Mediated Model of Adolescent Anxiety SEM Path Analysis Estimates.................56

8. Moderated Model of Adolescent Anxiety SEM Path Analysis Estimates.....................58 


\section{CHAP'TER 1}

\section{INTRODUCTION}

\section{Statement of the Problem}

Prior to the 1990s, many health professionals believed childhood and adolescent anxiety disorders to be infrequent; therefore, anxiety in these age groups received little attention in the literature (Rapee, Schniering, \& Hudson, 2009; Zahn--Waxler, KlimesDougan, \& Slattery, 2000). In fact, Orvaschel and Weissman's (1986) epidemiological analysis of anxiety yielded no data on child anxiety disorders in their review of the extant literature. However, epidemiological data since the 1990s suggest that anxiety disorders are one of the most common, if not the most common, disorders of childhood and adolescence (Albano, Chorpita \& Barlow, 1996; Costello \& Angold, 1995; Coyle, 2001; Rapee, Schniering, \& Hudson, 2009). Indeed, recent meta-analyses of community epidemiological studies indicate that approximately $5 \%$ to $17 \%$ of children meet the diagnostic criteria for an anxiety disorder between the ages of eight and 18 (Gosch \& Flannery-Schroeder, 2006; Vasa \& Pine, 2004). Anxiety diagnoses (e.g., social phobia, panic attack), expression of anxiety (e.g., intense fear), and age-based prevalence rates, however, exhibit variability across the life span, emphasizing the need for recognition of the role of developmental factors (Garber \& Strassberg, 1991).

Both clinical and subclinical anxiety symptoms in children have been associated with a variety of impairments across several domains, including significant social and academic dysfunction (Essau, Conradt, \& Peterman, 2000; Messer \& Beidel, 1994; 
Strauss, Frame, \& Forehand, 1987) and increased rates of socially withdrawn behavior (Goodwin, Fergusson, \& Horwood, 2004). In addition, anxiety is positively associated with alcohol abuse (Beidel \& Turner, 1998) and negatively associated with popularity and social competence (Giora, Gega, Landau, \& Marks, 2005; Strauss, et al., 1987). Children and adolescents with anxiety disorders are more likely to develop into young adults who exhibit a decreased quality of life, highlighting the importance of understanding the biological and environmental factors that play a role in this crucial developmental period (Caspi, Elder, \& Bem, 1988).

During the transition from childhood to adolescence, more biological, social, and cognitive changes occur than at any other developmental stage, aside from infancy (Holmbeck, 1996). Some of these changes include the attainment of puberty (e.g., development of abstract thinking, increased emphasis on peer relationships and social status) and the transition into and out of middle school into high school. Despite the Western popular culture myth that all adolescents inevitably experience a period of "storm and stress" including chronic adolescent conflict with parents, mood disruptions, and risky behavior (Arnett, 1999), there is little empirical support that these behaviors are triggered solely by biological changes, but are instead related to the interaction between biological and environment factors (Arnett, 1999; Offer \& Schonert-Reichl, 1992; Steinberg \& Levine, 1997).

However, the extant literature does support the notion that although not inevitable, the transition into and through adolescence is a period of increased likelihood for experiencing a broad range of issues including: increased emotional volatility (Larson \& Richards, 1994), increased conflict with parents (Laursen, Coy, \& Collins, 1998), and 
increased likelihood of developing a broad range of internalizing disorders such as anxiety and depression (Costello, Mustillo, Erkanli, Keeler, \& Angold, 2003). Current research continues to support the importance of gaining a comprehensive understanding of the factors that contribute to the development of anxiety symptomatology at this key developmental stage (Costello, Egger, \& Angold, 2005). Indeed, "There is mounting evidence that many, if not all, lifetime psychiatric disorders first appear in childhood or adolescence" (Costello et al., 2005, p. 972).

\section{REVIEW OF THE LITERATURE \\ Introductory Background}

More than 30 million Americans exhibit chronic anxiety across the lifespan, affecting work productivity, quality of life, and financial well being (Greenberg, Sisitsky, Kessler, Finkelstein, Berndt, Davidson, et al., 1999; Marciniak, Lage, Dunayevich, Russell, Bowman, Landbloom et al, 2005; Spitzer, Kroenke, Linzer, Hahn, Williams, deGruy III et al., 1995). In fact, the National Comorbidity Survey (NCS) conducted research on 8,098 adolescents and adults from 15 to 54 years old age and found that an astounding $24.9 \%$ of adults maintained a lifetime anxiety disorder $(12.2 \%$ exhibited a 12 month prevalence) based on retrospective report (Kessler, McGonagle, Zhao, Nelson, Hughes, Eshleman et al., 1994). In addition to being treated in a mental health setting, anxiety disorders are also one of the two most common (and costly) mental health diagnoses in a primary care setting (Kroenke, Spitzer, Williams, Monahan, \& Löwe, 2007). In fact, anxiety disorders cost the United States an estimated $\$ 42.3$ billion dollars per year (Greenberg et al., 1999). Anxiety disorders also tend to develop at a young age 
- the National Comorbidity Study Replication estimated the median age of onset to be 11 years old (Kessler, Chiu, Demler, \& Walters, 2005).

Not only are anxiety disorders common, they also rarely occur in isolation; as many as $50 \%$ of children and adolescents with anxiety disorders meet criteria for additional mental health disorders (Anderson, 1994; Rapee et al. 2009). For example, anxiety disorders have been found to be the most common comorbid disorder with depression - ranging from $30 \%$ to $75 \%$ in preadolescents and between $25 \%$ and $50 \%$ in adolescents (Angold, Costello, \& Erkanli, 1999; Brady \& Kendall, 1992).

Childhood anxiety disorders, even when treated, often follow a chronic course (Hirshfeld-Becker \& Biederman, 2002). Indeed, when one anxiety disorder is treated and remits, even children who recover are at an increased risk of developing other diagnoses - especially other anxiety disorders (Bittner, Egger, Erkanli, Costello, Foley, \& Angold, 2007; Ferdinand, Dieleman, Ormel, \& Verhulst, 2007). For example, Cantwell and Baker's (1989) study on children diagnosed with separation anxiety disorder, overanxious disorder (now known as generalized anxiety disorder), or avoidant disorder (now known as social phobia) revealed that $25 \%$ of the children who no longer met the criteria of the original diagnosis met the criteria for a different anxiety disorder four years later. Another study showed that in addition to future internalizing (e.g., anxiety) disorders, boys with anxiety at age 11 were almost six times more likely to exhibit externalizing problems (e.g., aggressive behaviors, damaging property) at age 15 than non-anxiety disordered boys (McGee, Feehan, Williams, \& Anderson, 1992). Understanding child and adolescent anxiety can be challenging because developmental differences and related factors cause symptoms to vary considerably. 
Additionally, there are a number of factors that relate to the development of anxiety that suggest both a biological predisposition and moderating environmental factors.

Therefore, both of these broad areas will be addressed in the study.

Theoretical Framework

Four theoretical models guide this study. These are the Bioecological Model of Development (Bronfenbrenner, 1986; Bronfenbrenner \& Morris, 1998), the Bioinformational Theory (Lang, 1985), Triple Vulnerabilities Theory (Barlow 2000, 2002) and Social Cognitive Theory (Bandura, 1986).

Bioecological Model of Development

Bronfenbrenner's Bioecological model (Bronfenbrenner, 1986; Bronfenbrenner and Morris, 1998) considers a children's development within the context of a complex and dynamic system of inter-relationships between children and the persons, objects, and symbols in both the immediate and larger environment. Indeed, Bronfenbrenner's model considers more than just interpersonal interactions, recognizing that interaction with objects and symbols that provoke "attention, exploration, manipulation, elaboration, and imagination" (p. 6) duly affect developmental outcomes (Bronfenbrenner, 1999). This model emphasizes the child as an evolving "biopsychological human organism" (p. 5) whose development initially depends on complex reciprocal interactions with the immediate environment called the microsystem (Bronfenbrenner, 1999). As the layer closest to the child, the microsystem encompasses relationships and interactions within the family, school, neighborhood, and childcare environments.

Bronfenbrenner (1999) referred to the reciprocal interactions that occur regularly over extended periods of time, and which become increasingly more complex (as 
opposed to increasingly more repetitious), as proximal processes. For example, if an eleven-year-old boy spent one weekend with his grandparents learning when it was appropriate to say "please" and "thank you," this experience would not be considered a proximal process because it did not occur regularly (only one weekend) and was increasingly more repetitious (as opposed to increasingly more complex).

To be considered a proximal process, an interaction must also be initiated and responded to in both directions (Bronfenbrenner, 1999). Understanding a child's developmental trajectory must also take into account that relationships are not unidirectional. For example, the type of parenting that the child receives affects the child's beliefs and behaviors which, in turn, affect parental, teacher, and peer behavior toward the child. Furthermore, proximal processes exhibit themselves not only in reciprocal parent-child activities, but also in solitary or group play, formal school endeavors such as art, reading and math, peer social interactions, and athletic activities. Obviously, no two proximal processes are exactly the same, as they vary in "form, power, content and direction" (Bronfenbrenner and Morris, 1998, p. 996), and are informed by the unique characteristics of the individual and his or her environment.

$$
\text { Bronfenbrenner's (1999) process - person - context - time model (PPCT) }
$$
operationalizes the multifarious nature of the bi-directional interaction between proximal processes and the characteristics of the developing person, the immediate and larger environment in which the processes are occurring, and the social continuities and changes occurring within the historical context of the time period in which the person is living. The child, as the center of the Bioecological model, appears twice in the PPCT modelfirst, as an influencer of the proximal processes and later as the product of the "joint, 
interactive, mutually reinforcing effects" of the process, person, context and time (Bronfenbrenner and Morris, 1998, p. 996). In other words, the bioecological model views a person's characteristics as both an indirect "producer" and "product" in any developmental outcome (Bronfenbrenner, 1999). For example, a behaviorally inhibited six-year-old child might exhibit extreme shyness toward neighbor children. The child's parents witness her fear of interaction and allow her to stay in the house with them and avoid social contact with the neighbor children to reduce her anxious apprehension. As a result, as the child grows older her shyness and avoidance of novel situations not only continues to increase, but also generalizes to other stimuli (e.g., school, going to the zoo, thunderstorms) and begins to manifest itself physically and cognitively. Her parents witness her subclinical anxious symptoms and attempt to control the environment as much as possible to minimize her exposure to these events. In this scenario the child's anxious disposition that was reinforced by the environment eventually results in her becoming an adolescent who develops an anxiety disorder.

\section{Bioinformational Theory}

Lang's (1985) Bioinformational Theory views anxiety as consisting of three components: a physiological component, a subjective cognitive component, and a behavioral component. For example, when an individual encounters a threatening "fight or flight" situation, the physiological component activates the autonomic nervous system (e.g., increased respiration rate, increased heart rate). The subjective cognitive component refers to an individual's selective and focused attention to threatening cues (e.g., a growling dog) for the purpose of protection or escape. Lastly, behavioral reactions include measures taken to avoid threatening events such as running away. 
Lang posits that emotions in their most basic form are neurophysiological circuits that mediate approach and avoidance by way of associated neural pathways working together to form action tendencies. These action tendencies play an essential role in such behaviors as perception, attention, memory, and physical action (Lang, 1994). Lang believes that pleasant and unpleasant emotions are expressed on a spectrum along three dimensions - arousal (from low to high), valence (from pleasant to unpleasant), and control (from lack of control to complete control). Lang's theoretical view suggests that emotions primarily reflect the autonomic and somatic activation of two biologically "hard-wired" motivational systems, the appetitive motive system and the defensive motive system, which evolved in order to promote the survival of individuals and their offspring (Lang, 1994). The appetitive motive system, the motive system linked to pleasant emotions, is associated with nourishment, sexual activity and care for offspring. Contrasting this, the defensive motive system is the motive system linked to unpleasant emotions, and is associated with perceived environmental threat, pain and/or danger.

This defensive motive system becomes activated when a specific feared stimulus matches information represented in one of three distinct but highly associated information structures: stimulus representations, response representations, and meaning representations. The purpose of the defensive motive system is to escape or avoid threats of danger or pain. However, this system is activated only when the stimulus, response, and meaning information are highly associated (Lang, McTeague, \& Cuthbert, 2006). Stimulus representations are perceived cues (e.g. sensory cues such as video or text) from the environment that prompt retrieval. Meaning representations are the associated semantic information associated with the context of the stimulus representation. 
Response representations are mediated behaviors, physiological reactions, and/or expressive language that occur in the emotional context of the stimulus (Lang \& McTeague, 2009).

For example, one can read aloud a statement, itself a stimulus representation, "While swimming in the ocean a large white shark lunged forward with its jaws wide open and teeth showing, and crunched into my arm causing an explosion of pain." This statement could easily elicit a brief uncomfortable image for most people. However, for an individual with a severe shark phobia, reading this sentence, delivered via a verbal cue, serves as the sensory representation stimulus that activates the meaning representations (e.g., "all sharks are extremely dangerous"). This, in turn, activates the physiological response representation of heart palpitations, excessive sweating, and running away.

\section{Social Cognitive Theory}

Social Cognitive Theory (SCT) (Bandura, 1986, 1989) posits that human functioning is explained in terms of dynamic, triadic reciprocality, in which behavior, individual personal factors, and environmental events all operate as interacting determinants of each other-a term called reciprocal determinism. Each of these three factors does not necessarily influence behavior equally and differs based on the person, the specific behavior being examined, and the specific circumstances in which the behavior takes place (Bandura, 1989). Bandura emphasizes the complex bidirectional influence of a person's thoughts, emotions, and expectations, along with individual biological properties such as ethnicity, sex, or temperament on individual behavior and how this behavior reciprocally affects personal thought, emotion, and expectations. 
Although SCT reflects the classical behavioral view that rewards or punishments influence the frequency of behaviors in a given situation, it also contends that behavior is largely regulated through cognitive processes. Bandura (1989) emphasized the role that cognitions play in constructing reality and how these cognitions (e.g. memory, reasoning skills) change over time as a function of individual maturation and experience. In fact, Bandura suggests that people exhibit unique cognitive capabilities that determine behavior: symbolizing, forethought capability, vicarious capability, and self reflective capability.

Bandura (1989) emphasizes the role symbols such as physical images, mental images, and words play in providing meaning to life experience. Symbols provide the mechanism for enabling people to encode and store information that can be retrieved to problem solve and guide future behaviors through foresight. The cognitive process of foresight allows a person to anticipate behavioral consequences without actually engaging in the behavior (Bandura, 1989). A person's evaluation of an anticipated outcome, based on a foresight evaluation, is called expectancy. As a result, expected outcomes, rather than actual outcomes, strongly influence whether or not a behavior will be performed again (Bandura, 1989).

SCT bifurcates from classical behaviorism by stating that humans exhibit the ability to learn by observing others, which is referred to as observational or vicarious learning (Bandura, 1989). Vicarious learning serves the important purpose of enabling people to learn quickly while also providing the advantage of avoiding time-consuming or potentially dangerous trial and error situations. For example, a child would learn caution around high-traffic areas by observing a parent who models caution by looking 
both ways before crossing the street. In this situation, vicarious learning enables the child to stay safe without undergoing the inherent danger of the trial and error method - which could result in injury or death.

The cognitive capability of self-reflection involves a person's ability to analyze their experiences, reflect on their thought processes, and consequently alter their beliefs (Bandura, 1989). SCT posits that achievement behavior and effort are guided by a person's self-evaluation of their personal abilities and characteristics. Perhaps the most renowned construct of SCT, self-efficacy, involves building a robust belief of personal efficacy based on mastery experiences where the individual achieves successful individual performance of a behavior in multiple scenarios (Bandura, 1989). Selfefficacy is influenced by personal success and failure, observing others' successes and failures, as well as receiving input from outside sources (e.g., parents, siblings, teachers) about their performance in a given area.

\section{Triple Vulnerabilities}

The Triple Vulnerabilities Theory (Barlow 2000, 2002) is a diathesis-stress model applicable to the development of anxiety, anxiety disorders, and related emotional disorders (e.g., depression). Diatheses are a combination of biologically based and socially learned predispositions that render people vulnerable to some disorder when life stress of a sufficient type, number, and/or intensity is experienced (Lazarus \& Folkman, 1984). Accordingly, people with multiple or severe underlying predispositions/ vulnerabilities require less situational life stress to activate a given disorder (Lazarus $\&$ Folkman, 1984). 
The triple vulnerabilities model posits that three interacting sets of vulnerabilities are involved in the etiology of anxiety: a generalized biological vulnerability, a generalized psychological vulnerability, and a specific psychological vulnerability based on early social learning experiences (Barlow, Allen, \& Choate, 2004). Nonspecific biological vulnerabilities include genetic contributions such as a behaviorally inhibited temperament or the personality trait of neuroticism (Barlow et al., 2004). People develop a generalized psychological vulnerability as a result of early life experiences (e.g., frequent family moving, parental divorce or separation) that produce a general sense of lack of personal control over the environment and result in the person exhibiting negative affect (Chorpita \& Barlow, 1998). When a person possesses these first two vulnerabilities and the experiences life stress of sufficient type, number, and/or intensity, the results, according to this model, are the clinical syndromes of generalized anxiety disorder (characterized by frequent and constant worry) and/or other internalizing disorders such as major depression (Barlow et al., 2004).

When early learning experiences result in an individual viewing somatic sensations (e.g., sweaty palms, heart palpitations), intrusive thoughts (e.g., thoughts of hurting family), or social evaluation (e.g., fear of people) as dangerous, they are said to have a specific psychological vulnerability (Barlow, 2002). Previous research indicates that when this vulnerability coincides with the generalized biological and psychological vulnerabilities previously mentioned, distinct anxiety disorders such as social phobia, obsessive-compulsive disorder, panic disorder, and specific phobias develop (e.g., Barlow, 2000, 2002; Bouton, Mineka, \& Barlow, 2001).

\section{Theoretical Interconnection}


The present study draws upon these four theoretical models. First, this study acknowledges that anxiety is a complex emotion that consists of a physiological, cognitive and behavioral component as in Lang's (1985) Bioinformational Theory. Second, this study recognizes that although children and adolescents are not "born" anxious, certain biological and psychological predispositions render some more vulnerable to developing anxiety when they encounter life stressors as reflected in Barlow's $(2000,2002)$ Triple Vulnerabilities Theory. Third, this study considers parentchild interactions from late childhood through early adolescence by focusing on parental anxiety symptoms through the lens of Bandura's (1989) Social Cognitive Theory. SCT recognizes the human ability to vicariously learn through observation and how observing parental anxiety behaviors might contribute to a child or adolescent's anxiety behaviors. Fourth, this study recognizes the role of the child characteristic of a behaviorally inhibited temperament in the development of child and adolescent anxiety. Specifically, this study acknowledges that certain children and adolescents exhibit a biological propensity toward behaving a certain way and that this behavior elicits certain responses from parents or other caregivers such as behavioral control. This reciprocal action is reflected in the triadic reciprocality of Bandura's (1989) Social Cognitive Theory and the give-and-take nature of proximal processes of Bronfenbrenner and Morris' (1998) Bioecological Model. Lastly, development plays a central role in this study. That is, adolescence, and specifically the transition from middle school to high school, is a period of rapid physical, emotional and cognitive change. Developmentally, it's also a time where adolescents' desire autonomy and time with peers while simultaneously relying on decision making guidance and support from parents (Zarett \& Eccles, 2006). Currently 
the longitudinal effects of the changing, continuous, and reciprocal interactions that occur over time between the individual characteristics of the child and adolescent (e.g., behaviorally inhibited temperament) and the environment (e.g., parental control, parental anxiety symptoms) on the development of child and adolescent anxiety are not well understood.

The following hypothetical case study of "Robert" illustrates how a child's exposure to empirically supported risk factors could put him on the trajectory to develop an anxiety disorder in adolescence.

Robert was born to White parents in a middle-class suburb in the Midwest. Robert's parents have always classified him as shy or behaviorally inhibited since he was a baby. At four years old, Robert's parents attended a neighborhood block party along with 20 other neighbors and their children. Robert was always labeled "shy" by his parents and, true to form, Robert stayed within a few feet of his parents during the entire four hour party, refusing to join in with the other same age children in activities. Robert's parents, attempting to reduce Robert's apprehension that accompanies his shyness, decided after the neighborhood party to forego attendance at future neighborhood gatherings. This parental decision reinforced Robert's biological predisposition of behavioral inhibition.

When Robert was seven years old, Robert's mother, Katie, asked her next-door neighbor during a social visit about her progress on a new exercise plan and received a very terse answer in response. Katie is a self labeled "worrier about everything" who constantly seeks the social approval of others, including her next-door neighbor. As a result, following this incident Katie perseverated about this interaction for several days. 
Katie's fear of negative social evaluation manifested itself in the form of preoccupation, wondering what her neighbor was thinking about her; as a result, she avoided social visits with the neighbor. Thus, Robert learned from his mother's behaviors that he was susceptible to interpersonal shortcomings and could easily fail and be embarrassed during social interactions with his own friends if he wasn't careful.

When Robert is 11 years old he participated in a group social activity during class when another student called him "Bobby Squarepants," which elicited raucous laughter from the class. As a person who is highly aware of and sensitive to perceived social judgments by others, this incident upset Robert and caused him to be even more reluctant to participate in group social interaction. When Robert arrived home after school that day, he appeared preoccupied and emotionally withdrawn to his mother, but retreated to his room she could engage him. Katie decided to wait until Robert's father came home to find out what was going on with Robert. During the family meal, Robert reluctantly recounted what happened earlier in the day. As Robert continued with the story, Katie became visibly upset and began breathing heavily. After observing his mother, Robert's own breathing and heart rate intensified and his belief that the world is "dangerous" was reinforced. Robert's father, Steven, made the immediate decision to withdraw Robert from the band and soccer programs and to drive Robert to school daily to avoid the namecalling classmate. This decision immediately diminished both Robert's and Katie's shortterm physiological symptoms, but reinforced the underlying cause of the anxiety.

For the next four years Robert's parents continued to minimize "potentially threatening" peer social interactions. As a 15-year-old freshman enrolled in speech class, Robert was assigned the task of giving a 15 minute presentation in front of 30 of his 
classmates. Immediately before Robert was supposed to give his presentation, he began noticing that his heart was beating rapidly and he started to experience severe breathing difficulty accompanied by what he described as a feeling of "sheer terror." As Robert stood up to move to the front of the class he began hyperventilating and was escorted out of the class by the teacher and brought to the school nurse. Eventually Robert visited a psychologist and was diagnosed with panic disorder with agoraphobia. Anxiety

It is universally accepted that all people have manifested "anxiety" in some form, whether as an excessive fear of public speaking, extreme discomfort in closed spaces, or simply feeling physically ill prior to taking a major test. However, anxiety takes many forms and therefore can be challenging to universally classify. So, how then does one operationalize anxiety?

Anxiety can be characterized as a "basic, fundamental, discrete emotion" experienced by all people, regardless of age, culture, or race (Barlow, 2004, p. 41). Izard (1977) viewed anxiety as an intermingling of emotions, theorizing that anxiety consists of a varied combination of fear, distress, sadness, anger, shame, guilt, interest and/or excitement. Although fear is the consistent emotion experienced in a situation in which a person is anxious, the context/setting, previous learning, and perceived threat dictates the specific blend of emotions (Izard, 1977).

Barlow (2004) characterized anxiety as a cognitive-affective process where people enter "a state of helplessness, because of a perceived inability to predict, control, or obtain desired results or outcomes in certain upcoming personally salient situations or contexts," (p. 64). He suggested that a more precise term for anxiety would be "anxious 
apprehension" from the standpoint that anxious people are continually in the process of attempting to cope with anticipated negative future upcoming events.

\section{Diagnosis and Classification}

Diagnosing and classifying anxiety disorders in the child and adolescent

population is a fairly recent phenomena. In fact, it was not until 1980 that the Diagnostic and Statistical Manual of Mental Disorders (DSM-III) (American Psychiatric

Association, 1980), created a separate diagnostic section entitled "anxiety disorders of childhood and adolescence" which included three diagnoses: separation anxiety disorder, overanxious disorder, and avoidant disorder of childhood or adolescence. The current version of the DSM, the DSM-IV-TR (American Psychiatric Association, 2000), subsumed overanxious disorder under generalized anxiety disorder and avoidant disorder under social phobia, leaving separation anxiety disorder as the only anxiety disorder unique to childhood and adolescence. The remaining existing anxiety disorders in the DSM-IV-TR are applicable to both adults and children: panic disorder, agoraphobia, specific phobia, social phobia, obsessive-compulsive disorder, generalized anxiety disorder and posttraumatic stress disorder (American Psychiatric Association, 2000).

Anxiety diagnoses differ considerably in children and adolescents due to the emotional, social and cognitive differences that develop across the lifespan (Costello \& Angold, 1995). These developmental factors affect the manner in which children and adolescents of varying ages experience and express anxiety (Garber \& Strassberg, 1991). For example, animal phobias (e.g., extreme terror of spiders) and separation anxiety disorder, the fear of separation from primary caretakers, primarily manifest during early childhood (Feigon, Waldman, Levy \& Hay, 2001; Sheehan, Sheehan, \& Minichiello, 
1981). Social phobia, such as a fear of writing on the blackboard in front of other peers, would primarily present during middle childhood and adolescence (Essau, Conradt, \& Petermann, 1999). The repetitive intrusive thoughts called obsessions and/or compulsive behaviors associated with obsessive-compulsive disorder arise primarily during early and middle childhood (Karno, Golding, Sorenson, \& Burnam, 1988). The pervasive excessive worries associated with generalized anxiety disorder occur most often in older children and adolescents (Masi, Millepiedi, Mucci, Poli, Bertini, et al., 2004). Lastly, panic disorder, along with its associated symptoms of paralyzing terror, raging heartbeat, and difficulty breathing, occur most frequently during adolescence (Last \& Strauss, 1989).

Spence (1997) conducted a confirmatory factor analysis on data from 1,397 children 8 to 12 years old in two separate communities to examine the degree to which child emotional, behavioral, cognitive and physiological symptoms that comprise anxiety disorder diagnoses cluster together. The results of his factor analysis revealed a model with six discrete and highly correlated first order factors (panic-agoraphobia, social phobia, separation anxiety, obsessive-compulsive problems, generalized anxiety, fear of physical injury) loading onto a single higher order factor that reflected overall anxiety. Spence (1997) suggested that the high intercorrelations between the six first order factors may explain the high levels of comorbidity often found among children diagnosed with anxiety disorders. These results highlight the existence of a global anxiety factor underlying all child anxiety disorder diagnoses (Spence, 1997).

\section{Demographic Correlates}


Demographically, sex has been the most clearly linked feature with anxiety, with several studies showing females demonstrating nearly twice the risk of anxiety disorders as their male counterparts (e.g., Costello et al., 2003; Lewinsohn, Zinbarg, Seeley, Lewinsohn, \& Sack, 1997). However, this association is not consistent, as some studies have revealed no significant sex differences in anxiety prevalence rates or differences based solely on the specific anxiety disorder studied (e.g., Canino, Shrout, Rubio-Stipec, Bird, Bravo, Ramirez, et al., 2004; Ford, Goodman, \& Meltzer, 2003). Besides sex, no demographic correlates have been clearly and consistently linked with anxiety (Rapee et al., 2009) including family size, parents' marital status, educational level, or ethnicity (Canino et al., 2004; Ford et al., 2004, Lewinsohn et al., 1997). Socioeconomic status has, as the exception, been shown to have a small negative association with anxiety, although results have been inconsistent (e.g., Cronk, Slutske, Madden, Bucholz, \& Heath, 2004; Xue, Leventhal, Brooks-Gunn, \& Earls, 2005).

Risk Factors Associated with Anxiety Disorders

Because the anxiety model is multi-factorial, namely, the result of multiple etiological elements acting in concert, one must consider not only the contributing individual risk factors, but also the empirically supported environmental risk factors, that shape the development and perpetuation of anxiety. Risk factors are precursors with a theoretical rationale and demonstrated ability to place children at an increased risk for later development of a problem - in this case, anxiety (Arthur, Hawkins, Pollard, Catalano, \& Baglioni, 2002). Several individual risk factors for the development of anxiety disorders in children and adolescents have been identified in the literature.

Temperament \& Behavioral Inhibition 
The definition of the word temperament has changed as advances in research have been made. Allport (1937) originally conceptualized temperament as being largely dependent on heredity and constitutional makeup calling it the "characteristic phenomena of an individual's emotional nature" (p. 54). Allport's temperament definition placed emphasis on emotional reactivity and the way in which a person responded to stimulation, as well as the person's accompanying mood. While Allport's temperament focused specifically on individual differences in emotional reactivity, later research revealed a much broader picture of temperament. Currently, temperament can best be viewed as two synergistic systems that work together to modulate a child's behavioral response to stimuli: reactivity and regulation (Rothbart \& Bates, 2006). Reactivity is the biologically based, general response style to stimuli in the environment. Regulation, on the other hand, is the system that acts to limit reactivity. Temperament is a tendency or disposition to behave in a certain way and is not continually expressed, but rather, it is elicited by the environment (Rothbart \& Bates, 2006). Temperament is best classified as the core affective, activational, and attentional component of personality that influences trajectories of development (Rothbart \& Bates, 2006).

Kagan (1989) conceptualized temperament as a psychological quality with a relatively stable biological basis in the individual's genotype, but with considerable variability between individuals. Kagan and colleagues' (Kagan, 1989; Kagan \& Snidman, 1991; Kagan, Snidman, \& Arcus, 1992) estimate heritability of temperament at .50 , while other researcher's findings were more conservative, ranging from .30 to .50 (see Saudino \& Cherny, 2001). Although temperament itself is stable, the expression of temperament varies as the environment activates and modulates an individual's 
biologically-based tendencies. Specifically, the temperamental predisposition toward behaviorally inhibited behavior has been identified in the literature as being a highly influential individual genetic factor in the development of anxiety (Hudson \& Rapee, 2004; Manassis \& Bradley, 1994; Hirshfeld et al., 1992; Turner, Beidel \& Wolff, 1996). But what is behavioral inhibition?

Kagan and colleagues' (Kagan, 1989; Kagan \& Snidman, 1991; Kagan et al., 1992) research of two-year-old Caucasian children revealed a temperament style characterized by restricted and inhibited social behavior towards strangers and novel situations, as well as the tendency to maintain close proximity to safety figures in approximately 15 to $20 \%$ of the sample. These children were classified as exhibiting an inhibited temperament style or being "high-reactive." While it will be referred to as behavioral inhibition in this paper, in the literature behavioral inhibition is also referred to as shyness, withdrawal, low approach and sociability (reverse scored) (Kagan, Reznick, Clarke, Snidman, \& Garcia-Coll, 1984; Sanson, Pedlow, Cann, Prior, \& Oberklaid, 1996; Rapee et al., 2009).

On the other hand, Kagan and colleagues' (Kagan, 1989; Kagan et al., 1984; Kagan et al., 1992; Kagan \& Snidman, 1991) found that approximately 30 to $35 \%$ of twoyear-old Caucasian children exhibited the exact opposite response, showing rapid approach to novel situations or unfamiliar objects/people. These children were classified as exhibiting uninhibited temperaments or being "low-reactive." This characteristic appears to be stable, with approximately $75 \%$ of the children classified as either inhibited or uninhibited at two years of age maintaining this classification at the age of eight (Kagan, Reznick, \& Snidman, 1988). 
Physiologically, individuals with an inhibited temperament also exhibit higher amygdala activation, resulting in increased salivary cortisol levels, increased muscle tension, high heart rates, and elevated urinary catecholamine levels (Kagan \& Snidman, 1999). Because of the noted and significant physiological differences between inhibited and uninhibited people, Kagan posits that people are qualitatively classified as either inhibited or uninhibited, as opposed to placed on a spectrum from inhibited to uninhibited (Kagan \& Snidman, 1991). For those people classified as inhibited, Kagan, Snidman, Zentner, and Peterson's (1999) research suggested that the level of behavioral inhibition affects the likelihood of developing later anxiety problems. During this experiment the researchers measured levels of behavioral inhibition in four-month-old infants and anxiety symptoms at seven years of age. The results showed a marked difference between high and low behaviorally inhibited children, with $45 \%$ of the high behaviorally inhibited, but only $15 \%$ of the low behaviorally inhibited children, exhibiting anxiety symptoms.

\section{Parenting Behaviors}

Parenting involves a collection of specific behaviors that influence child outcomes both individually and collectively (Hoghughi \& Long, 2004). Parents play a vital role in the developmental trajectory of their children (Fletcher, Steinberg, \& Sellers, 1999) as children and adolescents are reliant on their parents for physical, emotional, and financial support. As such, they usually have less control than their parents over a portion of their environment (e.g., where they live, what school they attend). Indeed, a parent influences and/or controls to varying degrees different elements of their offspring's physical, emotional, social, and intellectual opportunities and environments. Therefore, it would 
be expected that unhealthy parenting behaviors would at a minimum increase the likelihood of offspring to exhibit unhealthy behaviors and, perhaps, develop some type of emotional disorder.

Although most parents do not directly control or affect their adolescent's environment to the extent that they do with children, evidence suggests that parenting behaviors do profoundly affect the adolescent. In fact, Fletcher and colleagues' (1999) noted that "Research on child socialization over the past several decades has consistently demonstrated that one of the most potent influences on the psychological and behavioral well-being of adolescents is the type of parenting they experience"(p. 599).

In an attempt to quantify the quality of parenting received, Baumrind (1971, 1991) classified family parenting styles by examining the ways in which parental values, behaviors, and standards, as well as parental expectations for their offspring's behavior, are transmitted. As such, Baumrind's (1971) construct of parenting style is intended to capture the typical nature of parents' behaviors. Her concept of parenting styles relies on the assumption that the primary role of parents is to influence, control, and teach their children (Baumrind, 1991) and is meant to describe only "normal" variations in parenting behavior (as defined by the culture). Therefore, deviant parenting styles that included abusive or neglectful parenting behaviors were not included in her original typology (Baumrind, 1991).

Baumrind categorized parenting styles based on the parents' behavioral control (also known as demandingness) and responsiveness (also known as parental warmth or supportiveness). Demandingness refers to a parent's "maturity demands, supervision, disciplinary efforts and willingness to confront the child who disobeys" (Baumrind, 1991, 
p. 61). Parental responsiveness, on the other hand, is defined as "the extent to which parents intentionally foster individuality, self-regulation, and self-assertion by being attuned, supportive, and acquiescent to children's special needs and demands" (Baumrind, 1991, p. 62).

Baumrind categorized parents according to the extent to which they were both demanding and responsive, resulting in three parenting styles-authoritarian, authoritative, and indulgent - that encompassed naturally occurring parental values, practices, and behaviors (Baumrind, 1991). Later, Maccoby and Martin (1983) extended Baumrind's work to conceptualize a fourth parenting style — uninvolved.

Parents with a high degree of demandingness and a low degree of responsiveness were classified authoritarian. Authoritarian parents tend to maintain an emotionally distant and unresponsive attitude toward their offspring while simultaneously upholding rigid and absolute child behavior standards; they place an emphasis on unquestioned obedience and discourage verbal give-and-take between parent and child (Baumrind, 1991). Accordingly, Baumrind (1971) found that children raised with authoritarian parents tended to have lower levels of independence and social responsibility.

Parents classified as authoritative, in contrast, exhibit both a high degree of demandingness and a high degree of responsiveness (Baumrind, 1991). Authoritative parents enforce the rules as necessary, but do so in a warm and supportive manner. These parents also set clear, enforceable standards, practice open communication, and encourage child independence and individuality, as well as participate in a verbal giveand-take with their children (Baumrind, 1991). Not surprisingly, children of authoritative 
parents exhibit high levels of social and cognitive competence when compared to children from other parenting styles (Baumrind, 1991; Weiss \& Schwarz, 1996).

Indulgent (permissive) parents are high in responsiveness and low on demandingness. Indulgent parents avoid confrontation and imposing controls or restrictions and, therefore, rarely punish their children. These parents allow their children to regulate their own behavior for the most part and are tolerant and accepting of their child's impulses, resulting in low standards for mature behavior (Baumrind, 1971). Children of permissive parents are associated with several negative outcomes including: emotional immaturity, low levels of impulse control and self-reliance, and deficient social responsibility and independence (Baumrind, 1991).

Parents classified as uninvolved exhibit a parenting style low in both demandingness and responsiveness. Uninvolved parents are emotionally indifferent toward their children, lacking any type of interest, much less emotional intimacy (Darling \& Steinberg, 1993). When an uninvolved parent is forced to interact with his or her child due to a child's intrusion, the parent may respond with hostility and rejection (Darling \& Steinberg, 1993). Children of uninvolved parents perform poorly in nearly all domains, exhibiting sizeable academic and delinquency issues, as well as diminished social competence and psychosocial functioning (Maccoby \& Martin, 1983).

Virtually all of the early research on parenting styles is focused on maternal parenting style, with the assumption that both the mother and the father exhibit a homogenous parenting style (Simons \& Conger, 2007). While evidence suggests that most parental dyads have similar parenting styles, Baumrind (1973) revealed that she omitted approximately $1 / 4$ of the mothers and fathers from her analysis because they 
displayed different parenting styles. Simon and Conger's (2007) study reinforced Baumrind's findings, reviewing that a substantial number of mothers and fathers used different parenting styles. That is, child's report indicated that $22 \%$ of parents exhibited different parenting styles, while observer report showed that an astounding $42 \%$ of parents displayed different parenting styles. But why is this important?

Numerous theoretical models have emphasized the environmental mechanisms of parenting behaviors on the development, maintenance, or improvement of child anxiety disorders (e.g., Chorpita \& Barlow, 1998; Manassis \& Bradley, 1994; Hudson \& Rapee, 2001). Most previous studies that considered the contribution of parental factors to child anxiety, however, fail to take into account that mothers and fathers may influence children's anxiety in different ways (Bögels \& Phares, 2008). Current models of the etiology and maintenance of child and adolescent anxiety as they relate to parenting behaviors have focused on and been tested primarily with mothers and have failed to address the interaction between the sex and age of the child and maternal and paternal roles (Block, 1983; Bögels \& Phares, 2008; Connell \& Goodman, 2002). Indeed, "Fathers continue to be ignored in research related to many types of developmental psychopathology" (Bögels \& Phares, 2008; p. 540). For example, in Van Der Bruggen, Stams, and Bögels' (2008) meta-analysis of 22 observational studies involving the correlation between parental control and child anxiety, 13 considered mothers' behaviors only, eight considered a primary caregiver or mixed father and mother sample where mothers were routinely over-represented, and only one study considered fathers' behaviors. Thus, when considering the extant literature, failing to account for father 
behavior has resulted in both credit and blame for the transmission of anxiety disorders being placed on mothers (Bögels \& Phares, 2008).

Despite fathers having been mostly ignored in the literature, father involvement in raising children and adolescents continues to swell (Pleck \& Masciadrelli, 2004) with fathers becoming increasingly involved in the child rearing process (Bailey, 1994). The trend of increased father involvement is especially pronounced among two-parent families, but has been balanced by a marked decrease in father involvement when the father lives outside the child's home (Cabrera. Tamis-LeMonda, Bradley, Hofferth, \& Lamb, 2000). As both the level of child and adolescent anxiety (Twenge, 2000) and father absences has increased during the last 40 years (from $6 \%$ in 1960 to $24 \%$ in 2000 ) (Cabrera et al., 2000) the challenges of understanding the effects of one on the other has become increasingly more complex (Winsler, Madigan, \&Aquilino, 2005). Furthermore, a number of biological and socially reinforced differences between mothers and fathers predispose them to interact with their children differently (Bögels \& Phares, 2008). In fact, Block (1983) posited that previous research underestimated the degree to which parenting practices varied according to the gender of the child and that the dynamic nature of this relationship often caused these differences to be more pronounced during later stages of development. As such, these differences in interactions could either act as risk or protective factors against the development of child anxiety.

Parenting behaviors characterized by control or overprotectiveness has shown the clearest connection to child and adolescent anxiety in the literature (McLeod, Wood, \& Weisz, 2007; Murray, Creswell, \& Cooper, 2009). In fact, parental control has exhibited the largest effect sizes when compared with any other parenting behavior (e.g., lack of 
parental warmth, parental rejection) across several meta-analyses of parenting behaviors (see McLeod et al., 2007; Wood McLeod, Sigman, Hwang, \& Chu, 2003). While it will be referred to as parental control in this paper (the opposite of autonomy granting), this construct has been operationalized differently in the literature (e.g., overcontrol vs. healthy control, control vs. autonomy granting, control vs. independence) (Rapee et al., 2009).

Chorpita and Barlow (1998) posited that a child's level of healthy control, defined as the child's relative ability to "personally influence events and outcomes in one's environment," (Chorpita \& Barlow, 1998, p. 5) will either reduce or increase the child's likelihood of developing anxiety. Therefore, for normal, non-anxious development to occur, children and adolescents must be provided with the opportunity to experience ageappropriate control over events in the environment. Parents who manage the environment through the implementation of developmentally inappropriate or excessive control measures diminish the children's or adolescents' sense of self efficacy over their environment and create a sense of individual uncontrollability and helplessness (Barlow, 2002). The cognitive internalization of helplessness that results from a sense of uncontrollability over life events has been referred to as "a primary pathway to the development of anxiety" (Chorpita \& Barlow, 1998, p. 5).

As the definition of parental control has been refined through research, two types of control have emerged in the literature: psychological control and behavioral control. Psychological control consists of negative parental behaviors that control child behavior through manipulation of the love relationship between the parent and child as a means of inhibiting child independence and autonomy (Barber, 1996; Barber, Olsen, \& Shagle, 
1994; Pettit, Laird, Dodge, Bates, \& Criss, 2001). For example, parents exerting psychological control might: advocate perfectionistic expectations or unattainable standards and then withdraw love when the expectations/standards are not met; discourage the expression of negative emotions in their presence (e.g., anger, fear, sadness); or forbid the child from questioning or disagreeing with them or attempt to elicit guilt or disappointment in the event of child questioning or disagreement.

Conversely, behavioral control consists of parental behaviors that provide children and adolescents with developmentally appropriate monitoring, guidance and supervision (Pettit et al., 2001). Cummings, Davies, and Campbell (2000) found that behavioral control could be categorized into two subtypes, parental discipline and parental monitoring. Parental monitoring, defined in terms of parental awareness of their offspring's whereabouts, activities, and companions, has been identified as the key factor in effective behavioral control during the middle childhood and adolescent years (Brown, Mounts, Lamborn, \& Steinberg, 1993; Pettit et al., 2001; Stattin \& Kerr, 2000). Parental discipline involves setting clear standards and rules for behavior and the enforcement of consequences when the standards or rules are broken (Cummings et al., 2000).

While the link between parental control and child and adolescent anxiety has been empirically established, the factors that increase the likelihood of parental control are not easily distinguished (Ungar, 2009). Among children with no or diminished environmental and/or biological vulnerabilities, social factors have been identified as contributing factors to increased parental behavioral control (Ungar, 2007). Social factors that may contribute to the patterns of controlling parenting include such trends as smaller middle-class families (e.g., fewer children are "easier" to control), increased 
competition (e.g., academics, sports, performing arts) and pressure to succeed among children and adolescents, along with the parental perception that the world is becoming a more dangerous place despite evidence to the contrary (Schor, 2003; Ungar, 2009). In fact, Chesney-Lind and Belknap (2004) showed that the world is actually much safer place than it was 40 years ago. For example, their research found that girls growing up today compared to girls growing up in the 1960 s and 1970 s were: $50 \%$ less likely to be murdered, $60 \%$ less likely to be involved in a motor vehicle accident totality, $75 \%$ less likely to commit suicide, and $40 \%$ less likely to be arrested.

What has emerged in the literature is that high levels of parental behavioral control are healthy and adaptive for children and adolescents who are exposed to truly dangerous environmental stressors (e.g. neighborhoods with high levels of violence, drug and alcohol use, gang activity) but can serve as an anxiety risk factor for children and adolescents in low-risk environments (Baumrind, 1971; Chapman \& Woodruff -Borden, 2009; Lamborn, Dornbusch, \& Steinberg, 1996). In other words, parental behavioral control is healthy and adaptive when it is congruent with the actual level of environmental risk and is a risk factor for anxiety when the level of behavioral control is greater than the actual level of environmental risk.

\section{Parental Anxiety Symptoms}

Evidence from several studies demonstrates that offspring of parents with an anxiety disorder are up to seven times more likely to exhibit clinical levels of anxiety symptoms than offspring of non-anxious parents (Beidel \& Turner, 1997; Biederman, Petty, Faraone, Henin, Hirshfeld-Becker, Pollack, et al., 2006) with shared genes accounting for approximately $30-40 \%$ of the variance in anxiety symptoms (Eley \& Lau, 
2005). But how does one account for the remaining $60-70 \%$ of the variance in anxiety symptoms? While there is an abundance of evidence that illustrates the correlation between parental overcontrol and subsequent anxiety problems in offspring (McLeod et al., 2007), there is also evidence that anxious parents do not necessarily overcontrol their offspring. In fact, using a combination of interview, self-report and direct behavioral observation, Turner, Beidel, Roberson-Nay and Tervo's (2003) research on anxious parents and their offspring showed that anxious parents were neither overcontrolling during routine activities nor in a structured non-conflictual play task. On the other hand, anxious parents did report significantly higher levels of personal distress than nonanxious parents while observing their children during both scenarios, highlighting social learning as a route for the development of anxiety (Turner et al., 2003)

Specifically, the social learning construct of modeling has been identified for its role in the development of anxiety (Fisak \& Grills-Taquechel, 2007; Murray et al., 2009). In this context, modeling is a process where a person vicariously "learns" how to behave anxiously by observing another's response to stimuli. Research has documented the role of modeling in the acquisition of specific phobias (e.g., animal, blood), social phobia, and panic disorder (Mineka \& Zinbarg, 2006). In the parent-child and parent-adolescent dyad this could take the form of a parent exhibiting physical symptoms in front of the child or adolescent (e.g., hyperventilation, shaking) or observing parental avoidance to cope with anxiety provoking stimuli (e.g., crossing the street to avoid a dog on a leash). In a seminal study, Muris, Steernemen, Merckelbach, and Meesters (1996) examined the association between parental modeling of anxiety and child anxiety through a single parental self-report question rated on a 3-point likert scale ("never", "sometimes", or 
"always"): "To what extent do you generally express your fears in the presence of your children?" (p. 266). The results showed that modeling of anxiety mediated the relationship between anxiety of the mother and anxiety of the child. In other words, mothers who "always" expressed fears in the presence of their children had children who exhibited the highest fear scores. Furthermore, mothers who "never" expressed fears in the presence of the children had children who exhibited the lowest fear scores.

In a later series of studies, Muris and colleagues'(Grüner, Muris, \& Merckelbach, 1999; Muris, Meesters, Merckelbach \& Hülsenbeck, 2000; Muris \& Merckelbach, 1998; Roelofs, Meesters, ter Huurne, Bamelis, \& Muris, 2006) used a child report measure, the Anxious Rearing Scale of the My Memories of Upbringing for Children (EMBU-C; Markus, Lindhout, Boer, Hoogendijk, \& Arrindell, 2003), to examine the association between anxious parenting and child anxiety. This 10-item measure assesses child perception of anxious parenting behaviors and includes such items as: "Your parents are afraid that something might happen to you." Summarily, these studies found a statistically significant correlation between anxious parental rearing behaviors and child report of anxiety related symptoms (Grüner et al., 1999; Muris et al., 2000; Muris \& Merckelbach, 1998; Roelofs et al., 2006), further supporting the role of parental transmission of anxiety to children through parental modeling. Parents who consistently model anxious behavior tend to have children who exhibit anxiety symptoms more frequently, with greater intensity, and across a wider range of situations than children with non-anxious parents (Bögels \& Brechman-Toussaint, 2006). On the other hand, parental modeling can also have an anxiety buffering effect. For example, results from Egliston and Rapee's (2007) study showed that children whose mothers who reacted 
calmly toward novel, fear-relevant stimuli in their presence exhibited more positive affective reactions and approach behaviors when subsequent novel, fear-relevant stimuli were introduced without their mothers.

\section{Current Study}

The first purpose of this study is to examine the extent to which a set of key risk factors predict adolescent anxiety across a 36 month period (approximately age 12 to 15 years old). Despite a strong research base supporting individual connections between child behavioral inhibition, levels of parental control, parental anxiety symptoms and child and adolescent anxiety, the joint, longitudinal associations have received scant attention in the literature. Specifically, this study will examine the extent to which children's early behavioral inhibition, and levels of parental control and parental (both maternal and paternal) anxiety symptoms are related to adolescent anxiety during a key developmental period, the transition from middle to high school.

The second purpose of this study is to determine whether a mediated model of adolescent anxiety (see Figure 1) or a moderated model of adolescent anxiety (see Figure 2) best fits the data from the National Institute of Child Health and Human Development (NICHD) Study of Early Child Care and Youth Development (SECCYD). These models represent two different theoretical approaches by which behavioral inhibition, paternal anxiety, maternal anxiety, and parental control are related to the development of adolescent anxiety. Investigating moderators and mediators allows exploration of relationships beyond bivariate relationships by "addressing questions of why, how, and for whom the relation holds" (Fairchild \& McQuillin. 2010, p. 54). 
Mediator variables (M) are used to illustrate how or why the independent variable (X) and the outcome variable (Y) are related by using an intermediate variable to ascertain both the direct effect $(\mathrm{X}$ on $\mathrm{Y})$ and the indirect or mediated effect $(\mathrm{X}$ on $\mathrm{Y}$ through M) (Fairchild \& McQuillin. 2010). Mediator variable models enable researchers to describe the independent variable pathways of influence on the outcome variable. If the hypothesized mediated model of adolescent anxiety (Figure 1) is found to be true, an interdependent relationship between the independent variables (Behavioral Inhibition, Paternal Anxiety, Maternal Anxiety) and the mediator variable (Parental Control) on the outcome variable (Adolescent Anxiety) would exist. Specifically, each of the respective independent variables (Behavioral Inhibition, Paternal Anxiety, Maternal Anxiety) would predict the mediator variable (Parental Control), which would, in turn, predict the extent to which an adolescent exhibits anxiety.

Moderator variables $(Z)$ are hypothesized third variables or conditions that change or qualify the strength and/or direction of the relationship between an independent variable (X) and an outcome variable (Y) (Fairchild \& McQuillin, 2010). Contextually, moderator variables (Z) enhance external validity by enabling researchers to demonstrate the conditions under which the relationship between an independent variable $(\mathrm{X})$ and an outcome variable (Y) exist (Fairchild \& McQuillin, 2010). If the hypothesized moderated model of adolescent anxiety (Figure 2) is true, certain conditions of the moderator variable (Parental Control) will strengthen the relationship between the independent variables (Behavioral Inhibition, Paternal Anxiety, Maternal Anxiety) and the outcome variable (Adolescent Anxiety). That is, the interactions between the independent variables (Behavioral Inhibition, Paternal Anxiety, Maternal Anxiety) and 
the moderator variable (Parental Control) be significantly associated with the outcome variable (Adolescent Anxiety).

The specific research questions for the study follow.

1) To what extent do Behavioral Inhibition, Parental (Maternal and Paternal) Anxiety, and Parental Control jointly contribute to Adolescent Anxiety?

2) Does a mediated model of adolescent anxiety (Figure 1) or a moderated model of adolescent anxiety (Figure 2) best fit the data from the National Institute of Child Health and Human Development (NICHD) Study of Early Child Care and Youth Development (SECCYD)?

3) Are associations between ratings of Behavioral Inhibition at age $41 / 2$ years and ratings of Parental (Maternal and Paternal) Anxiety and Adolescent Anxiety when adolescents were approximately 12 and 15 years mediated by Parental Control at 12 and 15 years?

4) Are associations between ratings of Behavioral Inhibition at age $41 / 2$ years and ratings of Parental (Maternal and Paternal) Anxiety and Adolescent Anxiety when adolescents were approximately 12 and 15 years moderated by Parental Control at 12 and 15 years?

The following are my hypotheses.

1) Behavioral Inhibition at 54 months will be positively associated with Adolescent Anxiety at 12 and 15 years, and Parental Control and Parental (Maternal and Paternal) Anxiety at both 12 and 15 years will each be 
independently and positively associated with concurrent levels of Adolescent Anxiety at 12 and 15 years.

2) A mediated model of adolescent anxiety will best fit the data.

3) Parental Control will partially mediate the associations between Behavioral Inhibition and Adolescent Anxiety (12 and 15 years), and between Parental (Maternal and Paternal) Anxiety and Adolescent Anxiety at 12 and 15 years. Children with higher Behavioral Inhibition will elicit more Parental Controlling behaviors and these, in turn, will promote Adolescent Anxiety. Also, parents who are more anxious will exhibit more Parental Controlling behaviors and these, in turn, will promote Adolescent Anxiety.

4) Alternatively, Parental Control may moderate the associations between Behavioral Inhibition and Parental (Maternal and Paternal) Anxiety and Adolescent Anxiety at 12 and 15 years. That is, adolescents with higher Behavioral Inhibition and whose parents have higher Parental (Maternal and Paternal) Anxiety levels will display more Adolescent Anxiety when their parents display more controlling behaviors. 


\section{CHAPTER 2}

\section{METHODOLOGY}

\section{Participants}

Participants in the current study are children and their caregivers from the Study of Early Child Care and Youth Development (SECCYD), a study funded by the National Institute of Child Health and Human Development (NICHD). This study assessed family, child care and school experiences, as well as social, cognitive and emotional development, and behavioral adjustment issues; multiple methods were used, including observations, interviews, questionnaires, and standardized tests. The SECCYD's use of rigorous periodic data collections from birth to age 15 cost more than $\$ 150$ million to complete and was referred to as "indisputably the largest and most intensive investigation of the effects of child care ever undertaken" (Belsky, 2009, p. 3).

New mothers were recruited for the study shortly after giving birth in 1991 at hospitals at 10 locations in the United States: Little Rock, AR; Irvine, CA; Lawrence, KS; Boston, MA; Philadelphia, PA; Pittsburgh, PA; Charlottesville, VA; Morganton, NC; Seattle, WA; and Madison, WI. The participants reflected the economic, educational, and ethnic demographic characteristics of the areas from which they were recruited. A total of 5,416 two-parent and single-parent families with full-term, healthy newborns were eligible for the study. Of this group, 1,364 were enrolled into Phase I based on a conditional random sampling plan that ensured adequate demographic representation. 
Data collection was conducted in four phases: Phase I (1991-1994) from ages 0 to 3 years; Phase II (1995-1999) from ages 4 to 8 years (typically preschool to first grade); Phase III (2000-2004) from ages 9 to 13 years (typically second to 12 years old); and Phase IV (2005-2007) from ages 14 to 15 years (typically ninth grade).

The full sample in Phase I consisted of 1,364 child participants (659 girls and 705 boys). In terms of Phase I ethnic composition, $80 \%$ were White ( $\mathrm{n}=1097), 13 \%$ were Black/African American ( $\mathrm{n}=176)$, less than $2 \%$ were Asian/Pacific Islander $(\mathrm{n}=22)$, and the remaining $5 \%$ of participants belonged to other ethnic groups $(n=64)$. Across phases, however, several families discontinued participation in the study resulting in 1,226 children in Phase II, 1,061 pre-adolescents in Phase III, and 1,009 adolescents in Phase IV. For further information on the sample and selection, see the Manuals of Operation of the NICHD Study of Early Child Care (NICHD ECCRN, 1993).

\section{Procedures}

Data for use in the current study were collected at laboratory and home visits at three time points: when children were approximately 54 months, 12 years old, and 15 years old. Indicators of child Behavioral Inhibition were assessed at 54-months in the lab. Indicators of Parental Control were assessed by adolescent self-report during the 12 year old and 15 year old home visits. Indicators of Paternal and Maternal Anxiety symptoms were also assessed by parent-report at the 12 years old and 15 years old home visits. The Manuals of Operation of the NICHD Study of Early Child Care (NICHD ECCRN, 1993) contain additional information pertaining to data collection, measures, and procedures. 


\section{Measures}

\section{Temperament}

\section{Children's Behavior Questionnaire}

Scores from the Shyness and Fear subscales from an abbreviated version of the Children's Behavior Questionnaire (CBQ; Rothbart, Ahadi, \& Hershey, 1994) were summed to form the Behavioral Inhibition variable. The 10 items on the Shyness subscale measure parental report of child social inhibition for children from 3 to 8 years of age. The 10 items on the Fear subscale measure parental report of child negative affect resulting from anticipation of threat. The items were rated on a 7-point likert scale ranging from $1=$ "extremely untrue" to $7=$ "extremely true" with higher scores signifying greater shyness or fear. The Shyness subscale reflects how shyly a child behaved in various social situations during the past 6 months and included items such as "Sometimes prefers to watch rather than join other children playing" and "Sometimes seems nervous when talking to adults s/he has just met." The Fear subscale reflects the child's level of unease or nervousness in reaction to anticipated painful or potentially threatening situations during the past six months and included items such as "Is very frightened by nightmares" and "Is not afraid of the dark" (reverse scored). Together, these subscales have been used to assess Behavioral Inhibition (see Hastings, Sullivan, McShane, Coplan, Utendale, \& Vyncke, 2008; Talge, Donzella \& Gunnar, 2008). Cronbach's alphas for the Shyness subscale in the NICHD SECCYD as reported by Rudasill and Rimm-Kaufman (2009) are high (Cronbach's $\alpha=.87$ ). Cronbach's alphas for the Fear subscale as reported by Talge and colleagues' (2008) were adequate (Cronbach's $\alpha=.72$ ). Cronbach's alpha for the Shyness and Fear subscales together was .74 . 


\section{Child/Adolescent Anxiety}

\section{Child Behavior Checklist-Anxiety Scale}

The Child Behavior Checklist-Anxiety scale (CBCL-A; Kendall, Puliafico, Barmish, Choudhury, Henin, \& Treadwell, 2007) from the Child Behavior Checklist for Ages 6-18 (CBCL/6-18; Achenbach \& Rescorla, 2001) comprised the Adolescent Anxiety variable. The CBCL consists of 112 items and assessed parent-reported behaviors such as social, family and peer relationships and academic performance in youth ages 6-18. The CBCLA has been used to measure anxiety in children and adolescents and scores discriminate between those with and without anxiety disorders (see Dellava, Thornton, Hamer, Strober, Plotnicov, et al., 2010). The 16-items that comprise the CBCL-A measure parental report of child/adolescent somatic and behavioral anxiety symptoms and includes items such as "Cannot get his/her mind off certain thoughts," "Fears going to school" and "Worries." The behaviors were rated on a 3-point Likert scale where $0=$ "not true (as far as you know)," 1 = "somewhat or sometimes true," and $2=$ "very true or often true." Maternal and paternal ratings from this scale were summed and then averaged at 12 years and 15 years to yield an average parental anxiety score. The CBCLA was correlated significantly with other measures of child anxiety such as the State Trait Anxiety Inventory for Children-Parent Report-Trait version (STAIC-P-T; Strauss, 1987) $(\mathrm{r}=.77, \mathrm{p}<.01)$ and the Multidimensional Anxiety Scale for Children (MASC; March, Parker, Sullivan, Stallings, \& Conners, 1997) $(\mathrm{r}=.41, \mathrm{p}<.01)$ (Kendall et al., 2007). Cronbach's alphas in the current study were high for the CBLC-A at 12 years (Cronbach's $\alpha=.85$ ) (combined Maternal and Paternal ratings) and at 15 years (Cronbach's $\alpha=.86$ ) (combined Maternal and Paternal ratings). Individual Cronbach's 
alpha for paternal ratings at 12 years were (Cronbach's $\alpha=.80),($ Cronbach's $\alpha=.81$ ) for paternal ratings at 15 years, (Cronbach's $\alpha=.79$ ) for maternal ratings at 12 years, and (Cronbach's $\alpha=.78$ ) for maternal ratings at 15 years.

Parental Anxiety

\section{State-Trait Anxiety Inventory}

Parental Anxiety was measured by summing 10 of the 20 state anxiety items from an abbreviated version of the State-Trait Anxiety Inventory (STAI; Spielberger, Gorsuch, Lushene, Vagg, \& Jacobs, 1983). The STAI is a self-report instrument that consists of statements designed to assess how the participant felt during the past week and was designed to measure an individual's emotional response (e.g., apprehension, tension, worry) to stressful situations. The STAI reflects how often mothers and fathers/other caregivers (separately) felt a certain way (e.g., "jittery," "worried," or "tense") during the past week as rated on a 4-point Likert scale, ranging from $1=$ "not at all" to $4=$ "very much." Responses from this scale are summed for separate Maternal and Paternal Anxiety scores at each time point. This version of the STAI has been previously used to assess parental anxiety with the NICHD SECCYD data (see Mulvaney, Mebert \& Flint, 2007; Bell \& Belsky, 2008). Cronbach's alphas as reported by Spielberger, Gorsuch, and Lushene (1970) (Cronbach's $\alpha=.93$ ) and in the NICHD SECCYD are high (Cronbach's $\alpha=.87$ to .95 ). Cronbach's alphas in the current study were high for Paternal Anxiety with identical values (Cronbach's $\alpha=.87$ ) at both 12 years and 15 years. Cronbach's alphas for Maternal Anxiety were also high at 12 years (Cronbach's $\alpha=.87$ ) and at 15 years was (Cronbach's $\alpha=.89$ ).

Parental Control 


\section{Parental Control and Autonomy}

Parental Control was measured using a modified version of Epstein and McPartland's (1977) Family Decision-Making Scale (FDM), referred to as Parental Control and Autonomy by the NICHD SECCYD. This 8-item scale contains items asking children to report how decisions in their families were made by asking the stem question "In your family, how do you make most of the decisions about:" such topic items as "how late you can stay up on a school night," "which friends you can spend time with," and "how you dress." Items were rated on a 5-point scale where 1 = "my parents decide", 2 = "my parents decide after discussing it with me", 3 = "we decide together", 4 = "I decide after discussing it with my parents", 5 = "I decide all by myself." Responses from this scale are summed for a total Parental Control score with higher scores indicating that the child has greater autonomy (and less Parental Control). This assessment has been previously used to rate the negative aspects of Parental Control such as power assertion, as opposed to the positive aspects of Parental Control such as monitoring and supervision, in familial relationships (see Fuligni \& Eccles, 1993). Cronbach's alphas in the current study were adequate with identical values (Cronbach's $\alpha=.68$ ) at both 12 and 15 years. Despite having modest internal consistency, these coefficients are viewed as acceptable for research on family relationships (see Grotevant \& Carlson, 1989).

Data Analysis

\section{Preliminary Considerations}

Since the aim of this study was to examine numerous relationships simultaneously while controlling for the common variance among the independent variables, path analysis was used. The assumptions for path analysis (e.g., normality of distributions, 
linearity, multicollinearity, homoscedastcity, outliers; Munro, 1997) will be evaluated using Analysis of Moment Structures (AMOS) version 19.0 (Arbuckle, 2010). Next, correlations among the main study variables and demographic variables (gender, race/ethnicity, SES) were conducted to determine whether statistically significant relationships exist. Next, zero-order correlations among the main study variables were calculated. The strength of using structural equation modeling (SEM) is the ability to deal with missing data through the use of maximum likelihood estimation (MLE), a full estimation method (Kline, 2011). Handling missing data in this way is considered more effective than other methods such as similar response pattern imputation or listwise deletion (Craig \& Bandalos, 2001; Schafer \& Graham, 2002). Thus, I included all 1,364 participants from the original sample for all statistical analyses.

\section{Analytic Strategy}

Data analysis was completed primarily using path analysis. Path analysis is an analytical technique that uses non-experimental data to develop a theory grounded and empiricallysupported hypothesized causal explanation for an outcome (Polit, 1996); here, the outcome is adolescent anxiety. Path analysis, a generalized extension of the regression model, uses maximum likelihood regression and path diagrams to schematically depict complex relationships among observed variables by considering the unique contributions made by a set of observed predictor variables to an observed dependent variable (Tabachnick \& Fidell, 2007).

The individual path coefficients (i.e., standardized beta weights) were considered to determine the magnitude of relationship of one variable with another and to determine whether or not a path will be retained in the final model (all non-significant paths will be 
removed for the final model). In addition, goodness of fit indices were examined for each model. These fit statistics were compared to determine which model is provides the best fit with the data.

Specifically, the current study will longitudinally examine the bivariate relationships between multiple observed variables (Behavioral Inhibition, Maternal Anxiety, Paternal Anxiety, Parental Control) to one dependent variable (Adolescent Anxiety).

To test the mediated model (question 2) paths were estimated between all three predictor variables (i.e., Behavioral Inhibition, Maternal Anxiety, and Paternal Anxiety) and both Parental Control and Adolescent Anxiety at 12 and 15 years. In addition, paths between Parental Control at age 12 and 15 years and Adolescent Anxiety at 12 and 15 years were estimated (see Figure 1). To test the moderated model (question 3), paths were estimated between four predictor variables (i.e., Behavioral Inhibition, Maternal Anxiety, Paternal Anxiety, and Parental Control) and Adolescent Anxiety at 12 and 15 years. In addition, interaction terms were calculated between all three predictor variables and the hypothesized moderators (Behavioral Inhibition x Parental Control at 12 and 15, Maternal Anxiety at $12 \times$ Parental Control at 12, Paternal Anxiety at $12 \times$ Parental Control at 12, Maternal Anxiety at $15 \times$ Parental Control at 15, Paternal Anxiety at $15 x$ Parental Control at 15). Paths between the interaction terms examining Parental Control at 12 and Adolescent Anxiety at 12 were estimated, and paths between the interaction terms examining Parental Control at 15 and Adolescent Anxiety at age 15 were estimated. Finally, a path from Adolescent Anxiety at 12 to Adolescent Anxiety at 15 was estimated (see Figure 2). 


\section{Analytic Goals}

The first goal of this study was to determine the extent to which child Behavioral Inhibition, Parental Anxiety, and Parental Control predict Adolescent Anxiety across time. The second goal was to determine whether a mediated model of adolescent anxiety (Figure 1) or a moderated model of adolescent anxiety (Figure 2) best fits the data from the National Institute of Child Health and Human Development (NICHD) Study of Early Child Care and Youth Development (SECCYD). The third goal was to determine if Parental Control will partially mediate the associations between Behavioral Inhibition and Parental (Maternal and Paternal) Anxiety and Adolescent Anxiety at 12 and 15 years. The final goal was to determine if Parental Control moderates the associations between Behavioral Inhibition and Parental (Maternal and Paternal) Anxiety and Adolescent Anxiety at 12 and 15 years.

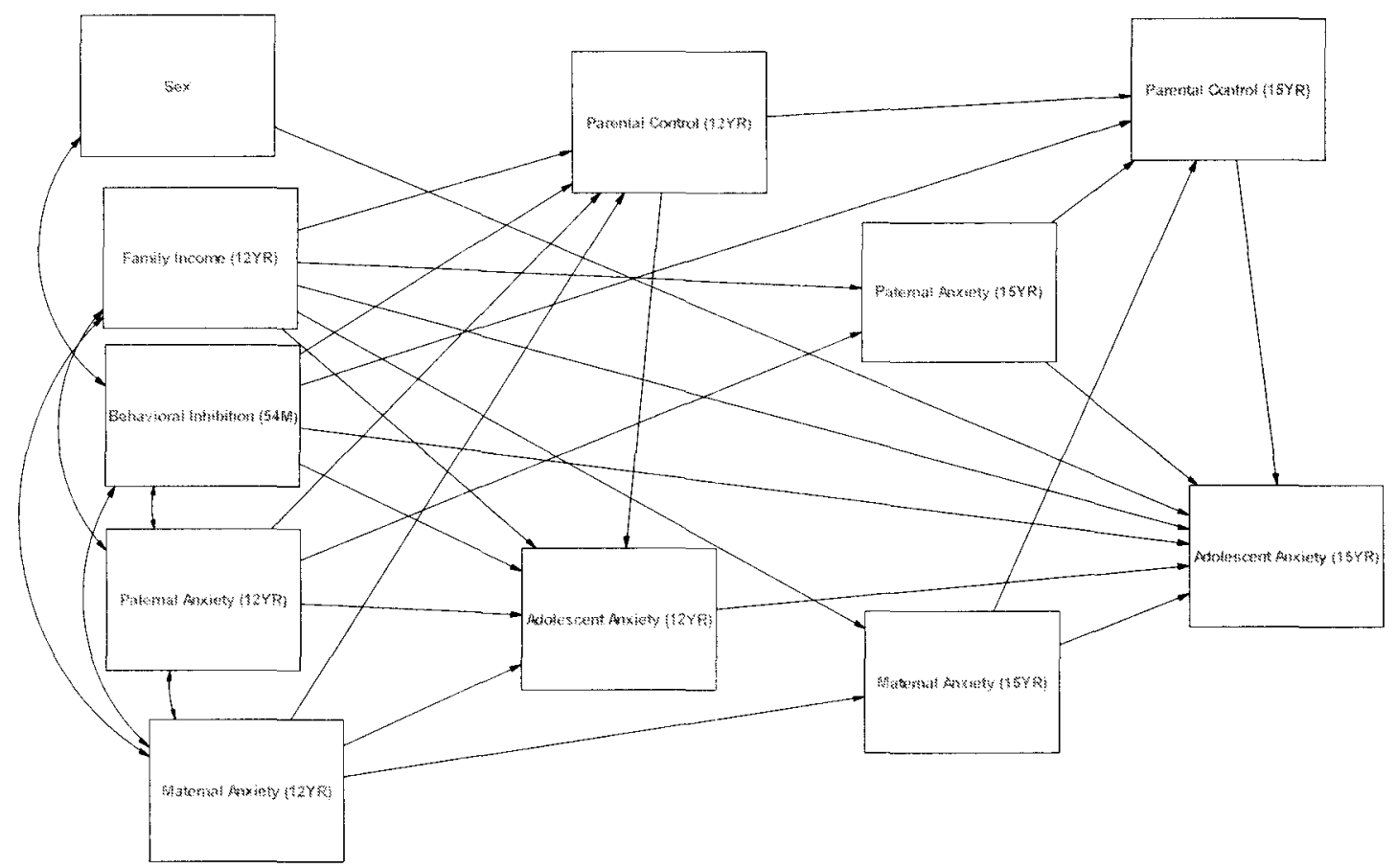

Fig. 1: Mediated model of adolescent anxiety. Note: $54 \mathrm{M}=54$ months. $12 \mathrm{Y}=12$ years. $15 \mathrm{Y}=15$ years. $\mathrm{BI}=$ Behavioral Inhibition. $\mathrm{PC}=$ Parental Control. $\mathrm{PA}=$ Paternal Anxiety. MA = Maternal Anxiety. FI = Family Income. 


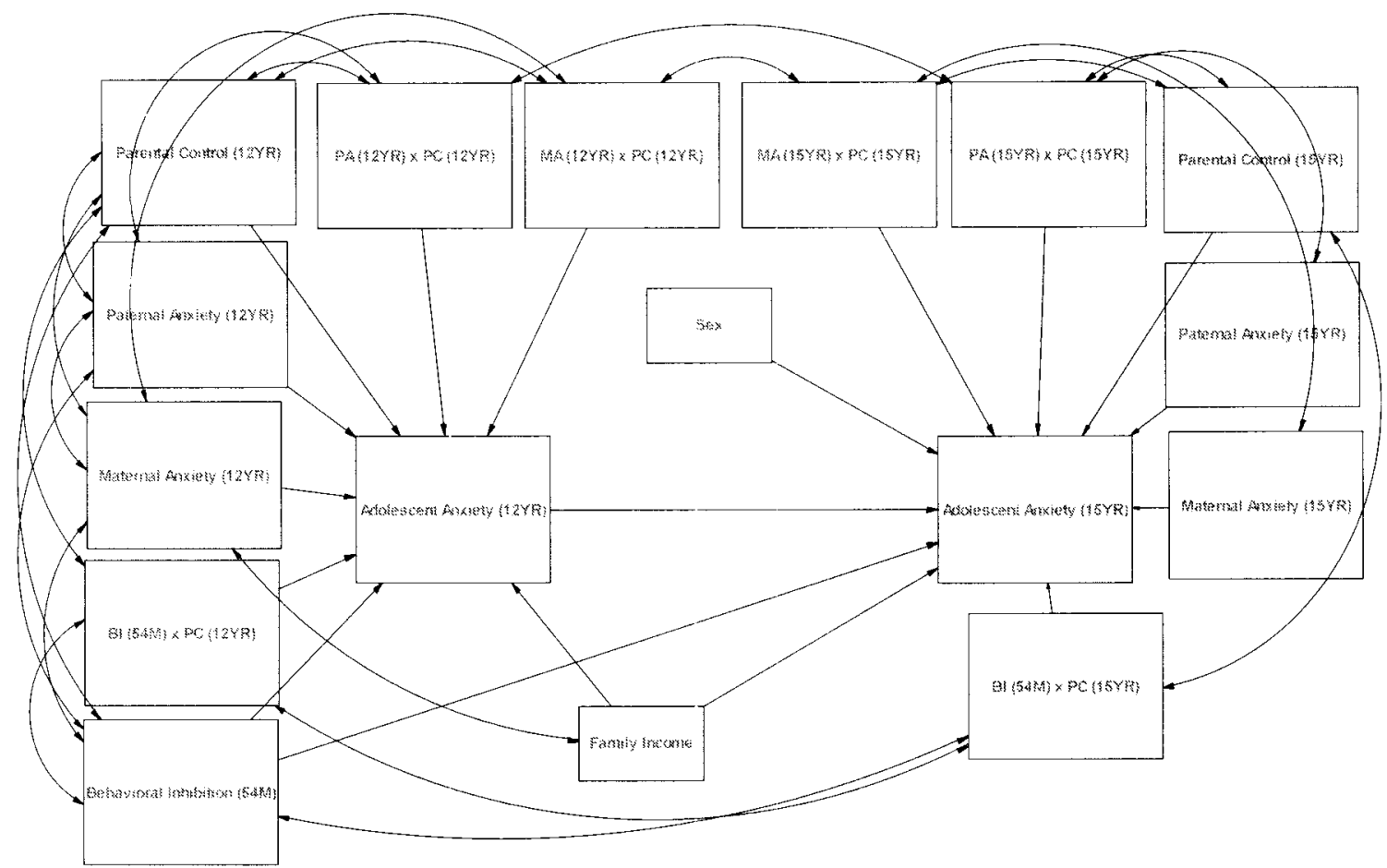

Fig. 2: Moderated model of adolescent anxiety. Note: $54 \mathrm{M}=54$ months. $12 \mathrm{Y}=12$ years. $15 \mathrm{Y}=15$ years. $\mathrm{BI}=$ Behavioral Inhibition. $\mathrm{PC}=$ Parental Control. $\mathrm{PA}=$ Paternal Anxiety. MA = Maternal Anxiety. FI = Family Income. 


\section{CHAPTER 3}

\section{RESULTS}

Descriptive statistics for the study's main variables (Behavioral Inhibition, Maternal Anxiety, Paternal Anxiety, Parental Control, Adolescent Anxiety) across all time points are presented in Table 1.

Table 1

Means, Standard Deviations, and Minimum and Maximum Values of the Main Study Variables

\begin{tabular}{llllll}
\hline Variables & $\mathrm{N}$ & Mean & SD & Minimum & Maximum \\
\hline Behavioral Inhibition (54M) & 817 & 7.62 & 1.55 & 2.90 & 11.90 \\
Paternal Anxiety (12Y) & 724 & 16.32 & 5.16 & 10 & 40 \\
Paternal Anxiety (15Y) & 700 & 16.35 & 4.85 & 10 & 36 \\
Maternal Anxiety (12Y) & 1021 & 17.41 & 5.41 & 10 & 40 \\
Maternal Anxiety (15Y) & 974 & 17.83 & 5.70 & 10 & 40 \\
Parental Control (12Y) & 1000 & 22.23 & 5.63 & 8 & 40 \\
Parental Control (15Y) & 949 & 17.37 & 5.02 & 8 & 38 \\
Adolescent Anxiety (12Y) & 1025 & 3.59 & 3.25 & 0 & 24 \\
Adolescent Anxiety (15Y) & 974 & 3.42 & 3.03 & 0 & 24
\end{tabular}

Note: $54 \mathrm{M}=54$ months. $12 \mathrm{Y}=12$ years. $15 \mathrm{Y}=15$ years.

Zero-order correlations were conducted to determine if there were significant associations between the study participants' demographic characteristics (family income 
at 12 years old, mother's education level) and Behavioral Inhibition at 54 months, Paternal Anxiety at 12 and 15 years, Maternal Anxiety at 12 and 15 years, Parental Control at 12 and 15 years and Adolescent Anxiety at 12 and 15 years. The results are presented in Table 2 and indicate an inverse relationship between Family Income and Paternal Anxiety (12 years/15 years), Maternal Anxiety (12 years/15 years), and Adolescent Anxiety (12 years/15 years) and a positive relationship between Family Income and Parental Control (12 years). Results also reflect an inverse relationship between Maternal Anxiety (12 years/15 years) and Adolescent Anxiety (15 years). As a result Family Income was included into each of the respective proposed models of Adolescent Anxiety.

Table 2

\begin{tabular}{lcc}
\multicolumn{3}{l}{ Zero order correlations between the Main Study Varic } \\
\hline Variables & $\mathrm{N}$ & $\begin{array}{l}\text { Income at } \\
12 \text { yrs old }\end{array}$ \\
\hline Behavioral Inhibition (54M) & 817 & .042 \\
Paternal Anxiety (12Y) & 724 & $-.128^{* * *}$ \\
Paternal Anxiety (15Y) & 700 & $-.143^{* * *}$ \\
Maternal Anxiety (12Y) & 1021 & $-.160^{* * *}$ \\
Maternal Anxiety (15Y) & 974 & $-.177^{* * *}$ \\
Parental Control (12Y) & 1000 & $.094^{* *}$ \\
Parental Control (15Y) & 949 & -.021 \\
Adolescent Anxiety (12Y) & 1025 & $-.118^{* * *}$ \\
Adolescent Anxiety (15Y) & 974 & $-.089^{* *}$ \\
\hline
\end{tabular}

Note: ${ }^{*} p<.05 .{ }^{* *} p<.01 .{ }^{* *} p<.001 .54 \mathrm{M}=54$ months. $12 \mathrm{Y}=12$ years. $15 \mathrm{Y}=15$ years. 
A one-way ANOVA was conducted to test for differences in the main study variables as a function of Race or ethnicity (White, African-American, Asian, AmericanIndian/Eskimo, Other). As reflected in Table 3, the results indicate no differences between groups in terms of race or ethnicity on any of the main study variables.

Table 3

Means, Standard Deviations and F ratios of the Main Study Variables as a function of Ethnicity

\begin{tabular}{|c|c|c|c|c|c|c|}
\hline Variable & White & $\begin{array}{l}\text { African- } \\
\text { American }\end{array}$ & Other & Asian & $\begin{array}{l}\text { American } \\
\text { Indian / } \\
\text { Eskimo }\end{array}$ & $F(d f)$ \\
\hline $\begin{array}{l}\text { Behavioral } \\
\text { Inhibition } \\
(54 \mathrm{M})\end{array}$ & $\begin{array}{l}7.60 \\
(1.57)\end{array}$ & $\begin{array}{l}7.70 \\
(1.37)\end{array}$ & $\begin{array}{l}7.58 \\
(1.43)\end{array}$ & $\begin{array}{l}8.48 \\
(1.47)\end{array}$ & $\begin{array}{l}7.63 \\
(2.69)\end{array}$ & $\begin{array}{l}(4,812)= \\
1.030\end{array}$ \\
\hline $\begin{array}{l}\text { Paternal } \\
\text { Anxiety (12Y) }\end{array}$ & $\begin{array}{l}16.30 \\
(5.15)\end{array}$ & $\begin{array}{l}16.83 \\
(5.03)\end{array}$ & $\begin{array}{l}16.14 \\
(5.83)\end{array}$ & $\begin{array}{l}14.78 \\
(4.21)\end{array}$ & $\begin{array}{l}17.5 \\
(3.54)\end{array}$ & $\begin{array}{l}(4,719)= \\
.383\end{array}$ \\
\hline $\begin{array}{l}\text { Paternal } \\
\text { Anxiety (15Y) }\end{array}$ & $\begin{array}{l}16.45 \\
(4.82)\end{array}$ & $\begin{array}{l}15.89 \\
(5.24)\end{array}$ & $\begin{array}{l}15.96 \\
(5.18)\end{array}$ & $\begin{array}{l}13.70 \\
(2.87)\end{array}$ & $\begin{array}{l}16.0 \\
(+)\end{array}$ & $\begin{array}{l}(4,695)= \\
.992\end{array}$ \\
\hline $\begin{array}{l}\text { Maternal } \\
\text { Anxiety (12Y) }\end{array}$ & $\begin{array}{l}17.25 \\
(5.58)\end{array}$ & $\begin{array}{l}17.86 \\
(5.17)\end{array}$ & $\begin{array}{l}18.38 \\
(5.23)\end{array}$ & $\begin{array}{l}17.78 \\
(5.99)\end{array}$ & $\begin{array}{l}23.67 \\
(10.60)\end{array}$ & $\begin{array}{l}(4,1016) \\
=1.722\end{array}$ \\
\hline $\begin{array}{l}\text { Maternal } \\
\text { Anxiety (15Y) }\end{array}$ & $\begin{array}{l}17.68 \\
(5.80)\end{array}$ & $\begin{array}{l}18.44 \\
(5.12)\end{array}$ & $\begin{array}{l}18.56 \\
(5.31)\end{array}$ & $\begin{array}{l}18.47 \\
(6.03)\end{array}$ & $\begin{array}{l}22.50 \\
(6.36)\end{array}$ & $\begin{array}{l}(4,969)= \\
1.049\end{array}$ \\
\hline $\begin{array}{l}\text { Parental } \\
\text { Control (12Y) }\end{array}$ & $\begin{array}{l}22.11 \\
(5.46)\end{array}$ & $\begin{array}{l}22.63 \\
(6.64)\end{array}$ & $\begin{array}{l}22.72 \\
(5.19)\end{array}$ & $\begin{array}{l}22.78 \\
(6.33)\end{array}$ & $\begin{array}{l}26.33 \\
(7.51)\end{array}$ & $\begin{array}{l}(4,995)= \\
.778\end{array}$ \\
\hline $\begin{array}{l}\text { Parental } \\
\text { Control (15Y) }\end{array}$ & $\begin{array}{l}17.38 \\
(4.93)\end{array}$ & $\begin{array}{l}17.34 \\
(5.67)\end{array}$ & $\begin{array}{l}17.75 \\
(5.38)\end{array}$ & $\begin{array}{l}16.15 \\
(3.53)\end{array}$ & $\begin{array}{l}13.00 \\
(4.24)\end{array}$ & $\begin{array}{l}(4,944)= \\
.640\end{array}$ \\
\hline $\begin{array}{l}\text { Adolescent } \\
\text { Anxiety (12Y) }\end{array}$ & $\begin{array}{l}3.61 \\
(3.26)\end{array}$ & $\begin{array}{l}3.56 \\
(3.21)\end{array}$ & $\begin{array}{l}3.22 \\
(2.91)\end{array}$ & $\begin{array}{l}4.14 \\
(4.20)\end{array}$ & $\begin{array}{l}2.00 \\
(.87)\end{array}$ & $\begin{array}{l}(4,1020) \\
=.450\end{array}$ \\
\hline $\begin{array}{l}\text { Adolescent } \\
\text { Anxiety }(15 \mathrm{Y})\end{array}$ & $\begin{array}{l}3.46 \\
(3.05)\end{array}$ & $\begin{array}{l}3.31 \\
(3.04)\end{array}$ & $\begin{array}{l}3.40 \\
(3.01)\end{array}$ & $\begin{array}{l}2.27 \\
(2.16)\end{array}$ & $\begin{array}{l}2.50 \\
(.71)\end{array}$ & $\begin{array}{l}(4,969)= \\
.657\end{array}$ \\
\hline
\end{tabular}

Note: ${ }^{*} p<.05 .{ }^{* *} p<.01 .{ }^{* *} p<.001 .+=$ only one participant. $54 \mathrm{M}=54$ months. $12 \mathrm{Y}$ $=12$ years. $15 \mathrm{Y}=15$ years. 
An independent samples t-test was conducted to test for differences in the main study variables as a function of Sex and indicated statistically significant differences between boys and girls on two main variables. As reflected in Table 4, girls were rated significantly higher than boys in Behavioral Inhibition and Adolescent Anxiety (at 15 years). Thus, Sex was included in each of the proposed models predicting Adolescent Anxiety.

Table 4

Means, Standard Deviations and $t$ scores of the Main Study Variables as a function of Sex

\begin{tabular}{llll}
\hline Variable & Boys & Girls & $t(\mathrm{df})$ \\
\hline $\begin{array}{l}\text { Behavioral } \\
\text { Inhibition } \\
(54 \mathrm{M})\end{array}$ & $7.50(1.52)$ & $7.75(1.56)$ & $(815)=-2.310^{*}$ \\
$\begin{array}{l}\text { Paternal } \\
\text { Anxiety }(12 \mathrm{Y})\end{array}$ & $16.09(4.76)$ & $16.54(5.52)$ & $(722)=-1.169$ \\
$\begin{array}{l}\text { Paternal } \\
\text { Anxiety (15Y) }\end{array}$ & $16.46(4.81)$ & $16.24(4.89)$ & $(698)=.622$ \\
$\begin{array}{l}\text { Maternal } \\
\text { Anxiety }(12 \mathrm{Y})\end{array}$ & $17.44(5.72)$ & $17.39(5.37)$ & $(1019)=.144$ \\
$\begin{array}{l}\text { Maternal } \\
\text { Anxiety (15Y) }\end{array}$ & $17.86(5.62)$ & $17.81(5.78)$ & $(972)=.146$ \\
$\begin{array}{l}\text { Parental } \\
\text { Control (12Y) }\end{array}$ & $21.92(5.78)$ & $22.54(5.45)$ & $(998)=-1.730$ \\
$\begin{array}{l}\text { Parental } \\
\text { Control (15Y) }\end{array}$ & $17.20(5.06)$ & $17.54(5.00)$ & $(947)=-1.019$ \\
$\begin{array}{l}\text { Adolescent } \\
\text { Anxiety (12Y) }\end{array}$ & $3.48(3.26)$ & $3.69(3.23)$ & $(1023)=-1.050$ \\
$\begin{array}{l}\text { Adolescent } \\
\text { Anxiety (15Y) }\end{array}$ & $3.06(2.90)$ & $3.77(3.12)$ & $(972)=-3.612^{* * *}$ \\
& & & \\
\end{tabular}

Note: ${ }^{*} p<.05 .{ }^{* *} p<.01 .{ }^{* *} p<.001 .54 \mathrm{M}=54$ months. $12 \mathrm{Y}=12$ years. $15 \mathrm{Y}=15$ years. 
Zero order correlations were calculated between all the main study variables and are shown in Table 5.

Table 5

Zero order correlations for the Main Study Variables

\begin{tabular}{|c|c|c|c|c|c|c|c|c|c|}
\hline Variable & 1 & 2 & 3 & 4 & 5 & 6 & 7 & 8 & 9 \\
\hline $\begin{array}{l}\text { 1. Behavioral } \\
\text { Inhibition }\end{array}$ & -- & .07 & -.04 & .07 & .041 & .026 & -.027 & $.10^{* *}$ & $.10^{* *}$ \\
\hline $\begin{array}{l}(54 \mathrm{M}) \\
\text { 2. Paternal } \\
\text { Anxiety }(12 \mathrm{Y})\end{array}$ & & -- & $.50 * *$ & $.25^{* *}$ & $.17 * *$ & -.02 & .01 & $.25^{* *}$ & $.22 * *$ \\
\hline $\begin{array}{l}\text { 3. Paternal } \\
\text { Anxiety }(15 Y)\end{array}$ & & & -- & $.19^{* *}$ & $.22 * *$ & -.01 & -.03 & $.19^{* *}$ & $.25^{* *}$ \\
\hline $\begin{array}{l}\text { 4. Maternal } \\
\text { Anxiety }(12 Y)\end{array}$ & & & & -- & $.48^{* *}$ & -.01 & -.02 & $.29^{* *}$ & $.26^{* *}$ \\
\hline $\begin{array}{l}\text { 5. Maternal } \\
\text { Anxiety }(15 \mathrm{Y})\end{array}$ & & & & & -- & -.01 & .01 & $.22 * *$ & $.26^{* *}$ \\
\hline $\begin{array}{l}\text { 6. Parental } \\
\text { Control }(12 \mathrm{Y})\end{array}$ & & & & & & -- & $.39 * *$ & .05 & .05 \\
\hline $\begin{array}{l}\text { 7. Parental } \\
\text { Control }(15 \mathrm{Y})\end{array}$ & & & & & & & -- & .06 & $.07^{*}$ \\
\hline $\begin{array}{l}\text { 8. Adolescent } \\
\text { Anxiety }(12 Y)\end{array}$ & & & & & & & & -- & $.61^{* *}$ \\
\hline $\begin{array}{l}\text { 9. Adolescent } \\
\text { Anxiety (15Y) }\end{array}$ & & & & & & & & & - \\
\hline
\end{tabular}

Associations of Behavioral Inhibition, Parental Anxiety, and Parental Control with Adolescent Anxiety

The first part of hypothesis one was that Behavioral Inhibition (at 54 months) would be positively related to Adolescent Anxiety at 12 and 15 years. This part of the hypothesis was supported by the data. The second part of this hypothesis was that each of the main independent study variables measured at 12 and 15 years old would be positively associated with concurrent ratings of Adolescent Anxiety. This part of the 
hypothesis was mostly supported at age 12. Scores for all of the variables at age 12 years were significantly correlated with Adolescent Anxiety at age 12 except for Parental Control. When adolescents were 15 , all of the variables from age 15 years were significantly correlated with concurrent ratings of Adolescent Anxiety.

A paired-samples t-test was conducted to detect differences between the main study variables from 12 (Time 1) to 15 years (Time 2) except Behavioral Inhibition which was measured only at age $4 \frac{1}{2}$ years. As shown in Table 6, Maternal Anxiety increased significantly from Time $1(\mathrm{M}=17.38, \mathrm{SD}=5.54)$ to Time $2(\mathrm{M}=17.86, \mathrm{SD}=$ 5.72), $t(590)=-2.558, p=.011$. Parental Control decreased significantly from Time 1 $(\mathrm{M}=22.23, \mathrm{SD}=5.63)$ to Time $2(\mathrm{M}=17.37, \mathrm{SD}=5.02), t(912)=24.777, p<.001$. Also of note were longitudinal scores for Adolescent Anxiety. Although the results were not quite statistically significant $(p=.070)$, Adolescent Anxiety showed a trend of decreasing from Time $1(\mathrm{M}=3.60, \mathrm{SD}=3.26)$ to Time $2(\mathrm{M}=3.43, \mathrm{SD}=3.06)$.

Table 6

Longitudinal Paired Samples Mean differences, Standard Deviations, and $t$ Scores of the Main Study Variables

\begin{tabular}{llll}
\hline Paired Variables & $\begin{array}{l}\text { Mean } \\
\text { Difference }\end{array}$ & $\mathrm{SD}$ & $\mathrm{t}(\mathrm{df})$ \\
\hline Paternal Anxiety $(12 \mathrm{Y} / 15 \mathrm{Y})$ & -.025 & 4.920 & $(590)=-.124$ \\
Maternal Anxiety $(12 \mathrm{Y} / 15 \mathrm{Y})$ & -.478 & 5.755 & $(949)=-2.558^{*}$ \\
Parental Control $(12 \mathrm{Y} / 15 \mathrm{Y})$ & 4.824 & 5.882 & $(912)=24.777^{* * *}$ \\
Adolescent Anxiety $(12 \mathrm{Y} / 15 \mathrm{Y})$ & .164 & 2.790 & $(952)=1.811$ \\
\hline
\end{tabular}

Note: ${ }^{*} p<.05 .{ }^{* *} p<.01 .{ }^{* * *} p<.001$.

Structural Equation Modeling Analyses 
To test hypothesis two and three, SEM using path analysis was used. The exogenous variables in the models were Behavioral Inhibition (measured at 54 months), Maternal Anxiety (measured at 12 years), and Paternal Anxiety (measured at 12 years). Because of their links to Adolescent Anxiety, Race/Ethnicity, Family Income at 12 years, and Sex were also included in the proposed model as exogenous variables. The endogenous variables were Parental Control (at 12 and 15 years), Maternal Anxiety (15 years), Paternal Anxiety (15 years), and Adolescent Anxiety (at 12 years and 15 years). All of the variables were observed or directly measured variables. The exogenous and endogenous variables were the same for the both the mediated and moderated models of adolescent anxiety.

To determine which model provided the best fit with the data, several different fit indices were used: the normed-fit index (NFI), the comparative fit index (CFI), the Tucker-Lewis Index (TLI) and root mean square error of approximation (RMSEA). Values for the NFI, CFI, and TLI greater than .95 are considered acceptable thresholds for good fit (Hooper, Coughlan \& Mullen, 2008). To be considered a good fit by the RMSEA statistic, values should optimally be below .05 (Hu \& Bentler, 1999), with .07 being viewed as the absolute upper limit (Steiger, 2007). Chi square was also used as a fit measure and should ideally be non-significant when the sample size is between 75 and 200 and approach significance for sample sizes larger than 200 as in the current study (Bollen \& Long, 1993; Schumacker \& Lomax, 2004). Path Analysis: Mediated Model of Adolescent Anxiety My second hypothesis was that the mediated model of adolescent anxiety (Figure 1) will best fit the data. Specifically, this model proposes mediation relationships at two 
time points: 1) Parental Control measured at 12 years will mediate the relationships between Behavioral Inhibition (54 months) and Adolescent Anxiety (12 years), Paternal Anxiety (12 years) and Adolescent Anxiety (12 years), and Maternal Anxiety (12 years) and Adolescent Anxiety (12 years); and 2) Parental Control measured at 15 years will mediate the relationship between Behavioral Inhibition (54 months) and Adolescent Anxiety (15 years), Paternal Anxiety (15 years) and Adolescent Anxiety (15 years), and Maternal Anxiety (15 years) and Adolescent Anxiety (15 years). Fit indices for the model indicate a good fit $(\mathrm{NFI}=.97, \mathrm{CFI}=.99, \mathrm{TLI}=.97, \mathrm{RMSEA}=.02)$. The model, with significant paths only, is shown with standardized coefficients in Figure 3. The chisquare test approaches significance, $\chi^{2}(25)=39.84, p=.030$, which is satisfactory given the sample size (Schumacker \& Lomax, 2004).

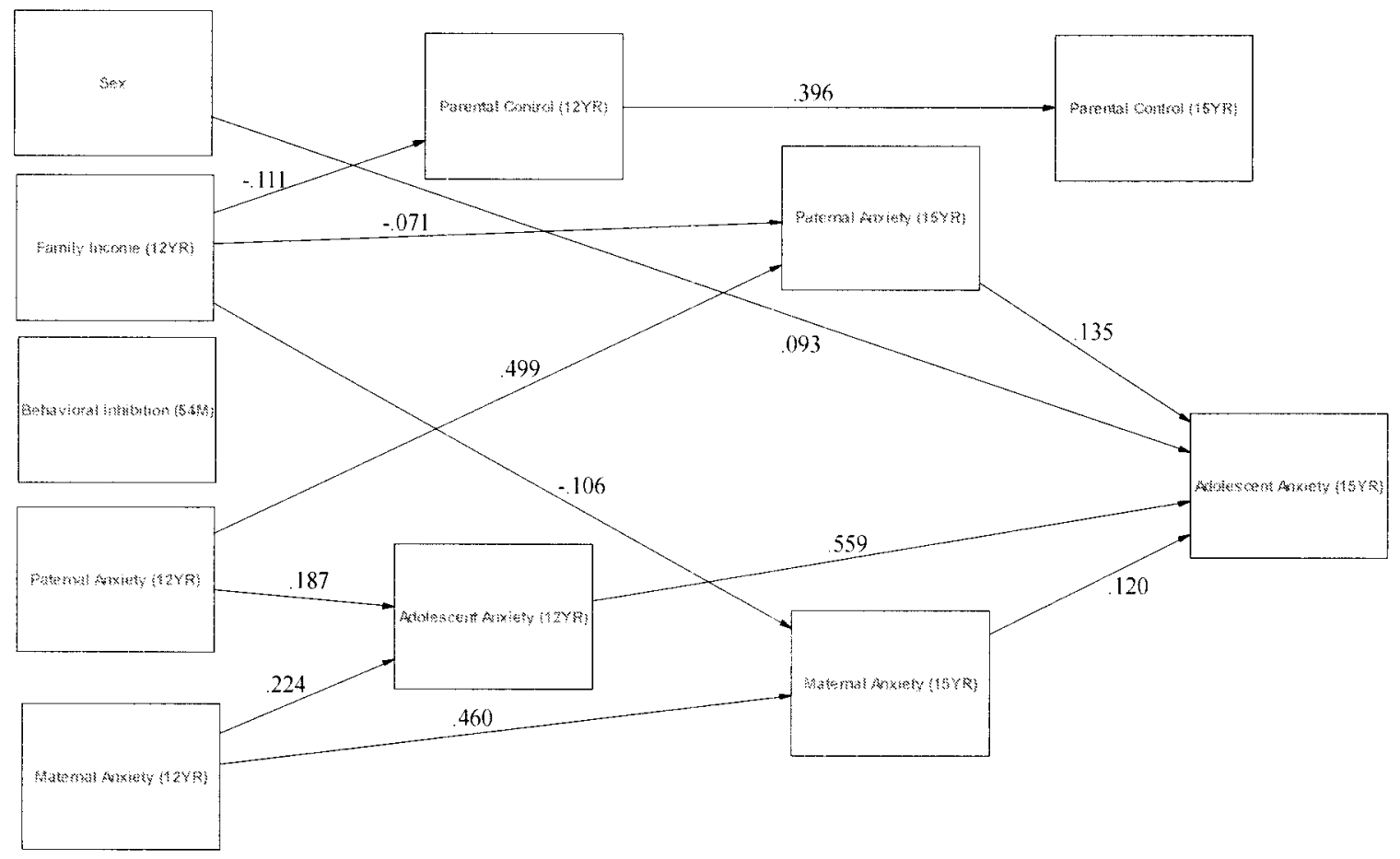

Fig. 3: Significant path estimates with standardized coefficients for the mediated model of adolescent anxiety 
Results indicate that Paternal Anxiety at 12 years $(\beta=.187, p<.001)$ and Maternal Anxiety at 12 years $(\beta=.224, p<.001)$ were directly associated with Adolescent Anxiety at 12 years such that adolescents who had either a father or mother with higher anxiety symptoms were more likely to exhibit anxiety symptoms. At 15 years, results indicated that Paternal Anxiety at 15 years $(\beta=.135, p<.001)$, Maternal Anxiety at 15 years $(\beta=.120, p<.001)$, Adolescent Anxiety at 12 years $(\beta=.559, p<$ $.001)$ and $\operatorname{Sex}(\beta=.093, p<.001)$ directly predicted Adolescent Anxiety at 15 years, such that girls, adolescents with higher anxiety at 12 years old, and those with either a father or mother with higher anxiety symptoms exhibited more anxiety symptoms at 15 . Neither Behavioral Inhibition at 54 months nor Parental Control at 12 years or 15 years were associated with Adolescent Anxiety at 12 or 15 years. Family Income at 12 years $(\beta=-.071, p=.036)$ predicted Paternal Anxiety at 15 years such that fathers in lower income families demonstrated more anxiety symptoms. Additionally, Paternal Anxiety at 12 years $(\beta=.499, p<.001)$ predicted Paternal Anxiety at 15 years such that fathers with higher levels of previous anxiety displayed higher current levels of anxiety. Family Income at 12 years $(\beta=.120, p<.001)$ predicted Maternal Anxiety at 15 years such that mothers from lower income families demonstrated more anxiety symptoms. Maternal Anxiety at 12 years $(\beta=.460, p<.001)$ predicted Maternal Anxiety at 15 years such that mothers with higher levels of previous anxiety displayed higher current levels of anxiety. Standardized and unstandardized estimates for all paths are presented in Table 7.

To test potential significant mediation effects by estimating asymmetric confidence limits (hypothesis 3), the PRODCLIN program (PRODCLIN; MacKinnon, Fritz, Williams, \& Lockwood, 2007) was used. Compared with other widely used 
mediation testing methods, this procedure has been shown to generate the most accurate confidence limits (MacKinnon, \& Fairchild, 2009; MacKinnon \& Fairchild, 2010). The mediation model is significant if the range of the confidence limits (upper and lower) produced by PRODCLIN does not include zero.

For this model, Parental Control was evaluated as a potential mediator between Paternal Anxiety, Maternal Anxiety, and Behavioral Inhibition and Adolescent Anxiety at both 12 years and 15 years, yielding six separate possible mediation scenarios.

Hypothesis three was partially accepted because although data fit the model the well, none of the six potential mediation scenarios was consistent with a statistically significant mediation effect as they all produced upper and lower $95 \%$ confidence intervals that did include zero.

Table 7

Mediated Model of Adolescent Anxiety SEM Path Analysis Estimates

\begin{tabular}{llll}
\hline Parameter & Unstandardized & SE & Standardized \\
& & & \\
\hline $\mathrm{BI}(54 \mathrm{M}) \rightarrow \mathrm{AA}(12 \mathrm{Y})$ & .137 & .073 & .065 \\
$\mathrm{PA}(12 \mathrm{Y}) \rightarrow \mathrm{AA}(12 \mathrm{Y})$ & $.116^{* * *}$ & .022 & .187 \\
$\mathrm{MA}(12 \mathrm{Y}) \rightarrow \mathrm{AA}(12 \mathrm{Y})$ & $.131^{* * *}$ & .018 & .224 \\
$\mathrm{PC}(12 \mathrm{Y}) \rightarrow \mathrm{AA}(12 \mathrm{Y})$ & .029 & .017 & .050 \\
$\mathrm{FI}(12 \mathrm{Y}) \rightarrow \mathrm{AA}(12 \mathrm{Y})$ & .000 & .000 & .055 \\
$\mathrm{BI}(54 \mathrm{M}) \rightarrow \mathrm{PC}(12 \mathrm{Y})$ & .144 & .135 & .040 \\
$\mathrm{PA}(12 \mathrm{Y}) \rightarrow \mathrm{PC}(12 \mathrm{Y})$ & -.055 & .041 & -.051 \\
$\mathrm{MA}(12 \mathrm{Y}) \rightarrow \mathrm{PC}(12 \mathrm{Y})$ & -.018 & .034 & -.018 \\
$\mathrm{FI}(12 \mathrm{Y}) \rightarrow \mathrm{PC}(12 \mathrm{Y})$ & $.000^{* * *}$ & .000 & -.111 \\
$\mathrm{BI}(54 \mathrm{M}) \rightarrow \mathrm{AA}(15 \mathrm{Y})$ & .065 & .058 & .034 \\
$\mathrm{PA}(15 \mathrm{Y}) \rightarrow \mathrm{AA}(15 \mathrm{Y})$ & $.083^{* * *}$ & .018 & .135 \\
$\mathrm{MA}(15 \mathrm{Y}) \rightarrow \mathrm{AA}(15 \mathrm{Y})$ & $.063^{* * *}$ & .014 & .120
\end{tabular}




\begin{tabular}{llll}
\hline PC $(15 Y) \rightarrow$ AA $(15 Y)$ & .023 & .015 & .039 \\
AA $(12 Y) \rightarrow$ AA $(15 Y)$ & $.517^{* * *}$ & .024 & .559 \\
SEX $\rightarrow$ AA $(15 Y)$ & $.560^{* * *}$ & .150 & .093 \\
FI $(12 Y) \rightarrow$ AA $(15 Y)$ & .000 & .000 & .018 \\
BI $(54 \mathrm{M}) \rightarrow$ PC $(15 Y)$ & -.125 & .115 & -.038 \\
PA $(15 Y) \rightarrow$ PC $(15 Y)$ & -.038 & .036 & -.037 \\
MA $(15 Y) \rightarrow$ PC $(15 Y)$ & .007 & .027 & .008 \\
PC $(12 Y) \rightarrow$ PC $(15 Y)$ & $.354^{* * *}$ & .027 & .396 \\
PA $(12 Y) \rightarrow$ PA $(15 Y)$ & $.465^{* * *}$ & .032 & .499 \\
FI $(12 Y) \rightarrow$ PA $(15 Y)$ & $.000^{*}$ & .000 & -.071 \\
FI $(12 Y) \rightarrow$ MA $(15 Y)$ & $.000^{* * *}$ & .000 & -.106 \\
MA $(12 Y) \rightarrow$ MA $(15 Y)$ & $.474^{* * *}$ & .029 & .460 \\
\hline
\end{tabular}

Note: ${ }^{*} p<.05 .{ }^{* *} p<.01 .{ }^{* * *} p<.001 .54 \mathrm{M}=54$ months. $12 \mathrm{Y}=12$ years. $15 \mathrm{Y}=15$ years. $\mathrm{BI}=$ Behavioral Inhibition. $\mathrm{PC}=$ Parental Control. $\mathrm{PA}=$ Paternal Anxiety. $\mathrm{MA}=$ Maternal Anxiety. FI = Family Income.

\section{Path Analysis: Moderated Model of Adolescent Anxiety}

The moderated model of adolescent anxiety (Figure 2) proposes moderation relationships at two time points: 1) Parental Control measured at 12 years will moderate the relationship between Behavioral Inhibition (54 months) and Adolescent Anxiety (12 years), Paternal Anxiety (12 years) and Adolescent Anxiety (12 years), and Maternal Anxiety (12 years) and Adolescent Anxiety (12 years); and 2) Parental Control measured at 15 years will moderate the relationship between Behavioral Inhibition (54 months) and Adolescent Anxiety (15 years), Paternal Anxiety (15 years) and Adolescent Anxiety (15 years), and Maternal Anxiety (15 years) and Adolescent Anxiety (15 years). The model, with significant paths only, is shown with standardized coefficients in Figure 4. 


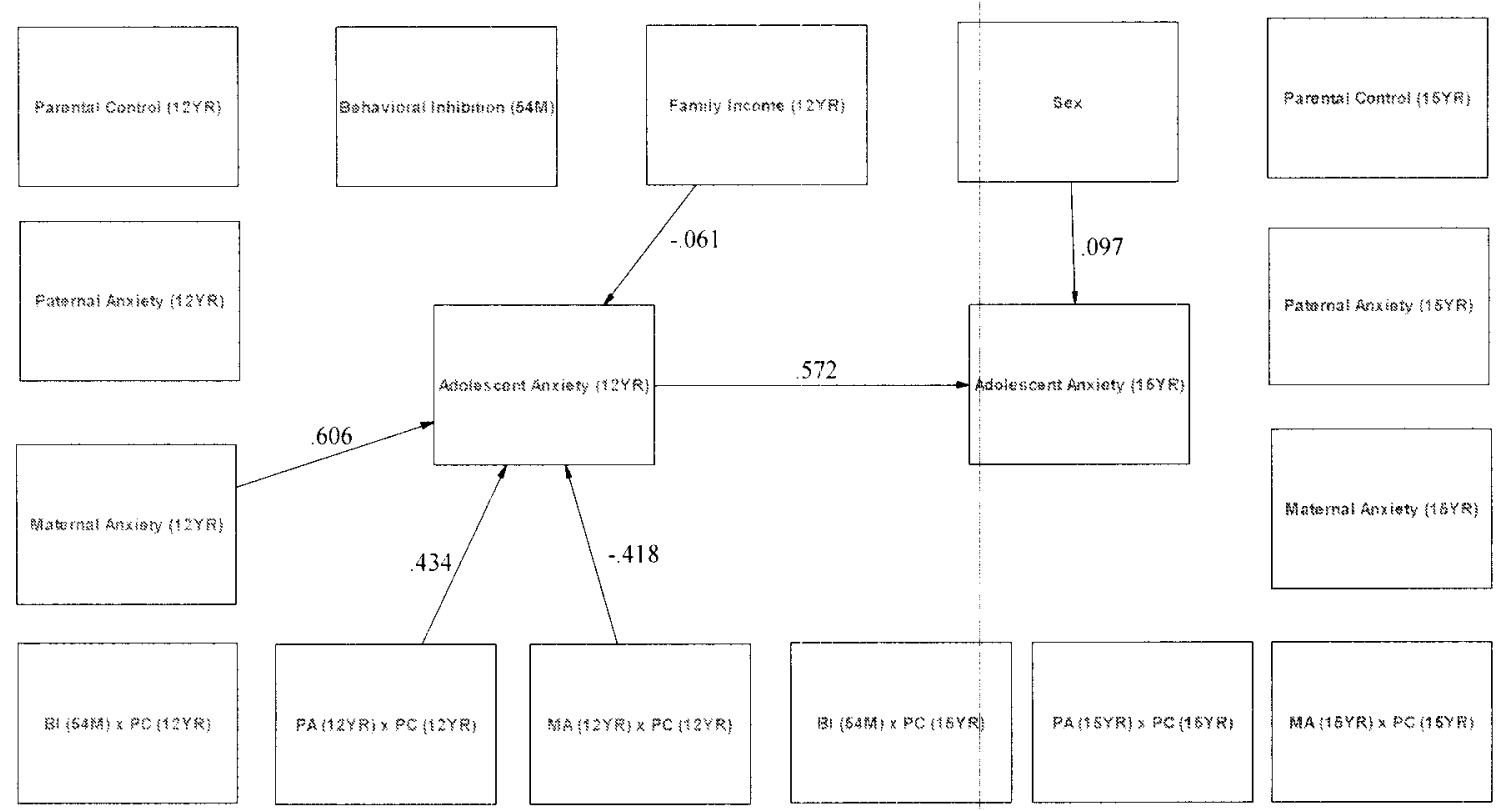

Fig. 4: Significant path estimates with standardized coefficients for the moderated model of adolescent anxiety

Fit indices for the model are inadequate and indicate a poor fit $(\mathrm{NFI}=.73, \mathrm{CFI}=.73, \mathrm{TLI}$ $=.57, \mathrm{RMSEA}=.190)$. The chi-square test does not approach significance also suggesting poor fit, $\chi^{2}(94)=4335.45, p<.00$. Because of the inadequate model fit, no conclusions about potential moderation relationships can be made from this model and hypothesis four is rejected. Standardized and unstandardized estimates for all paths are presented in Table 8.

Table 8

\begin{tabular}{ll:ll}
\multicolumn{4}{l}{ Moderated Model of Adolescent Anxiety SEM Path Analysis Estimates } \\
\hline Parameter & Unstandardized & SE & Standardized \\
& & & \\
\hline $\mathrm{BI}(54 \mathrm{M}) \rightarrow \mathrm{AA}(12 \mathrm{Y})$ & .043 & .213 & .023 \\
$\mathrm{PA}(12 \mathrm{Y}) \rightarrow \mathrm{AA}(12 \mathrm{Y})$ & -.078 & .092 & -.141 \\
$\mathrm{MA}(12 \mathrm{Y}) \rightarrow \mathrm{AA}(12 \mathrm{Y})$ & $.321^{* * *}$ & .092 & .606 \\
$\mathrm{PC}(12 \mathrm{Y}) \rightarrow \mathrm{AA}(12 \mathrm{Y})$ & -.006 & .122 & -.007 \\
$\mathrm{FI}(12 \mathrm{Y}) \rightarrow \mathrm{AA}(12 \mathrm{Y})$ & $.000^{*}$ & .000 & -.061 \\
$\mathrm{BI}(54 \mathrm{M}) \times \mathrm{PC}(12 \mathrm{Y}) \rightarrow \mathrm{AA}(12 \mathrm{Y})$ & .004 & .008 & .074
\end{tabular}




\begin{tabular}{lll:ll}
\hline $\mathrm{PA}(12 \mathrm{Y}) \times \mathrm{PC}(12 \mathrm{Y}) \rightarrow \mathrm{AA}(12 \mathrm{Y})$ & $.009^{*}$ & .004 & .434 \\
$\mathrm{MA}(12 \mathrm{Y}) \times \mathrm{PC}(12 \mathrm{Y}) \rightarrow \mathrm{AA}(12 \mathrm{Y})$ & $-.008^{* *}$ & .004 & -.418 \\
$\mathrm{BI}(54 \mathrm{M}) \rightarrow \mathrm{AA}(15 \mathrm{Y})$ & .032 & .065 & .019 \\
$\mathrm{PA}(15 \mathrm{Y}) \rightarrow \mathrm{AA}(15 \mathrm{Y})$ & .038 & .068 & .063 \\
$\mathrm{MA}(15 \mathrm{Y}) \rightarrow \mathrm{AA}(15 \mathrm{Y})$ & .048 & .052 & .092 \\
$\mathrm{PC}(15 \mathrm{Y}) \rightarrow \mathrm{AA}(15 \mathrm{Y})$ & -.060 & .086 & -.089 \\
$\mathrm{AA}(12 \mathrm{Y}) \rightarrow \mathrm{AA}(15 \mathrm{Y})$ & $.520 * * *$ & .024 & .572 \\
$\mathrm{SEX} \rightarrow \mathrm{AA}(15 \mathrm{Y})$ & $.568 * *$ & .150 & .097 \\
$\mathrm{FI}(12 \mathrm{Y}) \rightarrow \mathrm{AA}(15 \mathrm{Y})$ & .000 & .000 & .014 \\
$\mathrm{BI}(54 \mathrm{M}) \times \mathrm{PC}(15 \mathrm{Y}) \rightarrow \mathrm{AA}(15 \mathrm{Y})$ & .002 & .003 & .040 \\
$\mathrm{PA}(15 \mathrm{Y}) \times \mathrm{PC}(15 \mathrm{Y}) \rightarrow \mathrm{AA}(15 \mathrm{Y})$ & .003 & .004 & .121 \\
$\mathrm{MA}(15 \mathrm{Y}) \times \mathrm{PC}(15 \mathrm{Y}) \rightarrow \mathrm{AA}(15 \mathrm{Y})$ & .001 & .003 & .042 \\
\hline
\end{tabular}

Note: ${ }^{*} p<.05 .{ }^{* *} p<.01 .{ }^{* * *} p<.001 .54 \mathrm{M}=54$ months. $12 \mathrm{Y}=12$ years. $15 \mathrm{Y}=15$ years. $\mathrm{BI}=$ Behavioral Inhibition. $\mathrm{PC}=$ Parental Control. $\mathrm{PA}=$ Paternal Anxiety. $\mathrm{MA}=$ Maternal Anxiety. FI = Family Income. 


\section{CHAPTER 4}

\section{DISCUSSION}

The current study examined the prediction of anxiety symptoms over time during developmentally significant periods - the transition to middle school (12 years old) and the transition to high school (15 years old). Specifically, concurrent relationships between child behavioral inhibition, paternal anxiety, maternal anxiety, and parental control and adolescent anxiety each time point were identified and two different models of adolescent anxiety, a mediated model of adolescent anxiety and a moderated model of adolescent anxiety were compared to determine which better fit the data from the NICHD SECCYD.

Hypothesis One: Joint Relationships

The first purpose of this study was to determine the extent to which child behavioral inhibition, paternal anxiety, maternal anxiety, and parental control predicted concurrent levels of adolescent anxiety. The first part of hypothesis one was that each of the main study independent variables measured will be positively associated with adolescent anxiety.

The first part of hypothesis one was mostly confirmed when adolescents were 12 years old. Behavioral inhibition (at age $4 \frac{1}{2}$ years), paternal anxiety, and maternal anxiety were significantly correlated with concurrent levels of adolescent anxiety; parental control was not correlated with adolescent anxiety at age 12. The second part of 
hypothesis one was confirmed in that at 15 years old behavioral inhibition (at age 4 1/2 years), paternal anxiety, maternal anxiety, and parental control were all significantly correlated with concurrent levels of adolescent anxiety. These findings were consistent with the literature linking child behavioral inhibition, paternal anxiety, maternal anxiety, and parental control with adolescent anxiety (Chorpita \& Barlow 1998; Greco \& Morris 2002; Lieb et al., 2000; Rapee et al., 2009).

Adolescent anxiety and paternal anxiety were stable from 12 to 15 years, which was expected given previous research (Hirshfeld-Becker \& Biederman, 2002; Jorm, 2000; Henderson, Korten, Jacomb, Christensen \& Rodgers, 1998; Last, Perrin, Hersen \& Kazdin, 1996; Manassis et al., 2004). On the other hand, maternal anxiety increased significantly from 12 to 15 years, and this was unexpected given the extant literature (Jorm, 2000). For example, Henderson and colleagues' (1998) cross-sectional study of 2,725 people aged 18 to 79 years from the general population showed that women's anxiety symptoms declined significantly with age, but that men's anxiety tended to be more stable across the lifespan. Another cross-sectional study included 2,120 people aged 16 to 89 years and showed that anxiety scores declined with age for both sexes (Knight, Waal-Manning, \& Spears, 1983).

But why would maternal anxiety increase from 12 to 15 years? Perhaps the answer could be explained by considering the demographics of the mothers in the current study. By the time their adolescents reached 15 years, many of the mothers that remained in the study could be described as White, highly educated and wealthy. Research suggests that despite highly successful careers in the workplace, women tend to prioritize the role as caregiver over wage earner while men tend to prioritize the role as wage 
earner (Gati, Osipow, \& Givon, 1995; Vermeulen \& Minor, 1998). Furthermore, the results of Craig's (2006) study of over 4,000 Australian households showed a disparity between mothers and fathers with mothers undertaking more childcare responsibilities, spending more time multitasking and more time with their children. Schieman and colleagues' (Schieman, Milkie, \& Glavin, 2009; Schieman, Whitestone, \& Van Gundy, 2006) "stress of higher status" hypothesis posits that more highly educated people are exposed to increasingly demanding workplace stressors and subsequently experience increased work-to-home conflict resulting in stress that overflows into family life. In fact, there are now more women in corporate America than ever before (U.S. Bureau of Labor Statistics, 2006). Census statistics show that women fill approximately $51 \%$ of the executive, administrative and managerial positions in the United States - double the proportion of the same category from 30 years ago (U.S. Bureau of Labor Statistics, 2006). It could be that mothers in the current study are experiencing increased anxiety based on the competing demands of the workplace and the home during a time period of increased workplace responsibility and wage earning.

Research has also illustrated that more highly educated mothers tend to parent "harder" in the form of higher expectations and higher standards for themselves and their children than less educated mothers (Hays, 1996; Nelson, 2010). Indeed, Nomaguchi and Brown (2011) noted an increased likelihood of highly educated mothers to "be engaged in a labor-intensive, emotionally absorbing parenting method" (p. 621). It could be that the cumulative strain of attempting to meet self-imposed expectations and standards, coupled with the subsequent decrease in time for adult interpersonal relationships and personal time, may alternatively account for increased maternal anxiety. 


\section{Anxiety and Sex}

Although a paired samples t-test showed no difference in adolescent anxiety across the two time points, post-hoc paired samples t-tests comparing boys' and girls' anxiety revealed some sex differences. Although girl's anxiety did not change significantly from 12 years $(M=3.68, S D=3.20)$ to 15 years $(M=3.80, S D=3.13)$, boys' anxiety decreased significantly from 12 years $(\mathrm{M}=3.38, \mathrm{SD}=3.15)$ to 15 years $(\mathrm{M}$ $=3.06, \mathrm{SD}=2.97), t(430)=2.423, p=.016$. Since longitudinal studies examining gender differences in anxiety are sparse (Rapee et al., 2009), making a definitive conclusion about gender differences based on the literature can be difficult. One of the only studies that longitudinally assessed sex differences in anxiety was Roza, Marijke, Hofstra, van der Ende, and Verhulst's (2003) research that examined 1,580 children four to 16 years old. They found that both age and gender were associated with increased anxiety in that boys and younger children (four to 11 years old) were less likely to have anxiety symptoms and girls and adolescents (12 to 16 years old) were more likely to have anxiety symptoms. The current study's results are congruent with the findings from the Roza et al. (2009) study.

While girls exhibited higher levels of anxiety than boys at both time points in the current study, an independent samples t-test comparing adolescent anxiety levels at 12 years showed no significant difference between boys $(\mathrm{M}=3.38, \mathrm{SD}=3.15)$ and girls $(\mathrm{M}$ $=3.68, \mathrm{SD}=3.20$ ), confirming findings from Canino and colleagues' (2004) longitudinal study that showed no statistical differences in anxiety by gender. However, at 15 years, girls $(\mathrm{M}=3.80, \mathrm{SD}=3.13)$ exhibited significantly more adolescent anxiety than boys $(\mathrm{M}$ $=3.01, \mathrm{SD}=2.97), t(430)=-3.618, p<.000$. While boys experienced less anxiety than 
girls at both time points, the finding that boy's anxiety decreased as they got older contradicted Roza and colleagues' (2003) assertion that anxiety progressively increases as an individual enters middle to late adolescence.

The statistical difference between boys' and girls' anxiety at 15 years suggests a combination of biological and environmental factors. For example, the experience of stressful life events has been linked in the literature to anxiety (Goodyer, Wright, \& Altham, 1988; Murray, Creswell, \& Cooper, 2009). Whether or not girls objectively experience more stressors than boys, starting in early adolescence and continuing through young adulthood, girls subjectively report experiencing more stressors than boys (Compas, Howell, Phares, Williams, \& Giunta, 1989; Wichstrom, 1999). One specific stressor, the different ways that boys and girls experience puberty as it pertains to body image, may play a factor in the gender differences in adolescent anxiety. Empirical evidence supports the notion that girls worry more than boys about appearance and weight after puberty (Barker \& Galambos, 2003; Smolak, Levine, \& Thompson, 2001). The increased cultural expectations and media attention regarding adherence to female body image standards could play a role in provoking worry among girls. In fact, research shows that the physical changes experienced by boys that are associated with puberty (e.g., increased height and muscle, deeper voice) are viewed as culturally positive while the physical changes experienced by girls that are associated with puberty (e.g., increased body weight and hip size) are predominantly viewed as culturally negative (Harter, 2006). Given the fact that worry has been identified as a predictor of adolescent anxiety (Muris, Roelofs, Meesters, \& Boomsma, 2004) one could assert that key pubertal changes accentuate the sex disparity in anxiety at age 15 . However, sex differences in worry and 
subsequent anxiety could also be accounted for by cognitive factors. For example, adolescent girls have been shown to be more aware of conflict in interpersonal relationships than adolescent boys (Laursen, 1996). Given that interpersonal conflict also increases through adolescence (Hankin \& Abramson, 2001; Laursen, 1996), perhaps adolescent girls' concern or worry about friendships and decreasing interpersonal conflict may be an alternate explanation for the sex disparity.

The differences between males' and female' anxiety at 15 years could also stem from measurement error in that the anxiety instrument used in the current study could be also measuring depression. Although depression and anxiety are distinct negative affective states, the clinical overlap in symptomology has been well documented in the literature (Clark \& Watson, 1990; Gotlib \& Cane, 1989; Lovibond \& Lovibond, 1995). Indeed, in their analysis of the literature, Clark and Watson (1990) noted the high correlation between anxiety and depression scales across clinical and non-clinical populations (between .40 to .70 ) and that many depression and anxiety scales lack the specificity necessary to clearly identify whether depression or anxiety was being measured. Numerous studies have documented that depression rates among girls increase after age 13 and surpass boys who tend to exhibit stable levels of depression through the same developmental period (Cole, Martin, Peeke, Seroczynski, \& Fier, 1999; Ge, Lorenz, Conger, Elder, \& Simons, 1994; Wichstrom, 1999). The current study's findings of similar levels of anxiety at 12 years for boys and girls and statistically higher levels of anxiety for girls at 15 years mirror the findings in the aforementioned depression studies. Hypothesis Two: Mediated Model of Adolescent Anxiety 
The second hypothesis was that the mediated model of adolescent anxiety would best fit the data from the National Institute of Child Health and Human Development (NICHD) Study of Early Child Care and Youth Development (SECCYD). The results of the path analysis confirmed hypothesis two that the mediated model of adolescent anxiety best fits the data and is one possible explanation for the association between the variables in the study.

\section{Mediated Model: Paternal and Maternal anxiety}

At age 12 and 15, both paternal and maternal anxiety predicted concurrent levels of adolescent anxiety, confirming previous research showing strong associations between parent and child anxiety (Beidel \& Turner, 1997; Biederman et al., 2006; Fisak \& GrillsTaquechel, 2007; Murray et al., 2009). The results also indicated that paternal anxiety may be important in the development of adolescent anxiety, adding further support that both parents should be considered when seeking to understand adolescent anxiety. While previous research showed a positive correlation between parent and child anxiety, very few specifically examined associations between child and father anxiety. For example, in their literature review, Fisak and Grills-Taquechel (2007) identified 16 studies that examined the relationship between parental anxiety and child anxiety, but only four of the studies measured the unique contribution of paternal anxiety.

Parental anxiety was also remarkably stable in the current study with paternal and maternal anxiety at 12 years predicting subsequent paternal and maternal anxiety at 15 years. This finding was expected given the high percentage of adults exhibiting lifetime anxiety (Edwards et al, 2009; Hirshfeld-Becker \& Biederman, 2002; Gregory et al., 2007; Kessler et al., 1994). There is also some evidence that these relationships may be cross- 
predictive (e.g., maternal anxiety may predict paternal anxiety and vice versa). For example, one study of 519 pairs of spouses from the general population showed significant spousal association for lifetime presence of anxiety disorders (Galbaud du Fort, Bland, Newman \& Boothroyd, 1998).

\section{Mediated Model: Family Income}

The results do not illustrate a direct path between family income and adolescent anxiety at either time point. This finding is congruent with the bulk of the previous research that showed no direct association between family income and adolescent anxiety (Rapee et al., 2009). The results do, however, indicate a negative relationship between parental anxiety and family income with family income predicting both paternal and maternal anxiety at 15 years. But why is the path from family income to paternal and maternal anxiety significant at 15 years only?

Increased parental concern about the well-being of their children has been documented in the literature over the last decade (Farkas, Johnson, Dufett, Wilson, \& Vine, 2002). It could be that social factors such as increased parental awareness of the excessive financial burden associated with securing academic, sports, and performing arts success (e.g., private school tuition, summer camps, equipment, college tuition on the horizon), coupled with the pressure created by increased financial demands of the maturing adolescent at 15 years old (e.g., car, clothes, social activities), create the conditions for increased levels of parental anxiety. This parent-child interaction may then be viewed as circular in that an adolescent's financial desires (e.g., desire for expensive goods and services) may increase the likelihood of parental anxiety (e.g., increased worry about meeting these financial needs) which in turn increases the 
likelihood of adolescent anxiety (e.g., through parental modeling of anxiety symptoms). This hypothesized explanation is in line with previous research showing that anxiety may be transmitted through bi-directional parent-child interactions (Moore, Whaley, \& Sigman, 2004).

The current results also show family income was directly associated with parental control at 12 years such that families with higher incomes exhibited higher levels of concurrent parental control. This finding was surprising given previous research showing higher levels of parental control among lower income families when compared to families from middle or high socioeconomic backgrounds (Hoff, Laursen, \& Tardif, 2002). However, research suggests that families with higher incomes and education levels have fewer children (Becker, 1981; Edin \& Kefalas, 2005), and, as such, may have more financial resources and time to control their children's environments and activities. Indeed, the pop-culture term "helicopter parent" has been coined by the media to stereotypically describe higher educated, over-controlling, upper-middle-class parents who "hover" over their children's every move from birth through their college years (Gibbs, 2009; Marano, 2004). Research supports the existence of "helicopter parents" (Hoover, 2008; Lum, 2006). In fact, problems created by helicopter parents have caused colleges and universities to employ full-time "parent coordinators" to deal with the problems created by these parents' constant questions and concerns (Lum, 2006). It could be that for helicopter parents, 15 years old is the key time point where a highly involved approach to parenting crosses the line of healthy parental involvement and moves towards overcontrol as the adolescent progresses through high school and into college. 


\section{Mediated Model: Behavioral Inhibition}

Although behavioral behavioral inhibition was significantly correlated with adolescent anxiety at both time points, behavioral behavioral inhibition was not directly or indirectly associated with adolescent anxiety when put into the full model. This finding was somewhat surprising given that behavioral behavioral has been identified as one of the chief risk factors for the development of anxiety disorders (Chorpita \& Barlow, 1998; Gar, Hudson, \& Rapee, 2005; Hudson \& Rapee, 2004; Rapee et al., 2009). This finding may reflect the multi-finality of temperament. In other words, just because a child at $4 \frac{1}{2}$ years exhibits a collection of behaviors that suggests a behaviorally inhibited temperament does not necessarily mean that the child will develop anxiety as an adolescent. Congruent with temperament research pointing to the importance of interactions between temperament and context (Degnan \& Fox, 2007; Rothbart, Derryberry \& Posner, 1994), these results suggest that between four and 15 years old, children experience unique combinations of environmental stimuli that either buffer against or increase the likelihood of developing anxiety. Although the temperamental characteristic of behavioral inhibition is fairly stable, there is empirical evidence of discontinuity in behavioral inhibition for some individuals between childhood and adolescence (Kerr, Lambert, Stattin, \& Klackenberg-Larsson, 1994; Sanson et al., 1996). Perhaps assessing behavioral inhibition at a later time point would have resulted in a significant path to adolescent anxiety.

\section{Mediated Model: Parental Control}

Given the abundant empirical evidence connecting parental control and anxiety (Rapee, 2009; McLeod et al., 2007, Greco \& Morris, 2002), the finding that parental 
control was not a significant unique predictor of adolescent anxiety at either 12 or 15 years was unexpected. Also, parental control was not significantly correlated with adolescent anxiety at 12 years and only weakly (but significantly) correlated with adolescent anxiety at 15 years, and this was contrary to my hypothesis. There are several possible reasons for these findings.

First, parental control was assessed via questionnaire filled out by adolescents, and not by observation. While measuring parental control with observational methods does have drawbacks and is not necessarily the "gold standard," the literature does indicate that observational studies provide stronger support for the association between parental control and adolescent anxiety (Bogels \& Brechman-Toussaint, 2006; Moore, Whaley \& Sigman 2004; Wood et al., 2003). In other words, adolescent self-report creates the possibility that the adolescent's perception of parenting may not represent the actual parenting that's occurring in the household. Additionally, the questionnaire used did not ask adolescents to specify the parent for whom they were basing their answers. Thus, it is possible that some adolescents may have based their answers about parental control on their mother's parenting behaviors, while others may have based it on their father's parenting behaviors, and others may have based their answers on a combination of both their mother's and father's parenting behaviors. Indeed, research shows that fathers tend to be more autonomy granting than mothers, and mothers tend to exhibit more controlling parenting behaviors (Paquette, 2004; Popenoe, 1996; van der Bruggen, Stams, \& Bogels, 2008). Thus, the parent for whom the adolescent chose to base the responses may have had a powerful impact on the results of the current study. Additionally, given the field's lack of clear conceptualization of the construct of parental 
control, the current results may bring into question the construct validity of both this instrument and others used to measure parental control in that they may not be measuring both elements of parental control (behavioral control and psychological control).

Also of note was the current study's finding that parental control and adolescent anxiety were correlated at 15 years, but not 12 years. It could be that adolescents view a specific parenting behavior (e.g., "how late you can stay up on a school night") as appropriate parental control and monitoring at 12 years old and as inhibiting adolescent independence and parental overcontrol at 15 years old, resulting in a higher correlation with adolescent anxiety at 15 years. Concurrently, parental control decreased significantly from 12 to 15 years. In fact, when examining paired samples, parental control showed a significant mean decrease of 4.82 from 12 to 15 years - which could be considered developmentally appropriate (Baumrind, 1991). Taken together, these results suggest that parents who failed to adjust their levels of parental control to the developmental level of their adolescents as they mature inhibited their adolescents' ability to "personally influence events and outcomes in one's environment," (Chorpita \& Barlow, 1998, p. 5) resulting in an increased likelihood of adolescent anxiety at 15 years. Hypothesis Three: Assessing Mediation

Hypothesis three was that parental control would partially mediate the associations between behavioral behavioral inhibition and parental (maternal and paternal) anxiety and adolescent anxiety at 12 and 15 years. Although a mediated effect was not found in any of the six potential mediation scenarios using the PRODCLIN computer program, the overall fit of the model provides some evidence for the hypothesized mediation relationships (Fairchild \& McQuillin, 2010; James, Mulaik, \& 
Brett, 2006). The current results support previous research where parental control was shown to mediate the relationship between parental anxiety and subsequent child anxiety (Edwards, Rapee, \& Kennedy, 2009; Harvison, Chapman, Ballash \& Woodruff-Borden, 2008; McLeod et al., 2007).

\section{Hypothesis Four: Assessing Moderation}

Hypothesis four was exploratory in nature and was that parental control may moderate the associations between behavioral inhibition and Parental (maternal and paternal) anxiety and adolescent anxiety at 12 and 15 years. That is, adolescents with higher behavioral inhibition and whose parents have higher Parental (maternal and paternal) anxiety levels will display more adolescent anxiety when their parents display more controlling behaviors. In regard to behavioral inhibition, several researchers suggested that behavioral inhibition may be moderated by overprotective parenting (Manassis et al., 2004). Results from the current study, however, did not confirm moderation.

In regard to parental control, van der Bruggen and colleagues' (2008) metaanalysis examining the moderating effects of parental control on the relationship between parental anxiety and child anxiety showed a non-significant relationship $(\mathrm{d}=.08)$. While the effect size was not significant when including all 23 studies from the aforementioned meta-analysis, small but significant effects were found in studies with children under the age of 10 , in studies where parental control was assessed with a discussion task, and in samples with an over-representation of boys (van der Bruggen et al., 2008). Therefore, the second purpose of examining a moderated model of adolescent anxiety was to determine if moderation would occur under the conditions of the current study. In other 
words, one purpose of this study was to determine whether or not a moderating effect would occur with a sample of adolescents (instead of children under the age of 10), when parental control was assessed via adolescent questionnaire (instead of with a discussion task), and in a sample with equal representation between the sexes (instead of an overrepresentation of boys). The inadequate model fit of the moderated model of adolescent anxiety confirms the results of the van der Bruggen and colleagues' (2008) meta-analysis in that there was no evidence of significant moderation relationships.

\section{Limitations}

The current study contained several limitations. First, assessing behavioral inhibition at $4 \frac{1}{2}$ years does not taken into account changes in behavioral inhibition that may have occurred later in the child's development. Second, despite the large sample size, participants in the current study tended to be white, more highly educated, and to have higher family incomes, somewhat limiting the generalizability of the findings. Third, while the behavioral control aspect of parental control was assessed in the current study, the psychological control component of parental control was not, thus limiting the conclusions that can be made as they pertain to parental control. Fourth, the questionnaire measuring parental control did not ask adolescents to fill out two separate questionnaires to catalog the controlling behaviors of each parent. Mothers' and fathers' controlling behaviors may be quite different (Simons \& Conger, 2007), yet there was no way to determine if the adolescents' answers reflected the controlling behaviors of their mother only, their father only, or an average of both. Fifth, the current study was not experimental by design and therefore claims about causation cannot be made. Lastly, nearly $60 \%$ of unexplained variance in adolescent anxiety remains, suggesting that there 
are additional environmental and/or biological factors that contribute to the etiology of adolescent anxiety.

\section{Implications}

The findings from this longitudinal examination of children from $4 \frac{1}{2}$ to 15 years ascertain the key biological and environmental factors that work together to predict adolescent anxiety. Furthermore, the findings show that both adolescent and parental anxiety is moderately to highly stable over the period between 12 and 15 years, reinforcing the importance of early identification and treatment of anxiety. With new longitudinal research showing that earlier age of onset of anxiety disorders correlates with greater severity, worse course, and increased recurrence of anxiety over a 15 year time period (Ramsawh, Weisberg, Dyck, Stout \& Keller, in press), interventions focused on preventing child and adolescent anxiety should be developed.

One key environmental factor that emerged in this study, parental anxiety, indicates that selective clinical interventions geared toward ameliorating parental anxiety as a preventive measure for adolescent anxiety should be researched. Understanding the effects of parental anxiety on adolescent anxiety informs clinical practice and encourages collaboration between child and adult mental health providers. For example, an adolescent identified to have an anxiety disorder or subclinical anxiety symptoms could trigger parental involvement in the form of a joint parental/child anxiety treatment plan. By involving the parents in the intervention, the parents would preferably accept and reinforce the positive changes made by their adolescent while simultaneously acquiring skills that will help them overcome their own anxiety and prevent relapse. Indeed, previous research has documented that involving parents in their children's anxiety 
treatment has proven to be more efficacious than not involving them (Bernstein, Borchardt, \& Perwien, 1996). Future experimental research that compares adolescent anxiety outcomes with and without concurrent parental anxiety treatment would be ideal.

The finding that paternal and maternal anxiety at 12 years predicted subsequent paternal and maternal anxiety at 15 years could be explored. There is some evidence that the relationship between paternal and maternal anxiety may be cross-predictive (e.g., maternal anxiety may predict paternal anxiety and vice versa). For example, one study of 519 pairs of spouses from the general population showed significant spousal association for lifetime presence of anxiety disorders (Du Fort, Bland, Newman \& Boothroyd, 1998). Although the possible cross-predictive nature of these relationships was not taken into account for the current study, future models of adolescent anxiety could do so.

Results from this study also show the importance of accounting for father behavior in the transmission of adolescent anxiety disorders, something that has not been done consistently in the literature (Bögels \& Phares, 2008). With the 20 year trend of increased father involvement in raising children and adolescents (Pleck \& Masciadrelli, 2004), future studies need to consider paternal parenting behaviors as they pertain to the etiology of adolescent anxiety.

The findings from this study also have several implications for parenting practices. First, parents should be aware of the child characteristics that may increase vulnerability for adolescent anxiety such as sex and age of the adolescent. For example, parents should pay special attention to anxiety symptoms in their adolescent girls as they mature through mid-to-late adolescence, as girls in this developmental period appear to be more vulnerable for the development of anxiety than boys. Findings from this study 
also suggest that parents periodically re-examine the levels of parental control that they exert on their adolescents to ensure that the level of control is developmentally appropriate because overcontrolling parenting behaviors may promote adolescent anxiety.

In conclusion, the current study demonstrates associations between child behavioral inhibition, paternal anxiety, maternal anxiety, parental control and adolescent anxiety and suggests that they predict adolescent anxiety at 15 years. This study also indicates that earlier levels of adolescent and parental anxiety predict later levels of adolescent and parental anxiety and that parental anxiety symptoms have implications for concurrent and future levels of adolescent anxiety. Further research concerning the risk and protective factors as they relate to the etiology of adolescent anxiety should be explored to positively guide therapeutic interventions and shape appropriate parental behaviors. 


\section{REFERENCES}

Achenbach, T. M., \& Rescorla, L. A. (2001). Manual for the ASEBA school-age forms \& profiles. Burlington: University of Vermont, Research Center for Children, Youth, and Families.

Albano, A., Chorpita, B., \& Barlow, D. (1996). Childhood anxiety disorders: The Guilford Press.

Albano, A., \& Kendall, P. (2002). Cognitive behavioural therapy for children and adolescents with anxiety disorders: Clinical research advances. International Review of Psychiatry, 14(2), 129-134.

Allport, G.W., (1937). Personahty psychologtcal tnterpretatton. New York: Holt.

Anderson, J. (1994). Epidemiological issues. In T. Ollendick, N. King \& W. Yule (Eds.), International handbook of phobic and anxiety disorders in children and adolescents (pp. 43-66). New York: Plenum Press.

Angold, A., Costello, E., \& Erkanli, A. (1999). Comorbidity. Journal of Child Psychology and Psychiatry, 40(1), 57-87.

American Psychiatric Association. (1980). Diagnostic and statistical manual of mental disorders (3rd ed.). Washington, DC: Author.

American Psychiatric Association. (1994). Diagnostic and statistical manual of mental disorders (4th ed.). Washington, DC: Author.

American Psychiatric Association. (2000). Diagnostic and statistical manual of mental disorder (Revised 4th ed.). Washington, DC: Author. 
Arbuckle, J. L., (2010). Amos (Version 19.0) [Computer Program]. Chicago: SPSS.

Arnett, J. (1999). Adolescent storm and stress, reconsidered. American Psychologist, $54(5), 317-326$

Arthur, M., Hawkins, J., Pollard, J., Catalano, R., \& Baglioni, A. (2002). Measuring risk and protective factors for use, delinquency, and other adolescent problem behaviors. Evaluation Review, 26(6), 575-601.

Avenevoli, S., Stolar, M., Li, J., Dierker, L., \& Ries Merikangas, K. (2001). Comorbidity of depression in children and adolescents: Models and evidence from a prospective high-risk family study. Biological Psychiatry, 49(12), 1071-1081.

Bailey, W. (1994). A longitudinal study of fathers' involvement with young children: Infancy to age 5 years. The Journal of Genetic Psychology, 155(3), 331-339.

Bandura, A. (1986). Social foundations of thought and action: A social cognitive theory. Englewood Cliffs, NJ: Prentice Hall.

Bandura, A. (1989). Human agency in social cognitive theory. American Psychologist, $44(9), 1175-1184$

Barber, B. (1996). Parental psychological control: Revisiting a neglected construct. Child Development, 67(6), 3296-3319.

Barber, B., Olsen, J., \& Shagle, S. (1994). Associations between parental psychological and behavioral control and youth internalized and externalized behaviors. Child Development, 65(4), 1120-1136.

Barker, E. T., \& Galambos, N. L. (2003). Body dissatisfaction of adolescent girls and boys. The Journal of Early Adolescence, 23(2), 141-165. 
Barlow, D. (2000). Unraveling the mysteries of anxiety and its disorders from the perspective of emotion theory. The American Psychologist, 55(11), 1247-1263.

Barlow, D. (2002). The origins of anxious apprehension, anxiety disorders, and related emotional disorders: Triple vulnerabilities. In D. Barlow (Ed.), Anxiety and Its Disorders: The Nature and Treatment of Anxiety and Panic (2nd ed., pp. 252291). New York: Guilford.

Barlow, D. (2004). Anxiety and its disorders: The nature and treatment of anxiety and panic (2nd ed.). New York: The Guilford Press.

Barlow, D., Allen, L., \& Choate, M. (2004). Toward a unified treatment for emotional disorders. Behavior Therapy, 35(2), 205-230.

Baumrind, D. (1971). Current patterns of parental authority. Developmental Psychology Monograph, 4(1, Pt. 2), 1-103.

Baumrind, D. (1973). The development of instrumental competence through socialization. In A. Pick (Ed.), Minnesota symposium on child psychology (Vol. 7, pp. 3-46) Minneapolis: University of Minnesota Press.

Baumrind, D. (1991). The influence of parenting style on adolescent competence and substance use. The Journal of Early Adolescence, 11(1), 56-95.

Baumrind, D. (1991). Effective parenting during the early adolescent transition. In P E. Cowan \& E. M. Hetherington (Eds.), Advances in family research (pp. 111-163). Hillsdale, NJ: Lawrence Erlbaum Associates.

Becker, G. S. (1981). Altruism in the family and selfishness in the market place. Economica, 48(189), 1-15. 
Beidel, D., \& Turner, S. (1997). At risk for anxiety: I. Psychopathology in the offspring of anxious parents. Journal of the American Academy of Child \& Adolescent Psychiatry, 36(7), 918-924.

Beidel, D., \& Turner, S. (1998). Shy children, phobic adults: Nature and treatment of social phobia. Washington DC: American Psychological Association.

Bell, B., \& Belsky, J. (2008). Parents, parenting, and children's sleep problems: Exploring reciprocal effects. British Journal of Developmental Psychology, $26(4), 579-593$.

Belsky, J. (2009). Effects of child care on child development: Give parents real choice. Paper presented at the Institute for the Study of Children, Families and Social Issues.

Bernstein, G., Borchardt, C., \& Perwien, A. (1996). Anxiety disorders in children and adolescents: a review of the past 10 years. Journal of the American Academy of Child and Adolescent Psychiatry, 35(9), 1110-1119.

Biederman, J., Hirshfeld-Becker, D., Rosenbaum, J., Herot, C., Friedman, D., Snidman, N., et al. (2001). Further evidence of association between behavioral inhibition and social anxiety in children. American Journal of Psychiatry, 158(10), 16731679.

Biederman, J., Petty, C., Faraone, S., Henin, A., Hirshfeld-Becker, D., Pollack, M., et al. (2006). Effects of parental anxiety disorders in children at high risk for panic disorder: A controlled study. Journal of affective disorders, 94(1-3), 191-197. 
Bittner, A., Egger, H., Erkanli, A., Jane Costello, E., Foley, D., \& Angold, A. (2007). What do childhood anxiety disorders predict? Journal of Child Psychology and Psychiatry, 48(12), 1174-1183.

Block, J. (1983). Differential premises arising from differential socialization of the sexes: Some conjectures. Child Development, 54(6), 1335-1354.

Bögels, S., \& Brechman-Toussaint, M. (2006). Family issues in child anxiety: Attachment, family functioning, parental rearing and beliefs. Clinical Psychology Review, 26(7), 834-856.

Bögels, S., \& Phares, V. (2008). Fathers' role in the etiology, prevention and treatment of child anxiety: A review and new model. Clinical Psychology Review, 28(4), 539558.

Bollen, K. A., \& Long, J. (1993). Testing structural equation models (Vol. 154). Newbury Park, CA: Sage Publications, Inc.

Bouton, M., Mineka, S., \& Barlow, D. (2001). A modern learning theory perspective on the etiology of panic disorder. Psychological Review, 108(1), 4-32.

Brady, E., \& Kendall, P. (1992). Comorbidity of anxiety and depression in children and adolescents. Psychological Bulletin, 111(2), 244-255.

Bronfenbrenner, U. (1986). Ecology of the family as a context for human development: Research perspectives. Developmental Psychology, 22(6), 723-742.

Bronfenbrenner, U. (1999). In S. L. Friedman \& T.D. Wachs (Eds.), Measuring environment across the life span: Emerging methods and concepts (pp. 3-28). Washington, DC: American Psychological Association Press. 
Bronfenbrenner, U., \& Morris, P. (1998). The ecology of human development processes. In W. Damon \& R. Lerner (Eds.), Handbook of child psychology (Vol. 1, pp. 993-1028).

Brown, B., Mounts, N., Lamborn, S., \& Steinberg, L. (1993). Parenting practices and peer group affiliation in adolescence. Child Development, 64(2), 467-482.

Cabrera, N., Tamis-LeMonda, C., Bradley, R., Hofferth, S., \& Lamb, M. (2000). Fatherhood in the twenty first century. Child Development, 7l(1), 127-136.

Caspi, A., Elder, G., \& Bem, D. (1988). Moving away from the world: Life-course patterns of shy children. Developmental Psychology, 24(6), 824-831.

Canino, G., Shrout, P., Rubio-Stipec, M., Bird, H., Bravo, M., Ramirez, R., et al. (2004). The DSM-IV rates of child and adolescent disorders in Puerto Rico: Prevalence, correlates, service use, and the effects of impairment. Archives of General Psychiatry, 61(1), 85-93.

Cantwell, D., \& Baker, L. (1989). Stability and natural history of DSM-III childhood diagnoses. Journal of the American Academy of Child \& Adolescent Psychiatry, $28(5), 691-700$.

Chapman, L., \& Woodruff-Borden, J. (2009). The impact of family functioning on anxiety symptoms in African American and European American young adults. Personality and Individual Differences, 47(6), 583-589.

Chesney-Lind, M., \& Belknap, J. (2004). Trends in delinquent girls. In M. Putallaz \& K. Bierman (Eds.), Aggression and Violent Behavior: A Review of the Evidence (pp. 203-222). New York: The Guilford Press. 
Chorpita, B., Albano, A., \& Barlow, D. (1996). Cognitive processing in children: Relation to anxiety and family influences. Journal of Clinical Child \& Adolescent Psychology, 25(2), 170-176.

Chorpita, B., \& Barlow, D. (1998). The development of anxiety: The role of control in the early environment. Psychological Bulletin, 124(1), 3-21.

Clark, L. A. \& Watson, D. (1990). Theoretical and empirical issues in differentiating depression from anxiety. In Becker, J. \& Kleinman, A. (Eds), Advances in mood disorders, Vol. 1. Psychosocial aspects of depression. Erlbaum, Hillsdale, N.J.

Cole, D. A., Martin, J. M., Peeke, L. G., Seroczynski, A. D., \& Fier, J. (1999). Children's over- and underestimation of academic competence: A longitudinal study of gender differences, depression and anxiety. Child Development, 70, 459-473.

Compas, B. E., Howell, D. C., Phares, V., Williams, R. A., \& Giunta, C. T. (1989). Risk factors for emotional/behavioral problems in young adolescents: A prospective analysis of adolescent and parental stress and symptoms. Journal of Consulting and Clinical Psychology, 57(6), 732-740.

Connell, A., \& Goodman, S. (2002). The association between psychopathology in fathers versus mothers and children's internalizing and externalizing behavior problems: A meta-analysis. Psychological Bulletin, 128(5), 746-773.

Costello, E., Angold, A., \& March, J. (1995). Epidemiology In J. March (Ed.), Anxiety disorders in children and adolescents (pp. 109-124). New York: Guilford.

Costello, E., Egger, H., \& Angold, A. (2005). 10-year research update review: The epidemiology of child and adolescent psychiatric disorders. Journal of the American Academy of Child \& Adolescent Psychiatry, 44(10), 972-986. 
Costello, E., Mustillo, S., Erkanli, A., Keeler, G., \& Angold, A. (2003). Prevalence and development of psychiatric disorders in childhood and adolescence. Archives of General Psychiatry, 60(8), 837-844.

Coyle, J. (2001). Drug treatment of anxiety disorders in children. New England Journal of Medicine, 344(17), 1279-1285.

Craig, L. (2006). Does Father Care Mean Fathers Share? Gender \& Society, 20(2), 259281.

Craig, E., \& Bandalos, D., L. (2001). The relative performance of full information maximum likelihood estimation for missing data in structural equation models. Structural Equation Modeling, 8, 430-457.

Cronk, N., Slutske, W., Madden, P., Bucholz, K., \& Heath, A. (2004). Risk for separation anxiety disorder among girls: Paternal absence, socioeconomic disadvantage, and genetic vulnerability. Journal of Abnormal Psychology, 113(2), 237-247.

Cummings, E., Davies, P., \& Campbell, S. (2000). Developmental psychopathology and family process: Theory, research, and clinical implications. New York: Guilford Press.

Darling, N., \& Steinberg, L. (1993). Parenting style as context: An integrative model. Psychological Bulletin, 113(3), 487-496.

Degnan, K. A., \& Fox, N. A. (2007). Behavioral inhibition and anxiety disorders: Multiple levels of a resilience process. Development and Psychopathology, $19(03), 729-746$. 
Dellava, J., Thornton, L., Hamer, R., Strober, M., Plotnicov, K., Klump, K., et al. (2009). Childhood anxiety associated with low BMI in women with anorexia nervosa. Behaviour research and therapy, 48(1), 60-67.

Du Fort, G., Bland, R., Newman, S., \& Boothroyd, L. (1998). Spouse similarity for lifetime psychiatric history in the general population. Psychological medicine, $28(4), 789-802$.

Edin, K., \& Kefalas, M. (2005). Promises I can keep: Why poor women put motherhood before marriage. Los Angeles, CA: University of California Press.

Edwards, S. L., Rapee, R. M., \& Kennedy, S. (2010) Prediction of anxiety symptoms in preschool aged children: examination of maternal and paternal perspectives. Journal of Child Psychology and Psychiatry, 51(3), 313-321.

Egliston, K., \& Rapee, R. (2007). Inhibition of fear acquisition in toddlers following positive modeling by their mothers. Behaviour research and therapy, 45(8), 18711882.

Eley, T. (1997). General genes: A new theme in developmental psychopathology. Current Directions in Psychological Science, 6(4), 90-95.

Eley, T., \& Lau, J. (2005). Genetics and the family environment. In J. Hudson \& R. Rapee (Eds.), Psychopathology and the family (pp. 3-19). San Diego, CA: Elsevier Ltd.

Epstein, J. L., \& McPartland, J. M. (1977). Family and school interactions and main effects on affective outcomes (Report No. 235). Baltimore, MD: Johns Hopkins University, Center for Social Organization of Schools. 
Essau, C., Conradt, J., \& Petermann, F. (1999). Frequency and comorbidity of social phobia and social fears in adolescents. Behaviour research and therapy, 37(9), $831-843$

Essau, C., Conradt, J., \& Petermann, F. (2000). Frequency, comorbidity, and psychosocial impairment of specific phobia in adolescents. Journal of Clinical Child \& Adolescent Psychology, 29(2), 221-231.

Eysenck, M. (1992). Anxiety: The cognitive perspective. East Sussex, U.K.: Lawrence Erlbaum.

Fairchild, A. J., \& McQuillin, S. D. Evaluating mediation and moderation effects in school psychology: A presentation of methods and review of current practice. Journal of school psychology, 48(1), 53-84.

Farkas, S., Johnson, J., Duffett, A., Wilson, L. \& Vine, J. (2002). A lot easier said than done: Parents talk about raising children in today's America. New York: Public Agenda.

Feigon, S., Waldman, I., Levy, F., \& Hay, D. (2001). Genetic and environmental influences on separation anxiety disorder symptoms and their moderation by age and sex. Behavior Genetics, 31(5), 403-411.

Ferdinand, R., Dieleman, G., Ormel, J., \& Verhulst, F. (2007). Homotypic versus heterotypic continuity of anxiety symptoms in young adolescents: Evidence for distinctions between DSM-IV subtypes. Journal of abnormal child psychology, $35(3), 325-333$. 
Fisak, B., \& Grills-Taquechel, A. (2007). Parental modeling, reinforcement, and information transfer: Risk factors in the development of child anxiety? Clinical Child and Family Psychology Review, 10(3), 213-231.

Fletcher, A., Steinberg, L., \& Sellers, E. (1999). Adolescents' well-being as a function of perceived interparental consistency. Journal of Marriage and the Family, 61(3), 599-610.

Ford, T., Goodman, R., \& Meltzer, H. (2003). The British child and adolescent mental health survey 1999: The prevalence of DSM-IV disorders. Journal of the American Academy of Child \& Adolescent Psychiatry, 42(10), 1203-1211.

Fuligni, A., \& Eccles, J. (1993). Perceived parent-child relationships and early adolescents' orientation toward peers. Developmental Psychology, 29, 622-622.

Galbaud du Fort, G., Bland, R., Newman, S., \& Boothroyd, L. (1998). Spouse similarity for lifetime psychiatric history in the general population. Psychological Medicine: A Journal of Research in Psychiatry and the Allied Sciences. 28(4), 789-803.

Gar, N. S., Hudson, J. L., \& Rapee, R. M. (2005). Family factors and the development of anxiety disorders. In J. L. Hudson \& R. M. Rapee (Eds.), Psychopathology and the family (pp. 125-145). New York: Elsevier.

Garber, J., Clarke, G., Weersing, V., Beardslee, W., Brent, D., Gladstone, T., et al. (2009). Prevention of depression in at-risk adolescents: A randomized controlled trial. JAMA, 301(21), 2215-2224.

Garber, J. \& Strassberg, Z. (1991). Construct validity: History and application to developmental psychopathology. In Grawe, W. \& Ciachetti, D. (Eds), Personality and psychopathology. 219-258. Minneapolis: University of Minnesota Press. 
Gati, I., Osipow, S. H., \& Givon, M. (1995). Gender differences in career decision making: The content and structure of preferences. Journal of Counseling Psychology, 42(2), 204-216.

Ge, X., Lorenz, F. O., Conger, R. D., Elder, G. H., \& Simons, R. L. (1994). Trajectories of stressful life events and depressive symptoms during adolescence. Developmental Psychology, 30, 467-483.

Gibbs, N. (2009, November). The Growing Backlash Against Overparenting: Time Magazine.

Giora, A., Gega, L., Landau, S., \& Marks, I. (2005). Adult recall of having been bullied in attenders of an anxiety disorder unit and attenders of a dental clinic: A pilot controlled study. Behaviour Change, 22(1), 44-49.

Gladstone, G., Parker, G., Mitchell, P., Wilhelm, K., \& Malhi, G. (2005). Relationship between self-reported childhood behavioral inhibition and lifetime anxiety disorders in a clinical sample. Depression and Anxiety, 22(3), 103-113.

Goodyer, I., Wright, C., \& Altham, P. (1988). Maternal adversity and recent stressful life events in anxious and depressed children. Journal of Child Psychology and Psychiatry, 29(5), 651-667.

Goodwin, R., Fergusson, D., \& Horwood, L. (2004). Early anxious/withdrawn behaviours predict later internalising disorders. Journal of Child Psychology and Psychiatry, 45(4), 874-883.

Gosch, E., Flannery-Schroeder, E., Mauro, C., \& Compton, S. (2006). Principles of cognitive-behavioral therapy for anxiety disorders in children. Journal of Cognitive Psychotherapy, 20(3), 247-262. 
Gotlib, H. \& Cane, D. B. (1989). In Kendall, P. C. \& Watson, D. (Eds), Anxiety and depression; Distinctive and overlapping features. Academic Press: San Diego.

Graczyk, P. A., Connolly, S. D., \& Corapci, F. (2005). Anxiety disorders in children and adolescents: Theory, treatment, and prevention. In T. P. Gullotta and G. Adams (Eds.) The handbook of dysfunctional behavior in adolescence: Theory, practice, and prevention. New York: Kluwer Academic Publishing.

Greco, L. A., \& Morris, T. L. (2002). Paternal child-rearing style and child social anxiety: Investigation of child perceptions and actual father behavior. Journal of Psychopathology and Behavioral Assessment, 24(4), 259-267.

Greenberg, P., Sisitsky, T., Kessler, R., Finkelstein, S., Berndt, E., Davidson, J., et al. (1999). The economic burden of anxiety disorders in the 1990s. The Journal of Clinical Psychiatry, 60(7), 427-435.

Grotevant, H., \& Carlson, C. (1989). Family assessment: A guide to methods and measures. New York: The Guilford Press.

Grüner, K., Muris, P., \& Merckelbach, H. (1999). The relationship between anxious rearing behaviours and anxiety disorders symptomatology in normal children. Journal of Behavior Therapy and Experimental Psychiatry, 30, 27-35.

Hadwin, J., Frost, S., French, C., \& Richards, A. (1997). Cognitive processing and trait anxietyin typically developing children: Evidence for an interpretation bias. Journal of Abnormal Psychology, 106(3), 486-490.

Hankin, B. L., \& Abramson, L. Y. (2001). Development of gender differences in depression: An elaborated cognitive vulnerability-transactional stress theory. Psychological Bulletin, 127(6), 773-796. 
Harvison, K. W., Chapman, L. K., Ballash, N. G., \& Woodruff-Borden, J. (2008). Anxiogenic Patterns in Mother-Child Interactions. Child \& Family Behavior Therapy, 30(2), 137-151.

Harter, S. (2006). The Self, Handbook of Child Psychology (Vol. 3, pp. 505-570). Hoboken, NJ: John Wiley \& Sons.

Hastings, P., Sullivan, C., McShane, K., Coplan, R., Utendale, W., \& Vyncke, J. (2008). Parental socialization, vagal regulation, and preschoolers' anxious difficulties: Direct mothers and moderated fathers. Child Development, 79(1), 45-64.

Hays, S. (1996). The cultural contradictions of motherhood. New Haven, CT: Yale University Press.

Henderson, A., Jorm, A., Korten, A., Jacomb, P., Christensen, H., \& Rodgers, B. (1998). Symptoms of depression and anxiety during adult life: Evidence for a decline in prevalence with age. Psychological medicine, 28(6), 1321-1328.

Hirshfeld, D., Rosenbaum, J., Biederman, J., Bolduc, E., Faraone, S., Snidman, N., et al. (1992). Stable behavioral inhibition and its association with anxiety disorder. Journal of the American Academy of Child and Adolescent Psychiatry, 31(1), $103-111$.

Hirshfeld-Becker, D., \& Biederman, J. (2002). Rationale and principles for early intervention with young children at risk for anxiety disorders. Clinical Child and Family Psychology Review, 5(3), 161-172.

Hoff, E., Laursen, B., \& Tardif, T. (2002). Socioeconomic Status and Parenting. Handbook of Parenting: Biology and ecology of parenting, 2, 231-252. 
Holmbeck, G. (1996). A model of family relational transformations during the transition to adolescence: Parent-adolescent conflict and adaptation. In J. Graber, J. BrooksGunn \& A. Peterson (Eds.), Transitions through adolescence: Interpersonal domains and context (pp. 167-199). Mahwah, NJ: Lawrence Erlbaum Associates, Inc.

Hoghughi, M., \& Long, N. (2004). Handbook of parenting: Theory and research for practice. Thousand Oaks, CA: Sage Publications Ltd.

Hooper, D., Coughlan, J., \& Mullen, M. R. (2008). Structural equation modeling: Guidelines for determining model fit. The Electronic Journal of Business Research Methods, 6(1), 53-60.

Hoover, E. (2008). Surveys of Students Challenge" Helicopter Parent" Stereotypes. Chronicle of Higher Education, 54(21), 1-22.

Hu, L., \& Bentler, P. M. (1999). Cutoff criteria for fit indexes in covariance structure analysis: Conventional criteria versus new alternatives. Structural Equation Modeling, 6(1), 1-55.

Hudson, J., \& Rapee, R. (2001). Parent-child interactions and anxiety disorders: An observational study. Behaviour Research and Therapy. 39(12), 1411-1427.

Hudson, J., \& Rapee, R. (2004). From anxious temperament to disorder: An etiological model of generalized anxiety disorder. In R. Heimberg, C. Turk \& D. Mennin (Eds.), Generalized anxiety disorder: Advances in research and practice (pp. 5174). New York: The Guilford Press.

Izard, C. (1977). Human emotions. New York: Plenum Press. 
James, L. R., Mulaik, S. A., \& Brett, J. M. (2006). A Tale of Two Methods. Organizational Research Methods, 9(2), 233-244.

Jorm, A. (2000). Does old age reduce the risk of anxiety and depression? A review of epidemiological studies across the adult life span. Psychological medicine, $30(01), 11-22$

Kagan, J. (1989). Temperamental contributions to social behavior. American Psychologist, 44(4), 668-674.

Kagan, J., Reznick, J., Clarke, C., Snidman, N., \& Garcia-Coll, C. (1984). Behavioral inhibition to the unfamiliar. Child Development, 55(6), 2212-2225.

Kagan, J., Reznick, J., \& Snidman, N. (1987). The physiology and psychology of behavioral inhibition in children. Child Development, 58(6), 1459-1473.

Kagan, J., Reznick, J., \& Snidman, N. (1988). Biological bases of childhood shyness. Science, 240(4849), 167-171.

Kagan, J., \& Snidman, N. (1991). Temperamental factors in human development. American Psychologist, 46(8), 856-862.

Kagan, J., \& Snidman, N. (1999). Early childhood predictors of adult anxiety disorders. Biological Psychiatry, 46(11), 1536-1541.

Kagan, J., Snidman, N., \& Arcus, D. (1992). Initial reactions to unfamiliarity. Current Directions in Psychological Science, 1(6), 171-174.

Kagan, J., Snidman, N., Zentner, M., \& Peterson, E. (1999). Infant temperament and anxious symptoms in school age children. Development and Psychopathology, ll(02), 209-224. 
Karno, M., Golding, J., Sorenson, S., \& Burnarn, M. (1988). The epidemiology of obsessive-compulsive disorder in five US communities. Archives of General Psychiatry, 45(12), 1094-1099.

Kendall, P., Puliafico, A., Barmish, A., Choudhury, M., Henin, A., \& Treadwell, K. (2007). Assessing anxiety with the child behavior checklist and the teacher report form. Journal of Anxiety disorders, 21(8), 1004-1015.

Kendler, K., Neale, M., Kessler, R., Heath, A., \& Eaves, L. (1992). Generalized anxiety disorder in women: A population-based twin study. Archives of General Psychiatry, 49(4), 267-272.

Kerr, M., Lambert, W. W., Stattin, H., \& Klackenberg-Larsson, I. (1994). Stability of inhibition in a Swedish longitudinal sample. Child Development, 65(1), 138-146.

Kessler, R., Chiu, W., Demler, O., \& Walters, E. (2005). Prevalence, severity, and comorbidity of 12-month DSM-IV disorders in the National Comorbidity Survey Replication. Archives of General Psychiatry, 62(6), 617-627.

Kessler, R., McGonagle, K., Zhao, S., Nelson, C., Hughes, M., Eshleman, S., et al. (1994). Lifetime and 12-month prevalence of DSM-III-R psychiatric disorders in the United States: Results from the National Comorbidity Survey. Archives of General Psychiatry,5l(1), 8-19.

Kline, R. B. (2011). Principles and Practice of Structural Equation Modeling (3rd ed.), The Guilford Press.

Knight, R., Waal-Manning, H., \& Spears, G. (1983). Some norms and reliability data for the State--Trait Anxiety Inventory and the Zung Self-Rating Depression scale. 
The British journal of clinical psychology/the British Psychological Society, 22, 245-249

Kroenke, K., Spitzer, R., Williams, J., Monahan, P., \& Löwe, B. (2007). Anxiety disorders in primary care: Prevalence, impairment, comorbidity, and detection. Annals of Internal Medicine, 146(5), 317-325.

Krohne, H., \& Hock, M. (1991). Relationships between restrictive mother-child interactions and anxiety of the child. Anxiety, Stress \& Coping, 4(2), 109-124.

Lamborn, S., Dornbusch, S., \& Steinberg, L. (1996). Ethnicity and community context as moderators of the relations between family decision making and adolescent adjustment. Child Development, 67(2), 283-301.

Lang, P.J. (1985). The cognitive psychophysiology of emotion: Fear and anxiety. In A, H. Tuma \& J. D. Mazer (Eds.), Anxiety and the Anxiety Disorders (pp. 131-170). Hillsdale, NJ: Erlbaum.

Lang, P.J. (1994). The motivational organization of emotion: Affect-reflex connections. In S. VanGoozen, N.E. Van de Poll \& J.A. Sergeant (Eds.), Emotions: Essays on Emotion Theory (pp. 61-93). Hillsdale, NJ: Erlbaum.

Lang, P.J., \& McTeague, L.M. (2009). The anxiety disorder spectrum: Fear imagery, physiological reactivity, and differential diagnosis. Anxiety, Stress \& Coping, $22(1), 5-25$.

Lang, P.J., McTeague, L.M., \& Cuthbert, B.N. (2007). Fear, anxiety, depression, and the anxiety disorder spectrum: A psychophysiological analysis. In T. Treat \& T. Baker (Eds.), Psychological clinical science: Recent advances in theory and 
practice. Integrative perspectives in honor of Richard M. McFall (pp. 167-195).

Mahwah, NJ: Lawrence Erlbaum.

Larson, R., \& Richards, M. (1994). Family Emotions: Do young adolescents and their parents experience the same states? Journal of Research on Adolescence, 4(4), $567-583$.

Last, C. G., Perrin, S., Hersen, M., \& Kazdin, A. E. (1996). A prospective study of childhood anxiety disorders. Journal of the American Academy of Child \& Adolescent Psychiatry, 35(11), 1502-1510.

Last, C., \& Strauss, C. (1989). Panic disorder in children and adolescents. Journal of Anxiety Disorders, 3(2), 87-95.

Laursen, B. (1996). Closeness and conflict in adolescent peer relationships: Interdependence with friends and romantic partners. In W. M. Bukowski, A. F. Newcomb, \& W. W. Hartup (Eds.), The company they keep: Friendship in childhood and adolescence. Cambridge studies in social and emotional development (pp. 186-210). New York: Cambridge University Press.

Laursen, B., Coy, K., \& Collins, W. (1998). Reconsidering changes in parent-child conflict across adolescence: A meta-analysis. Child Development, 69(3), 817-832.

Lazarus, R., \& Folkman, S. (1984). Stress, appraisal, and coping. New York: Springer Publishing Company.

Lewinsohn, P., Zinbarg, R., Seeley, J., Lewinsohn, M., \& Sack, W. (1997). Lifetime comorbidity among anxiety disorders and between anxiety disorders and other mental disorders in adolescents. Journal of Anxiety Disorders, 11(4), 377-394. 
Lieb, R., Wittchen, H. U., Höfler, M., Fuetsch, M., Stein, M. B., \& Merikangas, K. R. (2000). Parental psychopathology, parenting styles, and the risk of social phobia in offspring: A prospective-longitudinal community study. Archives of General Psychiatry.

Lovibond, P. F., \& Lovibond, S. H. (1995). The structure of negative emotional states: Comparison of the Depression Anxiety Stress Scales (DASS) with the Beck Depression and Anxiety Inventories. Behaviour research and therapy, 33(3), 335343.

Lum, L. (2006). Handling" Helicopter Parents". Diverse: Issues in Higher Education, $23(20), 40-43$.

Maccoby, E. E., \& Martin, J. A. (1983). Socialization in the context of the family: Parentchild interaction. In E. M. Hetherington (Ed.), \& P. H. Mussen (Series Ed.), Handbook of Child Psychology: Socialization, Personality \& and Social Development. (Vol. 4, pp. 1-101). New York: John Wiley \& Sons.

MacKinnon, D. P., \& Fairchild, A. J. (2009). Current directions in mediation analysis. Current Directions in Psychological Science, 18(1), 16-20.

MacKinnon, D. P., Fritz, M. S., Williams, J., \& Lockwood, C. M. (2007). Distribution of the product confidence limits for the indirect effect: Program PRODCLIN. Behavior Research Methods, 39(3), 384-389.

Manassis, K., \& Bradley, S. (1994). The development of childhood anxiety disorders: Toward an integrated model. Journal of Applied Developmental Psychology, $15(3), 345-366$ 
Manassis, K., Avery, D., Butalia, S., \& Mendlowitz, S. (2004). Cognitive-behavioral therapy with childhood anxiety disorders: Functioning in adolescence. Depression and anxiety, 19(4), 209-216.

Marano, H. E. (2004, November/December). A nation of wimps. Psychology Today, 37, 58-103.

March, J. S., Parker, J. D., Sullivan, K., Stallings, P., \& Conners, C. K. (1997). The multidimensional anxiety scale for children (MASC): factor structure, reliability, and validity. Journal of the American Academy of Child and Adolescent Psychiatry, 36, 554- 565.

Marciniak, M., Lage, M., Dunayevich, E., Russell, J., Bowman, L., Landbloom, R., et al. (2005). The cost of treating anxiety: the medical and demographic correlates that impact total medical costs. Depression and anxiety, 21(4), 178-184.

Markus, M.T., Lindhout, I.E., Boer, F., Hoogendijk, T.H.G., \& Arrindell, W.A. (2003). Factors of perceived parental rearing styles: The EMBU-C examined in a sample of Dutch primary school children. Personality and Individual Differences, 34 , $503-519$.

Masi, G., Millepiedi, S., Mucci, M., Poli, P., Bertini, N., \& Milantoni, L. (2004). Generalized anxiety disorder in referred children and adolescents. Journal of the American Academy of Child \& Adolescent Psychiatry, 43(6), 752-760.

McGee, R., Feehan, M., Williams, S., \& Anderson, J. (1992). DSM-III disorders from age 11 to age 15 years. Journal of American Academy of Child \& Adolescent Psychiatry, 31(1), 50- 59. 
McLeod, B., Wood, J., \& Weisz, J. (2007). Examining the association between parenting and childhood anxiety: A meta-analysis. Clinical Psychology Review, 27(2), 155172.

Messer, S., \& Beidel, D. (1994). Psychosocial correlates of childhood anxiety disorders. Journal of the American Academy of Child and Adolescent Psychiatry, 33(7), 975-983.

Mineka, S., \& Zinbarg, R. (2006). A contemporary learning theory perspective on the etiology of anxiety disorders. American Psychologist, 6I(1), 10-26.

Moore, P. S., Whaley, S. E., \& Sigman, M. (2004). Interactions between mothers and children: impacts of maternal and child anxiety. Journal of Abnormal Psychology, $113(3), 471-476$.

Mulvaney, M., Mebert, C., \& Flint, J. (2007). Parental affect and childrearing beliefs uniquely predict mothers' and fathers' ratings of children's behavior problems. Journal of Applied Developmental Psychology, 28(5-6), 445-457.

Muris, P., Meesters, C., Merckelbach, H., \& Hülsenbeck, P. (2000). Worry in children is related to perceived parental rearing and attachment. Behaviour research and therapy, $38(5), 487-497$.

Muris, P., \& Merckelbach, H. (1998). Perceived parental rearing behaviour and anxiety disorders symptoms in normal children. Personality and Individual Differences, 25(6), 1199-1206.

Muris, P., Roelofs, J., Meesters, C., \& Boomsma, P. (2004). Rumination and worry in nonclinical adolescents. Cognitive Therapy and Research, 28(4), 539-554. 
Muris, P., Steerneman, P., Merckelbach, H., \& Meesters, C. (1996). The role of parental fearfulness and modeling in children's fear. Behaviour research and therapy, $34(3), 265-268$.

Muris, P., Rapee, R., Meesters, C., Schouten, E., \& Geers, M. (2003). Threat perception abnormalities in children: The role of anxiety disorders symptoms, chronic anxiety, and state anxiety. Journal of Anxiety disorders, 17(3), 271-287.

Murray, L., Creswell, C., \& Cooper, P. (2009). The development of anxiety disorders in childhood: An integrative review. Psychological Medicine, 39(09), 1413-1423.

Nelson, M. K. (2010). Parenting out of control:Anxious parents in uncertain times. New York: New York University Press.

NICHD ECCRN. (1993). The NICHD study of early child care: A comprehensive longitudinal study of young children's lives. ERIC Document Reproduction Service No. ED 3530870 .

Nomaguchi, K. M., \& Brown, S. L. Parental strains and rewards among mothers: The role of education. Journal of Marriage and Family, 73(3), 621-636.

Offer, D., \& Schonert-Reichl, K. (1992). Debunking the myths of adolescence: Findings from recent research. Journal of the American Academy of Child \& Adolescent Psychiatry, 31(6), 1003-1014.

Orvaschel, H., \& Weissman, M. (1986). Epidemiology of anxiety disorders in children: A review. Anxiety Disorders of Childhood, 58-72.

Paquette, D. (2004). Theorizing the father-child relationship: Mechanisms and developmental outcomes. Human Development, 47(4), 193-219. 
Pettit, G., Laird, R., Dodge, K., Bates, J., \& Criss, M. (2001). Antecedents and behavior problem outcomes of parental monitoring and psychological control in early adolescence. Child Development, 72(2), 583-598.

Phares, V. (1996). Conducting nonsexist research, prevention, and treatment with fathers and mothers. Psychology of Women Quarterly, 20(1), 55-77.

Phares, V., \& Compas, B. (1992). The role of fathers in child and adolescent psychopathology: Make room for daddy. Psychological Bulletin, 111(3), 387-412.

Pleck, J., \& Masciadrelli, B. (2004). Paternal involvement by US residential fathers. In M. Lamb (Ed.), The role of the father in child development (Vol. 4, pp. 222-271). Hoboken, NJ: John Wiley \& Sons.

Popenoe, D. (1996). Life without father: Compelling new evidence that fatherhood and marriage are indispensable for the good of children and society. New York, NY: Free Press.

Prior, M., Smart, D., Sanson, A., \& Oberklaid, F. (2000). Does shy-inhibited temperament in childhood lead to anxiety problems in adolescence? Journal of the American Academy of Child \& Adolescent Psychiatry, 39(4), 461-468.

Ramsawh, H., Weisberg, R., Dyck, I., Stout, R., \& Keller, M. (in press). Age of onset, clinical characteristics, and 15-year course of anxiety disorders in a prospective, longitudinal, observational study. Journal of affective disorders.

Rapee, R. (2009). Early adolescents' perceptions of their mother's anxious parenting as a predictor of anxiety symptoms 12 months later. Journal of abnormal child psychology, 37(8), 1103-1112. 
Rapee, R., Schniering, C., \& Hudson, J. (2009). Anxiety disorders during childhood and adolescence: Origins and treatment. Annual review of clinical psychology, 5, 311341.

Resnick, M., Bearman, P., Blum, R., Bauman, K., Harris, K., Jones, J., et al. (1997). Protecting adolescents from harm: Findings from the National Longitudinal Study on adolescent health. JAMA, 278(10), 823-832.

Robinson, J., Kagan, J., Reznick, J., \& Corley, R. (1992). The heritability of inhibited and uninhibited behavior: A twin study. Developmental Psychology, 28(6), 10301037.

Roelofs, J., Meesters, C., ter Huurne, M., Bamelis, L., \& Muris, P. (2006). On the links between attachment style, parental rearing behaviors, and internalizing and externalizing problems in non-clinical children. Journal of Child and Family Studies, 15(3), 319-332.

Rothbart, M. K., \& Bates, J. E. (2006). Temperament. In W. Damon, R. Lerner, \& N. Eisenberg (Eds.), Handbook of child psychology, Sixth edition: Social, emotional, and personality development (Vol. 3). 99-106. New York: Wiley.

Rothbart, M., Ahadi, S., \& Hershey, K. (1994). Temperament and social behavior in childhood. Merrill-Palmer Quarterly, 40(1), 21-39.

Rothbart, M. K., Derryberry, D., \& Posner, M. I. (1994). A psychological approach to the development of temperament. In J. E. Bates \& T. D. Wachs (Eds.), Temperament: Individual differences at the interface of biology and behavior (pp. 83-116). Washington, DC: American Psychological Association. 
Roza, S. J., Hofstra, M. B., van der Ende, J., \& Verhulst, F. C. (2003). Stable prediction of mood and anxiety disorders based on behavioral and emotional problems in childhood: A 14-year follow-up during childhood, adolescence, and young adulthood. American Journal of Psychiatry, 160(12), 2116-2121.

Rudasill, K., \& Rimm-Kaufman, S. (2009). Teacher-child relationship quality: The roles of child temperament and teacher-child interactions. Early Childhood Research Quarterly, 24(2), 107-120.

Sanson, A., Pedlow, R., Cann, W., Prior, M., \& Oberklaid, F. (1996). Shyness ratings: Stability and correlates in early childhood. International Journal of Behavioral Development, 19(4), 705-724.

Saudino, K., \& Cherny, S. (2001). Sources of continuity and change in observed temperament. In R. Emde \& J. Hewitt (Eds.), Infancy to early childhood: Genetic and environmental influences on developmental change (pp. 89-110). New York: Oxford University Press.

Schafer, J. L. \& Graham, J. V. (2002). Missing data: Our view of the state of the art. Psychological Methods, 7, 147-177.

Schieman, S., Glavin, P., \& Milkie, M. A. (2009). When work interferes with life: Worknonwork interference and the influence of work-related demands and resources. American Sociological Review, 74(6), 966-988.

Schieman, S., Whitestone, Y. K., \& Van Gundy, K. (2006). The nature of work and the stress of higher status. Journal of Health and Social Behavior, 47(3), 242-257.

Schor, E. (2003). Family pediatrics: Report of the Task Force on the Family. Pediatrics, ll I (6), 1541-1571. 
Schumacker, R. E., \& Lomax, R. G. (2004). A beginner's guide to structural equation modeling (2 ed.). Mahwah, NJ: Lawrence Erlbaum Associates.

Sheehan, D., Sheehan, K., \& Minichiello, W. (1981). Age of onset of phobic disorders: A reevaluation. Comprehensive Psychiatry, 22(6), 544-553.

Simons, L., \& Conger, R. (2007). Linking mother-father differences in parenting to a typology of family parenting styles and adolescent outcomes. Journal of Family Issues, 28(2), 212-241.

Smolak, L., Levine, M. P., \& Thompson, J. K. (2001). The use of the Sociocultural Attitudes Towards Appearance Questionnaire with middle school boys and girls. International Journal of Eating Disorders, 29(2), 216-223.

Spence, S. (1997). Structure of anxiety symptoms among children: A confirmatory factor- analytic study. Journal of Abnormal Psychology, 106(2), 280-297.

Spielberger, C., Gorsuch, R., \& Edward, L. (1970). STAI manual. Palo Alto, CA: Consulting Psychologists Press.

Spielberger, C.D., Gorsuch, R.L., Lushene, R., Vagg, P.R., \& Jacobs, G.A. (1983). Manual for the state-trait anxiety inventory. Palo Alto, CA: Consulting Psychologists Press.

Spitzer, R., Kroenke, K., Linzer, M., Hahn, S., Williams, J., deGruy III, F., et al. (1995). Health-related quality of life in primary care patients with mental disorders: Results from the PRIME-MD 1000 Study. JAMA, 274(19), 1511-1517.

Stattin, H., \& Kerr, M. (2000). Parental monitoring: A reinterpretation. Child Development, 71(4), 1072-1085. 
Steiger, J. H. (2007). Understanding the limitations of global fit assessment in structural equation modeling. Personality and Individual Differences, 42(5), 893-898.

Stein, M., Jang, K., \& Livesley, W. (2002). Heritability of social anxiety-related concerns and personality characteristics: a twin study. The Journal of Nervous and Mental Disease, 190(4), 219-224.

Steinberg, L., \& Levine, A. (1997). You and your adolescent: A parent's guide for ages 10 to 20. New York: Harper Perennial.

Strauss, C. (1987). Modification of the trait portion of State-Trait Anxiety Inventory for Children-Parent Form. Gainesville, FL: University of Florida.

Strauss, C., Frame, C., \& Forehand. R. (1987). Psychosocial impairment associated with anxiety in children. Journal of Clinical Child \& Adolescent Psychology, 16(3), 235-239.

Talge, N., Donzella, B., \& Gunnar, M. (2008). Fearful temperament and stress reactivity among preschool aged children. Infant and child development, 17(4), 427-445.

Thapar, A., \& McGuffin, P. (1995). Are anxiety symptoms in childhood heritable? Journal of Child Psychology and Psychiatry, 36(3), 439-447.

Turner, S., Beidel, D., Roberson-Nay, R., \& Tervo, K. (2003). Parenting behaviors in parents with anxiety disorders. Behaviour Research and Therapy, 41(5), 541-554.

Turner, S., Beidel, D., \& Wolff, P. (1996). Is behavioral inhibition related to the anxiety disorders? Clinical Psychology Review, 16(2), 157-172.

Twenge, J. (2000). The age of anxiety? Birth cohort change in anxiety and neuroticism, 1952-1993. Journal of Personality and Social Psychology, 79(6), 1007-1021. 
United States Bureau of Labor Statistics. (2006). Women in the Labor Force: A databook. Downloaded May 1, 2011 from http://www.bls.gov.

Ungar, M. (2007). Too safe for their own good: How risk and responsibility help teens thrive. Toronto, Canada: McClelland \& Stewart.

Ungar, M. (2009). Overprotective parenting: Helping parents provide children the right amount of risk and responsibility. The American Journal of Family Therapy, $37(3), 258-271$

van der Bruggen, C., Stams, G., \& Bögels, S. (2008). Research Review: The relation between child and parent anxiety and parental control: A meta analytic review. Journal of Child Psychology and Psychiatry, 49(12), 1257-1269.

Vasa, R. A., \& Pine, D. S. (2004). Neurobiology. In T. L. Morris \& J. S. March (Eds.), Anxiety Disorders in Children and Adolescents, Second Edition. New York, NY: Guilford Publications Incorporated.

Vermeulen, M. E., \& Minor, C. W. (1998). Context of career decisions: Women reared in a rural community. Career Development Quarterly, 46(3), 230-245.

Warren, S., Huston, L., Egeland, B., \& Sroufe, L. (1997). Child and adolescent anxiety disorders and early attachment. Journal of the American Academy of Child \& Adolescent Psychiatry, 36(5), 637-644.

Watson, J., \& Rayner, R. (1920). Conditioned emotional responses. Journal of Experimental Psychology, 3, 1-14.

Weiss, L., \& Schwarz, J. (1996). The relationship between parenting types and older adolescents' personality, academic achievement, adjustment, and substance use. Child Development, 67(5), 2101-2114. 
Wichstrom, L. (1999). The emergence of gender difference in depressed mood during adolescence: The role of intensified gender socialization. Developmental Psychology, 35(1), 232-245.

Wigfield, A., Eccles, J., MacIver, D., Reuman, D., \& Midgley, C. (1991). Transitions during early adolescence: Changes in children's domain-specific self-perceptions and general self-esteem across the transition to junior high school. Developmental Psychology, 27(4), 552-565.

Winsler, A., Madigan, A., \& Aquilino, S. (2005). Correspondence between maternal and paternal parenting styles in early childhood. Early Childhood Research Quarterly, $20(1), 1-12$.

Wood, J., McLeod, B., Sigman, M., Hwang, W., \& Chu, B. (2003). Parenting and childhood anxiety: Theory, empirical findings, and future directions. Journal of Child Psychology and Psychiatry, 44(1), 134-151.

Xue, Y., Leventhal, T., Brooks-Gunn, J., \& Earls, F. (2005). Neighborhood residence and mental health problems of 5-to 11-year-olds. Archives of General Psychiatry, 62(5), 554-563.

Zahn-Waxler, C., Klimes-Dougan, B., \& Slattery, M. (2000). Internalizing problems of childhood and adolescence: Prospects, pitfalls, and progress in understanding the development of anxiety and depression. Development and Psychopathology, I2(03), 443-466.

Zarrett, N., \& Eccles, J. (2006). The passage to adulthood: Challenges of late adolescence. New Directions for Youth Development, (111), 13-28. 


\title{
APPENDICES
}

\author{
APPENDIX A \\ Children's Behavioral Questionnaire \\ (CBQ; Rothbart, Ahadi, \& Hershey, 1994)
}

On the next several pages you will see a set of statements that describe children's reactions to a number of situations. We would like you to tell us what your $41 / 2$ yearold's reaction is likely to be in those situations. Of course, there are no "correct" ways of reacting; children differ widely in their reactions, and it these differences we are trying to learn about. Please read each statement and decide whether it is a "true" or "untrue" description of your $41 / 2$ year-old's reaction within the past six months. Use the following scale to indicate how well the statement describes your $41 / 2$ year-old:

Circle \# if the statement is:

$1 \ldots \ldots \ldots \ldots \ldots \ldots \ldots \ldots \ldots$ extremely untrue of your $41 / 2$ year-old

$2 \ldots \ldots \ldots \ldots \ldots \ldots \ldots \ldots$ quite untrue of your $41 / 2$ year-old

$3 \ldots \ldots \ldots \ldots \ldots \ldots$................... slightly untrue of your $41 / 2$ year-old

$4 \ldots \ldots \ldots \ldots \ldots \ldots \ldots \ldots$ neither true nor false of your $41 / 2$ year-old

$5 \ldots \ldots \ldots \ldots \ldots \ldots \ldots . . \ldots \ldots$ slightly true of your $41 / 2$ year-old

$6 \ldots \ldots \ldots \ldots \ldots \ldots \ldots \ldots$ quite true of your $41 / 2$ year-old

$7 \ldots \ldots \ldots \ldots \ldots \ldots \ldots$ extremely true of your $41 / 2$ half year-old

If you cannot answer one of the items because you have never seen your $41 / 2$ year-old in that situation, for example if the statement is about your $41 / 2$ year-old's reaction to your singing and you have never sung to your 4 1/2 year-old, then circle 8 (Not Applicable). Please be sure to circle a number for every item.

My 4 1/2-year-old:

Shyness items (Note: $*=$ Reverse scored):

3. Sometimes prefers to watch rather than join other children playing

*8. Seems to be at ease with almost any person

14. Gets embarrassed when strangers pay a lot of attention to her/him

* 18 . Acts very friendly and outgoing with new children

*22. Joins others quickly and comfortably, even when they are strangers

28. Is sometimes shy even around people s/he has known a long time

33. Sometimes seems nervous when talking to adults s/he has just met

39. Acts shy around new people 
*45. Is comfortable asking other children play

*51. Talks easily to people

Fear items (Note: $*=$ Reverse scored):

*5. Is not afraid of large dogs and/or other animals

21 . Is afraid of loud noises

*23. Doesn't worry about injection by the doctor

$* 26$. Is not afraid of the dark

31. Is afraid of fire

34 . Is very frightened by nightmares

52 . Is afraid of the dark

*55. Is rarely frightened by "monsters" seen on TV or at movies

$* 63$. Is not afraid of heights

$* 70$. Is rarely afraid of sleeping alone in a room 


\section{APPENDIX B}

\section{Child Behavior Checklist-Anxiety Scale \\ (CBCL-A; Kendall et al., 2007)}

Below is a list of items that describe children and youths. For each item that describes your child now or within the past six months, please circle the 2 if the item is very true or often untrue of your child area. Circle the 1 if the item is somewhat or sometimes true of your child. If the item is not true of your child, circle the 0 . Please answer all items as well as you can, even if some do not seem to apply to your child.

$0=$ Not True (as far as you know)

$1=$ Somewhat or Sometimes True

$2=$ Very True or Often True

9. Cannot get his/her mind off certain thoughts

11. Clings to adults or too dependent

29. Fears certain animals, situations, or places other than school

30. Fears going to school

31. Fears he/she might think or do something bad

32. Feels he/she has to be perfect

45. Nervous, high-strung, or tense

46. Nervous moments or twitching

50. Too fearful or anxious

55a. Aches or pains

55 b. Headaches

55c. Nausea, feels sick

55f. Stomachaches or cramps

71. Self-conscious or easily embarrassed

75. Shy or timid

112. Worries 


\section{APPENDIX C \\ State-Trait Anxiety Inventory \\ (STAI; Spielberger, Gorsuch, Lushene, Vagg, \& Jacobs, 1983)}

Now we'd like to focus on your feelings during the past week. A number of statements that people use to describe themselves are given below. Read each statement and then circle the appropriate number to the right of the statements to indicate how you felt during the past week. There are no right or wrong answers do not spend too much time on any one statement but give the answer that seems to describe your feelings best.

$1=$ Not at all

$2=$ Somewhat

$3=$ Moderately

$4=$ Very much

Note: $*=$ Reverse scored

*1. I felt calm.

3. I was tense.

*5. I felt at ease.

7. I was worrying over possible misfortune.

9. I felt nervous.

11 . I was jittery.

*13. I was relaxed.

15. I was worried.

*17. I felt steady.

19. I felt frightened. 


\section{APPENDIX D}

\section{Parental Control and Autonomy}

This next set of questions about how decisions are made in your family. In your family, how you make most of the decisions about the following topics?

1 - My parent(s) decide

2 - My parents decide after discussing it with me

3 - We decide together

4 - I decide after discussing it with my parents

5 - I decide all by myself

1. How late you can stay up on a school night:

2. Which friends you can spend time with:

3. Which after-school activities you take part in:

4. Whether you can go on an afternoon outing with a friend:

5. How you dress:

6. What you do with your money:

7. What you watch on TV or whether you watch TV at all:

8 . Whether you take part in religious training or education: 


\title{
CURRICULUM VITAE
}

\section{Benjamin M. Keizer}

\author{
195 Roaring Springs Lane \\ Midway, KY 40347 \\ (502) 542-0000 \\ bmkeiz01@louisville.edu
}

\section{EDUCATION}

8/2008 - present Candidate, Doctor of Philosophy in Counseling Psychology Expected graduation: August 2012

University of Louisville, Louisville, KY

Advisors: Kathleen Rudasill, Ph.D. and Linda Shapiro, Ph.D.

Dissertation Title: Child behavioral inhibition, parental overcontrol, and parental anxiety as predictors of adolescent anxiety.

6/2003 - 11/2006 Master of Science in Counseling Psychology

University of West Alabama, Livingston, AL

Advisor: Robert Ware, Ph.D.

9/1994 - 12/1998 Bachelor of Science in Business Economics

South Dakota State University, Brookings, SD

\section{CERTIFICATES/LICENSES}

4/2009 - Psychological Associate, State of Kentucky (\#0889), EPPP Completion at Doctoral level

\section{SUPERVISED PRACTICA EXPERIENCE}

\section{8/2010 - 12/2020 Central State Hospital, Louisville, KY}

Supervisor: Susan Brittain, Ph.D.

Responsibilities: Provide direct care to severely mentally ill adults in an inpatient facility; Conduct a broad range of psychological tests; Write psychological reports; Facilitate individual therapy; Serve as a member of an interdisciplinary team; 
Responsibilities: Provided outpatient individual, group, and marital therapy to Veterans of all eras who experienced trauma including Veterans with co-occurring substance dependence disorders; Conducted intake interviews, including psychosocial/health histories; Conducted admission consultations, including chart reviews, clinical interviews, and psychological evaluations; Facilitated group psychoeducation classes; Served as a member of an interdisciplinary team

$8 / 2009-12 / 2009$

Robley Rex VA Medical Center, Louisville, KY Neuropsychological Testing - Polytrauma Supervisor: Jeanne Bennett, Psy.D.

Responsibilities: Performed psychological and neuropsychological assessments with adult outpatients; Administered, scored and interpreted a variety of intelligence, personality and neuropsychological tests (i.e., WAIS-IV, MMPI-2, MCMI-2, PAI, WMS-III, TAT, Incomplete Sentences, Rey Osterrieth); Integrated data into full psychological and neuropsychological reports

$1 / 2009-8 / 2009$

\section{Louisville Archdiocese Family Ministry Counseling Center,} Louisville, KY

Supervisor: Thomas Robbins, Ph.D.

Responsibilities: Provided individual, family, pre-marital and marital therapy to children, adolescents and adults at a non-profit community mental health agency; Conducted marital and premarital assessments

\section{9/2007 - 1/2008 Renewed Hope, Frankfort, KY}

Supervisor: Lyle Carlson, Ph.D.

Responsibilities: Administered and scored psychological and neuropsychological assessments including the WMS-R, WMS-III, CVLT-II, WMT, WRAT-4, WASI, WCST, COWAT, Manual Finger Tapping, Trail Making, Grooved Pegboard, MMPI-2, PAI, and Boston Naming Test

2/2006 - 6/2006 Ireland Army Hospital, Department of Behavioral Health, Ft. Knox, KY

Supervisors: John Embry, Ph.D. and James Andrews, M.D. Responsibilities: Conducted intake interviews, including psychosocial/health histories; Wrote psychological evaluations for medical boards; Provided outpatient individual therapy to Active 
Duty military personnel with a variety of mood, anxiety, and personality disorders

\section{OTHER WORK EXPERIENCE}

7/2008 - present Chief, Human Resources, 3rd Brigade, 95th Division Army Reserve, Lexington, KY (Rank: Major)

Responsibilities: Direct and supervise all personnel functions including duty assignments, legal support, pay, awards and decorations, and performance evaluations for an organization with over 1,100 personnel; Supervise a team of eight administrative specialists and one supervising specialist; Serve as Equal Opportunity officer; Recommend remedies to eliminate or prevent discrimination and sexual harassment

9/2007-8/2008 Psychology Technician, Renewed Hope, Frankfort, KY Supervisor: Lyle Carlson, Ph.D.

Responsibilities: Administered and scored psychological and neuropsychological assessments; Ordered and maintained the organization of testing materials

9/2007-6/2008 Assistant Human Resources Officer, 3rd Brigade, 95th Division Army Reserve, Lexington, KY (Rank: Captain)

Responsibilities: Assisted chief of human resources in personnel functions including duty assignments, legal support, pay, awards and decorations, and performance evaluations for an organization with over 1,100 personnel; Supervised a team of three administrative specialists

7/2005 - 7/2007 Chief, Human Resources, 16th Cavalry Regiment Active Army, Fort Knox, KY (Rank: Captain) Responsibilities: Directed and supervised all personnel functions including duty assignments, legal support, pay, awards and decorations, and performance evaluations for an organization with over 2,300 personnel; Supervised a team of two military and four civilian administrative specialists

5/2004 - 6/2005 Company Commander, 516th Personnel Services Battalion Active Army, Seoul, South Korea (Rank: Captain) Responsibilities: Responsible for the health, welfare and mission accomplishment of a personnel services company with approximately 40 U.S. military administrative specialists and six attached South Korean military administrative specialists

4/2002 - 10/2003 Chief, Personnel Plans and Operations Branch, 1st Cavalry Division, Active Army, Fort Hood, Texas (Rank: 1st Lieutenant/Captain) 
Responsibilities: Supervised a team of eight administrative specialists that provided personnel support to a Division of 15,000 personnel; Served as the personnel planner during tactical planning and overseas deployments

4/2000 - 3/2002 Various Developmental Military Assignments Active Army, Fort Hood, Texas (Rank: 2nd Lieutenant/1st Lieutenant)

\section{LEADERSHIP \& VOLUNTEER WORK}

8/2009-7/2010 Volunteer Peer Mentor, University of Louisville, Louisville, KY Mentored incoming doctoral students; Assisted in the academic, psychological, and professional transition to graduate school; Ensured peers have necessary social and academic support systems

9/2007-6/2008 Volunteer Student Mentor, Kentucky State University, Frankfort, KY

Met weekly with students at only historically African-American University in KY; Discussed relevant student behavioral health, social, racial, academic, and relationship issues

5/2004-6/2005 Volunteer English Instructor, Seoul, South Korea

Provided weekly language lessons to students at Namsan and Doeksoo Elementary School

\section{TEACHING/LECTURING EXPERIENCE}

1/2009-5/2011 Co-Instructor (3 semesters)

Course: Human Development for Helping Professionals

(Graduate level)

University of Louisville, Louisville, KY

11/2008 - 12/2009 Guest Lecturer (2 times)

Course: Learning Theory and Human Development (Graduate level)

University of Louisville, Louisville, KY

Lecture Topic: Motivation

11/2009 Invited Speaker

Title: The Importance of Parenting With a Plan: Adolescence

The Point Community Church, Frankfort, KY 
Title: The Importance of Parenting With a Plan: Pre-School The Point Community Church, Frankfort, KY

9/2008 - 10/2008 Invited Speaker

Titles: Parenting 101 and Parenting 201

The Frankfort Christian Academy, Frankfort, KY

\section{RESEARCH EXPERIENCE}

9/2008 - present Graduate Research Assistant/Research Team Member Department of Educational and Counseling Psychology University of Louisville, Louisville, KY

Supervisor: Kathleen Rudasill. Ph.D.

Responsibilities: Proofread/edit manuscripts; Conduct literature searches and reviews; Produce article summaries; Collect and analyze quantitative data

\section{PROFESSIONAL MEMBERSHIP \& SERVICE}

9/2008 - present University of Louisville Doctoral Student Organization

9/2007-present Kentucky Psychological Association, Student Affiliate

9/2007 - present American Psychological Association, Student Affiliate

$12 / 2010$ - present University of Louisville Multicultural Committee, Member 